LBL-37349

UC-401

\title{
Ultrafast Studies of Photodissociation in Solution: Dissociation, Recombination and Relaxation
}

\author{
Jason Christopher King \\ Ph.D. Thesis \\ Department of Chemistry \\ University of California, Berkeley \\ and \\ Chemical Sciences Division \\ Lawrence Berkeley Laboratory \\ University of Califormia \\ Berkeley, California 94720
}

May 1995

This work was supported by the Director, Office of Energy Research, Office of Basic Energy Sciences, Chemical Sciences Division, of the U.S. Department of Energy under Contract No. DE-AC03-76SF00098. 


\section{DISCLAIMER}

This report was prepared as an account of work sponsored by an agency of the United States Government. Neither the United States Government nor any agency thereof, nor any of their employees, make any warranty, express or implied, or assumes any legal liability or responsibility for the accuracy, completeness, or usefulness of any information, apparatus, product, or process disclosed, or represents that its use would not infringe privately owned rights. Reference herein to any specific commercial product, process, or service by trade name, trademark, manufacturer, or otherwise does not necessarily constitute or imply its endorsement, recommendation, or favoring by the United States Government or any agency thereof. The views and opinions of authors expressed herein do not necessarily state or reflect those of the United States Government or any agency thereof. 


\section{DISCLAIMER}

Portions of this document may be illegible in electronic image products. Images are produced from the best available original document. 


\author{
Abstract \\ Ultrafast Studies of Photodissociation in Solution: \\ Dissociation, Recombination and Relaxation \\ by \\ Jason Christopher King \\ Doctor of Philosophy in Chemistry \\ University of California at Berkeley \\ Professor Charles B. Harris, Chair
}

Ultrafast spectroscopy has been used to study both basic and complex processes that occur during chemical reactions in solution. One of the most basic processes in any chemical reaction, bond formation, has been studied in several systems. The photodissociation of $\mathrm{M}(\mathrm{CO})_{6}(\mathrm{M}=\mathrm{Cr}, \mathrm{Mo}, \mathrm{W})$ and the formation of the solvated $\mathrm{M}(\mathrm{CO})_{5} \cdot \mathrm{S}$ complex was studied in cyclohexane. The rate limiting step in the formation of the stable chemical bond is vibrational energy relaxation, the transfer of energy from the vibrationally excited new bond to the solvent. For both $\mathrm{Cr}(\mathrm{CO})_{5} \cdot \mathrm{S}$ and $\mathrm{Mo}(\mathrm{CO})_{5} \cdot S$ the primary vibrational relaxation occurs in $18 \mathrm{ps}$. For $\mathrm{Cr}(\mathrm{CO})_{5} \cdot \mathrm{S}$ there is an additional vibrational relaxation on a 150 ps time scale that is assigned to vibrational relaxation of a 
$\mathrm{CO}$ group that is poorly coupled to the other modes of the complex. The vibrational relaxation of $\mathrm{W}(\mathrm{CO})_{5} \cdot \mathrm{S}$ occurs in $42 \mathrm{ps}$ twice as long as the lighter pentacarbonyl complexes. Several possible mechanisms that could cause longer cooling of $\mathrm{W}(\mathrm{CO})_{5} \cdot \mathrm{S}$ are discussed. Vibrational relaxation is also investigated in two ionic species, $\mathrm{I}_{2}$ - and $\mathrm{IBr}^{-}$. The vibrationally excited $\mathrm{I}_{2}$ and $\mathrm{IBr}-$ were produced by the photodissociation of $\mathrm{I}_{3}$ - and $\mathrm{IBr}_{2}$, respectively. The vibrational relaxation was studied in a variety of nonpolar and slightly polar solvents to minimize the effect of the charge. Despite the nonpolar solvent, $\mathrm{CCl}_{4}$, the vibrational relaxation is exceedingly fast, $5 \mathrm{ps}$. This is almost as fast as the vibrational relaxation of $I_{2}-$ in methanol and ethanol. Several attempts were made to discover the mechanism for such fast energy transfer in a nonpolar solvent. The longer time scale dynamics of $\mathrm{I}_{3}$ - and $\mathrm{IBr}_{2}-$ were also studied. Both systems formed a metastable complex following photodissociation and $90-95 \%$ return to the ground state in 100 ps. This implies a barrier to recombination of $4.3 \mathrm{kcal} / \mathrm{mol}$ and a barrier to escape of at least $5.5 \mathrm{kcal} / \mathrm{mol}$. The more complex and technologically interesting photochemistry of $\mathrm{M}_{3}(\mathrm{CO})_{12}(\mathrm{M}=\mathrm{Fe}, \mathrm{Ru})$ is also investigated. Visible excitation of $\mathrm{Fe}_{3}(\mathrm{CO})_{12}$ causes both isomerization to a carbonyl bridging structure and fragmentation. Ninety percent of the molecules which formed the $\mathrm{CO}$ bridged structure revert back to the all terminal $\mathrm{CO}$ structure with a time constant of 150 ps. Ultraviolet excitation of both $\mathrm{Fe}_{3}(\mathrm{CO})_{12}$ and $\mathrm{Ru}_{3}(\mathrm{CO})_{12}$ causes dissociation of a $\mathrm{CO}$ ligand. Seventy five percent of the $\mathrm{Ru}_{3}(\mathrm{CO})_{11}$ fragments geminately recombine with the dissociated $\mathrm{CO}$ and vibrationally relax to reform $\mathrm{Ru}_{3}(\mathrm{CO})_{12}$ in 25 ps. The other molecules form a bridging structure which reacts with the solvent to produce $\mathrm{Ru}_{3}(\mathrm{CO})_{11} \cdot \mathrm{S}$ and isomerize to form the all-terminal structure in $50 \mathrm{ps}$. No $\mathrm{Fe}_{3}(\mathrm{CO})_{11}$ geminately recombines with the $\mathrm{CO}$. Instead the molecules adopt a $\mathrm{CO}$ 
bridging structure that reverts to an all-terminal structure in 400 ps. A portion of the molecules fragment to mono and dinuclear metal carbonyls. Attempts to extend ultrafast spectroscopy into the mid-infrared are also discussed. A cw infrared source, a carbon monoxide laser, was combined with an ultrafast visible laser system. Although the infrared upconversion apparatus did work, the signal-to-noise characteristics were not sufficient to make the system generally applicable to the study of chemical reactions in solution. 


\title{
Ultrafast Studies of Photodissociation in Solution: Dissociation, Recombination and Relaxation
}

\author{
Copyright $\odot 1995$ \\ by \\ Jason Christopher King
}

The U.S. Department of Energy has the right to use this document for any purpose whatsoever including the right to reproduce all or any part thereof 
To my inspiration, Dena. 


\section{Table of Contents}

Acknowledgements vi

Introduction viii

Chapter 1: Experimental 1

I. Ultrafast Visible Experiments 1

II. Ultrafast Infrared Upconversion Spectroscopy 5

A. Introduction 5

B. The Carbon Monoxide Laser 8

$\begin{array}{ll}\text { C. Actual Performance } & 15\end{array}$

Chapter 2: Vibrational Energy Relaxation of Ions

in Nonpolar and Moderately Polar Solvents 21

I. Introduction 21

II. Experimental 25

$\begin{array}{ll}\text { III. Results } & 27\end{array}$

IV. Discussion $\quad 30$

A. Vibrational Relaxation 31

B. The Long Component 45

$\begin{array}{ll}\text { V. Conclusion } & 49\end{array}$

Chapter 3: Vibrational Relaxation of $\mathrm{M}(\mathrm{CO})_{6}(\mathrm{M}=\mathrm{Cr}, \mathrm{Mo}, \mathrm{W})$ :

Effect of Metal Mass on Vibrational Cooling Dynamics and NonBoltzmann Internal Energy Distributions 52

I. Introduction 52

II. Experimental 54

A. Experimental Procedures $\quad 54$

B. Materials 55

III. Results 55 
IV. Discussion 57

V. Conclusion 71

Chapter 4: The Ultrafast Photochemistry of $\mathrm{Fe}_{3}(\mathrm{CO})_{12}$ and $\mathrm{Ru}_{3}(\mathrm{CO})_{12} \quad 73$

I. Introduction 73

II. Ultrafast Studies of Metal-Metal Bond

Cleavage in $\mathrm{Fe}_{3}(\mathrm{CO})_{12}$ in Solution $\quad 74$

III. Ultrafast Dynamics of Trinuclear Metal Carbonyl Complexes Following Ligand Dissociation $\quad 82$

A. Introduction 82

B. The Ultraviolet Excitation of $\mathrm{Ru}_{3}(\mathrm{CO})_{12}$

C. The Ultraviolet Excitation of $\mathrm{Fe}_{3}(\mathrm{CO})_{12}$

IV. Conclusion 98

$\begin{array}{ll}\text { Conclusion } & 100\end{array}$

$\begin{array}{ll}\text { References } & 103\end{array}$ 


\section{Acknowledgements}

While I have enjoyed the academic environment and active research community at Berkeley, it is the people that I have met and worked with during my time here that I will remember most of all. I want to thank my research advisor, Charles Harris for bringing all these people together and providing a rich environment in which to do research. I also want to thank him for the freedom he has given me to develop my own style of doing research. I would like to thank Vijaya Narasimhan. If I listed all the things she has done to help me during graduate school, it would certainly be longer than this dissertation. If it were not for her devotion to the group, the Harris group would be a very different place to work. I would also like to acknowledge the National Science Foundation for my funding and the Department of Energy for equipment funding.

I want to thank the people that mentored me when I joined the group. Niva Tro was my first boss and has since become a good friend. He taught me how to focus on the important issues and how to get things done (as well as how to sea kayak). Karen Schultz really made the lab a friendly place to work and showed me the ins and outs of the picosecond laser system. Jin Zhang and Ben Schwartz were my mentors and collaborators during the middle years of my graduate work. We made an excellent team (the three stooges?) with each of us bringing a different point-of-view to the table. Those were certainly my most productive scientific years during graduate school.

I also want to thank the younger students who I have worked with, Matt Asplund, Steve Bromberg and Carsten Vala (a.k.a. the ducklings). I have learned more from these three than anyone else in graduate school. They have shown me the best way to learn is to teach. 
There have been many others in the group that I did not work with directly, but who I have learned a great deal from and who made me look forward to coming into work everyday (well almost everyday). Robert Lingle, Robert Jordan, Jennifer Hane, Tim Lian, Steve Gadd and Jason McNeill have all been great coworkers. The younger students, Nien-Hui Ge, Haw Yang and Chung Wong, have all added a breathe of fresh air and enthusiasm to the group. The camaraderie with these students (and high paid postdocs) is what I will cherish most about graduate school.

I want to thank my parents for their love, support and strong encouragement over the years. It was their love of leaming that motivated me to go to graduate school.

Lastly, I would like to thank the most important person in my life, my wife Dena. She has inspired me on a daily basis for almost thirteen years and this work would not have been possible without her love and support over the last six years. She has not only made this work possible, but has made these last six years the happiest of my life. 


\section{Introduction}

The development of ultrafast lasers has resulted in a new era in the study of chemical dynamics. These new tools have extended our ability to study events twelve orders of magnitude shorter than our senses allow. Just as the telescope and microscope have opened up the world of the very large and small, ultrafast lasers have opened a new and very fleeting world to study. Processes that were once only postulated from extrapolating behavior on long time scales back to the very earliest times, are now amenable to direct study. It is this new perspective on chemistry, watching it as it happens, that has made this field so interesting to me.

My research has focussed on getting a better understanding of how chemical reactions occur in solution. Despite the fact that most chemistry occurs in solution, the basic processes involved in a chemical reaction in solution are not well characterized or understood. It is hoped that by studying these processes, useful insight can be gained into what controls the outcome of a chemical reaction. My research has been directed at studying chemical reactions from two perspectives. One way is to characterize each of the basic steps that can occur during a chemical reaction. Basic chemical processes such as bond breaking, bond formation, solvent caging, vibrational relaxation and isomerization are some of the ingredients in almost all chemical reactions, but yet are still not well understood. From studying these basic steps individually, one can buildup an understanding of the more complex processes involving many basic steps that occur

during most chemical reactions. Another way to address these questions is to look directly at more complicated but very useful chemical reactions. From looking at many such reactions, it is hoped that patterns will appear that would not be obvious from studying the 
basic steps individually. The patterns can then provide guidelines for the prediction of more complex behavior and help provide insight into the underlying principles that govern the basic processes.

There are a number of different, basic processes that my research has addressed. One of the most important areas studied is the formation of a chemical bond. Until recently this process has been poorly understood in the solution environment. The process can, in general, be broken down into two parts: the initial encounter of the two reactive species in the solvent cage and the dissipation of excess vibrational energy to form a stable chemical bond. Caging of reactive species by solvent molecules was first postulated over 60 years ago [1], but the time scale of this process has not been well characterized and remains a central problem in liquid phase reaction dynamics. In work which I collaborated in and presented elsewhere [2], the caging effect has been examined by studying primary geminate recombination, the nondiffusive recombination of fragments following photodissociation. To study this, transient absorption spectroscopy was used to directly follow the production and disappearance of $\mathrm{CH}_{2} \mathrm{I}$ radical fragments produced after the photodissociation of methylene iodide $\left(\mathrm{CH}_{2} \mathrm{I}_{2}\right)$ with femtosecond time resolution. The results provide the first direct observation of primary geminate recombination. The data indicates that a portion of the $\mathrm{CH}_{2} \mathrm{I}$ fragments recombine with the dissociated iodine atom in 350 fs. This time scale allows for only a single collision of the photofragments with the surrounding solvent cage after which recombination becomes unlikely. This shows that encounters between reactive species in solution are very fleeting. The reactive species generally have only a single opportunity during an encounter to form a chemical bond. Previous ideas of the solvent forming a "cage" around the reactive species, holding them 
together for many collisions, are qualitatively incorrect.

My research has also involved the study of the next step in bond formation, vibrational energy relaxation, in several chemical reactions. The vibrational relaxation dynamics following the dissociation of $\mathrm{C} \equiv \mathrm{O}$ from $\mathrm{M}(\mathrm{CO})_{6}(\mathrm{M}=\mathrm{Cr}, \mathrm{Mo}, \mathrm{W})$, discussed in Chapter 3, were studied with picosecond transient absorption spectroscopy. After dissociation of the $\mathrm{C} \equiv \mathrm{O}$ the pentacarbonyl species forms a complex with a solvent molecule. The cooling of this solvated pentacarbonyl complex was monitored from $1 \mathrm{ps}$ to $1 \mathrm{~ns}$ in this study. The vibrational relaxation of each of these three compounds was different. The $\mathrm{W}(\mathrm{CO})_{5} \cdot \mathrm{S}(\mathrm{S}=$ cyclohexane) vibrationally relaxed in $42 \mathrm{ps;}$ whereas, $\mathrm{Mo}(\mathrm{CO})_{5} \cdot \mathrm{S}$ relaxed twice as quickly, $18 \mathrm{ps}$. This is surprising because the higher density of states in $\mathrm{W}(\mathrm{CO})_{5} \cdot \mathrm{S}$ would be expected to lead to faster cooling of the hot solvated complex. The primary cooling of $\mathrm{Cr}(\mathrm{CO})_{5} \cdot \mathrm{S}$ is completed in $18 \mathrm{ps}$, just as in $\mathrm{Mo}(\mathrm{CO})_{5} \cdot \mathrm{S}$, but a slower component in the relaxation, approximately $150 \mathrm{ps}$ is also present for $\mathrm{Cr}(\mathrm{CO})_{5} \cdot \mathrm{S}$. This component is assigned to vibrational relaxation of the $\mathrm{C} \equiv \mathrm{O}$ stretching mode. From comparisons with other studies, it appears that the existence of this slower cooling component is only present in first row transition metal carbonyls.

The most recent work on bond formation is studying vibrational relaxation in ions, see chapter 2. In previous work, the vibrational relaxation of ions was found to be more than ten times faster than similar neutrals. The explanation for this accelerated transfer of energy to the solvent was that the polar solvents used (e.g. water, methanol, ethanol) could couple strongly to the charge on the ion. To test this hypothesis, the vibrational relaxation of $\mathrm{I}_{2}$ - has been studied in a nonpolar and moderately polar solvents. Surprisingly, the vibrational relaxation rate for $\mathrm{I}_{2}$ - in $\mathrm{CCl}_{4}$ is $5 \mathrm{ps}$, just as fast as in more polar alcohols. The 
contribution of charge/dipole interactions is additionally probed by using the increasingly polar $\mathrm{CHCl}_{3}$ and $\mathrm{CH}_{2} \mathrm{Cl}_{2}$ solvents, but no change in the relaxation rate is seen in going to these more polar solvents. The contribution of charge flow between the iodine nuclei to the relaxation rate is studied using the asymmetric $\mathrm{IBr}$ - ion. The relaxation rate of $\mathrm{IBr}$ - in $\mathrm{CHCl}_{3}$ is $5 \mathrm{ps}$ - the same as $\mathrm{I}_{2}$. This suggests that for these ions in fairly nonpolar solvents, charge flow is not the primary mechanism for energy transfer to the solvent. The vibrational relaxation of a polar diatomic, $\mathrm{IBr}$, is also studied in the chloromethane solvents. The process is found to be more like $\mathrm{I}_{2}$ than $\mathrm{I}_{2}$, and no trend in relaxation rate with solvent polarity is seen, indicating that dipole/dipole interactions do not dominate in this system. For the anions, the possibility of an intermediate, such as the counter ion or solvent impurities, acting as a conduit for energy transfer from the ion to the solvent is also investigated and is found to be unimportant. Finally, following photodissociation the majority of $\mathrm{I}_{3}$ - and $\mathrm{IBr}_{2}$ - ions form a metastable complex with a barrier of $4.3 \mathrm{kcal} / \mathrm{mol}$ to reform the trihalide ion and at least $5.5 \mathrm{kcal} / \mathrm{mol}$ to "dissociate."

In addition to these studies of very basic processes, a number of more complex, technologically useful, reactions have also been studied. One example is the study of the photochemistry of $\mathrm{Fe}_{3}(\mathrm{CO})_{12}$ and $\mathrm{Ru}_{3}(\mathrm{CO})_{12}$ discussed in chapter 4 . These species undergo a wide variety of chemical reactions, some of which are technologically useful, and some show novel chemical behavior, such as dynamic structure, quantum yields exceeding 100 for photocatalyzed reactions and semi-stable isomeric structures. Also these trinuclear carbonyl have several types of ultraviolet/visible absorptions that lead to distinctly different chemistry. The longer wavelength absorptions generally involve metal-metal bond excitations while shorter wavelength absorptions are metal-ligand bond excitations. 
This variety of chemistry and structures make these very interesting, but complex systems to study. This work studied three different reactions. The photochemistry of $\mathrm{Fe}_{3}(\mathrm{CO})_{12}$ was studied following excitation at $295 \mathrm{~nm}$ and $590 \mathrm{~nm}$ while the photochemistry of $\mathrm{Ru}_{3}(\mathrm{CO})_{12}$ was studied at just $295 \mathrm{~nm}$. The results show some interesting patterns. Some dynamics are common to all three reactions studied here while others occur in only one or two of the reactions. The most interesting common feature is that all species isomerize to a similar bridged structure immediately after excitation. In the case of long wavelength excitation of $\mathrm{Fe}_{3}(\mathrm{CO})_{12}$ the bridged species is an isomer that reverts back to the ground state in approximately $150 \mathrm{ps}$. In the shorter wavelength excitation of $\mathrm{Fe}_{3}(\mathrm{CO})_{12}$ and $\mathrm{Ru}_{3}(\mathrm{CO})_{12}$, the molecule loses a $\mathrm{CO}$ ligand to produce a $\mathrm{CO}$ bridged intermediate $\mathrm{M}_{3}(\mathrm{CO})_{11}$ which has a lifetime of $400 \mathrm{ps}$ for $\mathrm{Fe}_{3}(\mathrm{CO})_{11}$ and $50 \mathrm{ps}$ for $\mathrm{Ru}_{3}(\mathrm{CO})_{11}$. Why this isomerization to the bridged structure occurs in all these reactions is still unclear. On the other hand while a majority of the photodissociated $\mathrm{Ru}_{3}(\mathrm{CO})_{12}$ 's undergo geminate recombination and vibrational relaxation in $25 \mathrm{ps}$, no direct geminate recombination and vibrational relaxation occurs following the excitation of $\mathrm{Fe}_{3}(\mathrm{CO})_{12}$ at either $295 \mathrm{~nm}$ or 590 $\mathrm{nm}$. Perhaps the isomerization to the more stable bridged structures of the iron systems precludes immediate geminate recombination. It is hoped that additional studies of other complicated chemical behavior will begin to provide a better picture of how chemistry really happens.

The remainder of my work has centered on extending the technique of ultrafast spectroscopy to allow more systems to be studied and be better understood. The primary emphasis of this work was the construction of an infrared upconversion system discussed in chapter 1 . This system combined a cw infrared source, a carbon monoxide laser, with a 
standard visible picosecond system. Just as with the other experiments discussed in this work, the chemistry is initiated by a ultrashort pulse of visible or ultraviolet light. The cw infrared beam which is overlapped with this excitation pulse is then used to monitor the structurally diagnostic changes in the infrared spectrum. These changes in the infrared are then "read" by combining the $\mathrm{cw}$ infrared beam with another picosecond pulse in a nonlinear crystal. The intensity of upconverted light, produced in the nonlinear crystal, is directly proportional to the infrared intensity, so changes in the infrared spectrum of the sample are reflected in the upconverted light. Some samples were studied with this system, but ultimately, the inherent noise in the technique, combined with the specifics of our visible ultrafast laser system, did not allow the use of this system for general studies. The continued extension of all these directions - the study of basic processes, the study of more complicated chemistry and the development of new more general techniques - are all important for the development of a sophisticated understanding of chemical reactions in solution.

\section{References}

1. J. Franck and E. Rabinowitch, Trans. Faraday Soc. 30, 120 (1934).

2. B. J. Schwartz, J. C. King, J. Z. Zhang and C. B. Harris, Chem. Phys. Lett. 203, 503 (1993). 


\section{Chapter I: Experimental}

\section{Ultrafast Visible Experiments}

The laser system used for most of this work is a picosecond pulsed laser system that has been described previously [1]. A schematic of this system is shown in figure 1.1. The picosecond pulses are produced by a synchronously pumped dye laser pumped by a modelocked argon ion laser. The output of the argon ion laser is $120 \mathrm{ps}, 3-5 \mathrm{~nJ}$ pulses at $514 \mathrm{~nm}$ and $76 \mathrm{MHz}$. With this input the dye laser produces $2-3 \mathrm{ps}, 200-400 \mathrm{pJ}$ pulses at 580-590 nm (R6-G dye) and $76 \mathrm{MHz}$. The dye laser pulses are then amplified in a three stage dye amplifier line. The cells are all optically isolated by saturable absorber dye jets (crystal violet). This amplifier line is pumped by the doubled output of a Q-switched Nd:YAG laser. The $250 \mathrm{~mJ} /$ pulse output is divided between three amplifier cells with $4 \%$, $6 \%$ and $90 \%$ going to the first, second and third cell, respectively. The amplified pulses are $1 \mathrm{ps}, 1 \mathrm{~mJ}$ pulses at $580-590 \mathrm{~nm}$ and $10 \mathrm{~Hz}$. In all experiments discussed, a pump-probe configuration is used to study ultrafast dynamics. The beam is split into two parts, a stronger pump beam and a much weaker probe beam. The stronger pump beam excites the sample and the ensuing photodynamics are spectroscopically monitored by the probe beam. A portion of the beam can then be frequency doubled ( $1 \mathrm{~mm}, \mathrm{KDP}$, type 1 crystal) to produce the excitation (or pump) pulse. The pump pulse is then sent onto a computer controlled translation stage to provide a variable delay between the pump and probe pulses. The minimum step size for the stage used in these experiments is $10 \mu \mathrm{m}$, providing a minimum time step of $66 \mathrm{fs}$ for the single pass configuration on the 1 meter stage. The height of the pump beam is then adjusted using a two mirror configuration which changes the polarization of the pump to vertical. The polarization of the pump beam can then be 


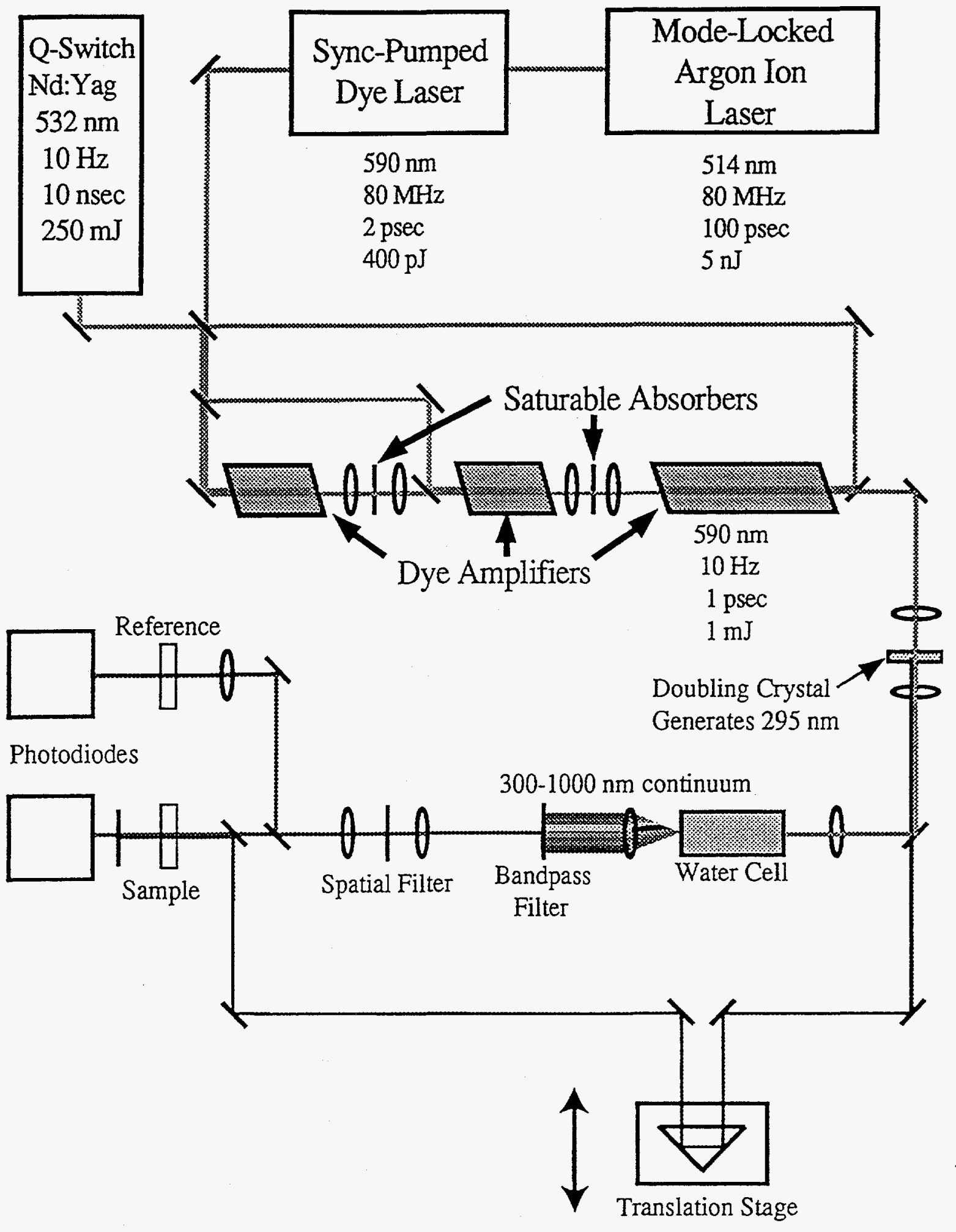

Figure 1.1 - Picosecond Laser System and Transient Absorption Apparatus. 
selected using a UV (Glan-Thompson) polarizer. The portion of the beam not used in the pump beam is focussed into a liquid cell producing a picosecond continuum from $380 \mathrm{~nm}$ to $900 \mathrm{~nm}$. Different portions of the continuum are enhanced by raman shifting from different liquids. A bandpass (notch) filter is then used to select a small portion of the continuum (10 nm FWHM) for use as the probe. The probe is then loosely spatially filtered (pinhole diameter $800 \mathrm{~nm}$ ). Two fused silica flats are then used to produce a reference and sample beam. Thick flats must be used to separate the front and back reflections off the flats. The sample beam is focussed and overlapped with the pump beam in the sample. For UV excitation experiments the two beams are overlapped collinearly and for visible excitation experiments the two beams are aligned at a small angle $\left(\sim 5^{\circ}\right)$. When the UV excitation/collinear arrangement is used, the same lens is used to focus the pump and probe beams into the sample. Because of difference in the wavelength of the pump beam $(295 \mathrm{~nm})$ and the probe beam $(380-900 \mathrm{~nm})$, the focal length of the two beams can differ significantly $(1 \mathrm{~cm}$ for a $10 \mathrm{~cm}$ lens). The maximum signal is produced when the size of the pump beam and probe beam is the approximately the same, so it is important to adjust the focal properties of one of the beams, so that the focal lengths match. This was done either by putting a lens with a long positive focal length in the probe beam or a slightly misaligned galilean telescope in the pump which causes some divergence. These lenses also provide a means for fine tuning the overlap of the two beams in the sample which is very important for maximizing the signal.

Several methods have been used for sample handling. In general, the sample must be flowed to minimize buildup of photoproducts in the sample volume being probed. Early experiments used a high capacity pump combined with a $1 \mathrm{~mm}$ to $1 \mathrm{~cm}$ long sample cell. However, this combination required a large volume of sample and did not prevent 
buildup of photoproduct on the walls of the sample cell. The latter problem was solved by switching from a quartz cell to a laminar flow jet. The solution would then be probed just under the nozzle in the laminar portion of the jet. This solved the problem of photoproduct buildup on the cell walls, however, it has the inherent difficulties of requiring very precise positioning of beams in the jet, prohibiting use of some solvents because of poor jet quality, prohibiting use of air sensitive samples, and prohibiting use of samples with low solubilities or low absorption cross sections because of the thinness of the jet $(\sim 100 \mu \mathrm{m})$. If photoproduct buildup was not a concern a better alternative was a peristaltic pump and quartz cell. This allowed smaller samples to be used and made changing samples a very quick and easy process.

Following the sample, the pump beam is removed either by blocking it (off angle experiments) or with optical filters (collinear experiments). The probe beam is then focussed into a silicon photodiode. The reference beam is similarly focussed into another photodiode. If the sample has any absorption at the wavelength being studied (in the ground state) it is important to put a sample cell of the same path length and concentration in the reference beam otherwise a neutral density optical filter works fine. The photodiodes are reverse biased to produce a short output pulse. This pulse is then electronically gated and integrated. The integrated intensities are then ratioed to give the signal to reference ratio. At a given translational stage delay, these ratios are averaged to decrease the noise. When operating well the standard deviation of the signal to reference ratios is $2.0 \times 10^{-3}$. With averaging, the noise can be reduced so that changes of one part in ten thousand can be measured. After data are collected at one translation stage position for a given number of laser shots, the position of the stage is moved to provide incremental changes in the delay between the two beams. In the data scans, a number of points correspond to the probe 
pulse getting to the sample before the pump (noted as $t<0$ ) to determine the unperturbed ratio between the sample and reference. As the path length of the pump pulse is reduced, the situation changes and the pump pulse arrives first and the probe follows and spectroscopically probes the chemical changes in the sample at specified times. The stage is scanned both backwards and forwards to compensate for any long term drift. After collection, the data are edited to remove any bad points (due to a bubble in the sample, bad laser shot, etc.) summed and changed from transmission to absorption. The data are then fit on a fitting program designed within our group.

\section{Ultrafast Infrared Upconversion Spectroscopy}

\section{A. Introduction}

A primary emphasis of my early graduate work was the extension of ultrafast spectroscopy from the traditional ultraviolet and visible regions of the spectrum to the midinfrared region. This is scientifically attractive because the absorptions in this region of the spectrum are structurally diagnostic, however ultrafast infrared spectroscopy is technically difficult because of the lack of ultrafast infrared sources. To overcome this problem the method decided upon was upconversion of a continuous wave (CW) infrared source.

The infrared upconversion system was an extension of the ultraviolet/visible picosecond system previously described. A schematic of the system is shown in figure 1.2. The $1 \mathrm{ps}, 1 \mathrm{~mJ}$ pulses at $590 \mathrm{~nm}$ and $10 \mathrm{~Hz}$ were again split into two parts. The pump beam (at $590 \mathrm{~nm}$ or doubled to $295 \mathrm{~nm}$ ) was used to excite the sample and the gating (or upconversion) pulse. The pump beam went through a fixed delay and was then overlapped with the infrared beam in the sample. The infrared beam was the output of a 


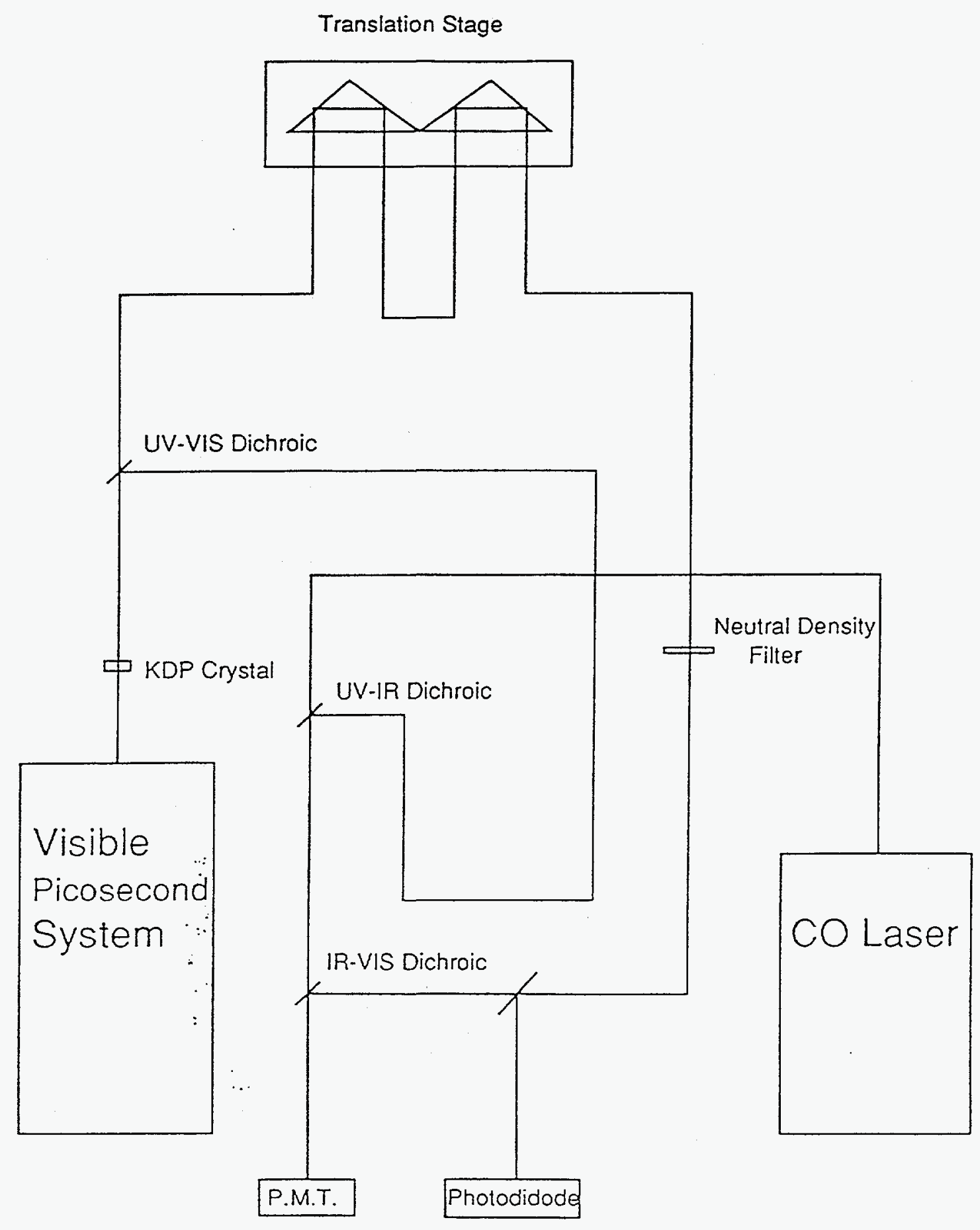

Figure 1.2 - Schematic of the Infrared Upconversion Apparatus. 
$\mathrm{CW}$ carbon monoxide laser (see below). This $\mathrm{CW}$ infrared source was chosen because of its tunability, high power, and output in the region of the spectrum where transition metal carbonyl complexes absorb. When the pump pulse excites the sample, dynamics of the molecules changed the infrared absorption of the sample. The dynamics of the molecules were therefore reflected in the $\mathrm{CW}$ infrared beam. After the sample the pump beam was blocked by a dichroic mirror that reflected the visible and ultraviolet and transmitted the infrared. This dichroic mirror was also used to overlap the infrared beam collinearly with the upconverting pulse. The upconverting pulse's delay was controlled with a computer controlled translation stage. These two beams (infrared and upconverting) were then sent into a nonlinear optical crystal $\left(\mathrm{LiO}_{3}\right)$ aligned to produce the sum frequency of the two beams. The summed output had the sum frequency of the two beams $(530 \mathrm{~nm})$, the duration of the upconverting pulse (1 ps), and the intensity was linearly dependent on the intensity of the two input beams. After the crystal the two input beams were blocked with optical filters, and the upconverted light was detected with a photomultiplier tube (PMT). The PMT was necessary because of the low intensity of the infrared pulses. A portion of the upconverting pulse was sent into a photodiode to act as a reference. The electronic measurement and data treatment were then the same as used in the visible/ultraviolet system (see above).

Infrared upconversion spectroscopy has the advantage of providing good time and frequency resolution, simultaneously. The frequency resolution is defined by the $\mathrm{CW}$ output of the carbon monoxide laser which is approximately $0.1 \mathrm{~cm}^{-1}$. The time resolution is determined by the cross correlation between the pump pulse and the upconversion pulse which in this case is approximately 2 ps. The ability to precisely determine the frequency that the sample is being probed at and the time it is being probed at does not violate the 
uncertainty principle for time and energy because the two quantities are not being determined simultaneously. The frequency which interacts with sample is determined at the sample while the time determination is made at the upconversion crystal. It is similar to a standard pump-probe experiment using a monochromator. In that case the time is determined at the sample and the wavelength is determined by the monochromator.

\section{B. The CO Laser}

The carbon monoxide laser was chosen as the infrared source for the ultrafast infrared upconversion apparatus for several reasons. It has a high output power compared to other sources in this region of the spectrum. The output is tunable between $1600 \mathrm{~cm}^{-1}$ and $2000 \mathrm{~cm}^{-1}$ which is the region of the spectrum where organic and organometallic carbonyl groups absorb. In addition the laser was straightforward to assemble and operate.

The laser is based upon the inversion of the vibrational and rotational levels of the carbon monoxide molecule by impact excitations with ions in a low pressure plasma [2]. A schematic of the laser is shown in figure 1.3. The laser tube was quartz with calcium fluoride windows oriented at brewster's angle $\left(55.8^{\circ}\right.$ for $\left.\mathrm{CaF}_{2}\right)$. The laser tube was wrapped in a jacket for liquid nitrogen cooling. This jacket had an input and output spout and held about 6 liters of liquid nitrogen. A liquid nitrogen sensor was placed near the top of the jacket and attached to a solenoid which controlled liquid nitrogen input to allow automatic filling of the jacket. The violent boiling off of the liquid nitrogen when filling significantly increased the noise on the laser output, to the extent that data could not be collected while the jacket was being filled. The laser tube, end mirror and tuning grating were all mounted on an I-beam for stability in the early experiments and later transferred to 


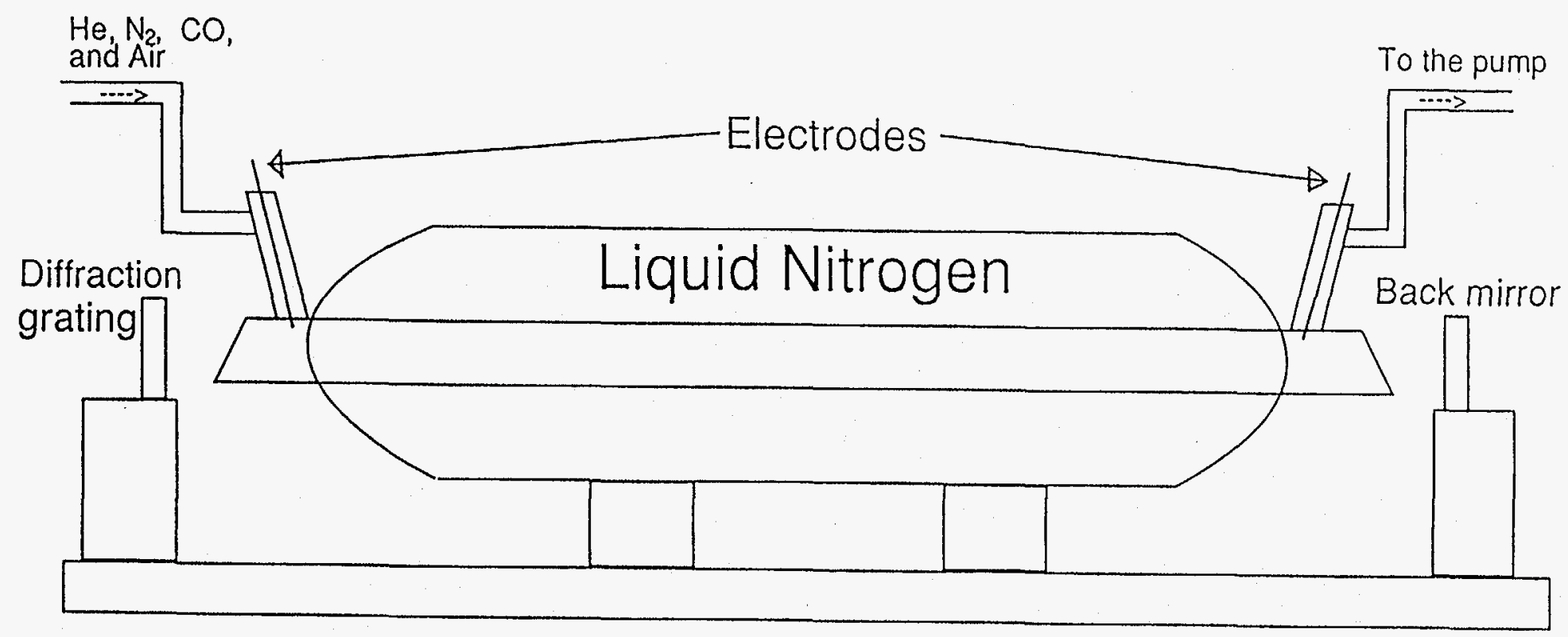

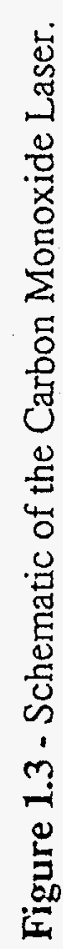


an optical table which improved noise somewhat. The end mirror was gold coated and had a radius of curvature of $10 \mathrm{~m}$. The diffraction grating was blazed for $6 \mu \mathrm{m}$. The first order diffraction was aligned with the end mirror and the zeroth order diffraction (at the angle of the reflection) was coupled out of the cavity. The grating was mounted on a rotational stage to allow wavelength tunability. Two irises were placed in the cavity to produce a $\mathrm{TEM}_{\infty}$ mode. This required the irises to be closed down to $1 \mathrm{~cm}$. The input gases were a mixture of helium, nitrogen, air and carbon monoxide. The pressure for each gas (as measured by a pressure gauge connected to the laser tube) was:

$$
\begin{aligned}
& \text { Helium }-5.5 \text { torr } \\
& \text { Nitrogen }-0.5 \text { torr } \\
& \text { Air }-0.05 \\
& \text { Carbon Monoxide }-0.25 \text { torr }
\end{aligned}
$$

The air was filtered and run through drierite to remove any moisture that might absorb in this region of the spectrum. The gases were mixed in a small ballast bulb. The laser tube was evacuated and gases pulled through using a small mechanical pump from which the exhaust was connected to a fume hood. The carbon monoxide tank was enclosed and also vented to the fume hood to protect against carbon monoxide buildup from slow leaks.

Originally a home-built unregulated power supply was used to produce the discharge inside the laser tube, but a ripple at $360 \mathrm{~Hz}$ was seen in both the output of the power supply and the output of the laser. A regulated power supply removed this noise. The power supply was connected to a ballast box with five $100 \mathrm{k} \Omega, 225 \mathrm{~W}$ resistors in series. The high voltage was then connected to the electrode at the end of the laser where the gases exited. This electrode would sometimes arc to the pump through the exiting gas line. It was therefore very important to ground the pump well, so that it was never floating 
at high voltage. The electrode at the gas input end was also securely attached to ground. The voltage of the power supply was adjusted to $12 \mathrm{kV}$ which produced a current of 5-10 $\mathrm{mA}$ with the correct gas mixture for lasing. Prolonged operation of the laser produced a buildup of material on and around the electrodes. To clean the tube and electrodes a discharge of just helium (about 5 torr) was used for several hours after each day of operation. No liquid nitrogen, was used and the voltage and current were $12 \mathrm{kV}$ and $15-20$ $\mathrm{mA}$. It is potentially unsafe to clean the tube immediately after operation (see below).

The output of the laser was tunable in approximately $4 \mathrm{~cm}^{-1}$ increments from 1600 $\mathrm{cm}^{-1}$ to $2000 \mathrm{~cm}^{-1}$ by tuning the diffraction grating (see figure 1.4). The output frequency was continuously monitored by catching a weak reflection off the brewster window and sending it through a 1-meter Jarrell-Ash monochromator into a Ge:Au detector. The detector input was chopped because the detector was AC coupled. Several laser lines seemed to be missing, especially in the $1650 \mathrm{~cm}^{-1}$ to $1800 \mathrm{~cm}^{-1}$ region, probably because of atmospheric absorptions (especially $\mathrm{H}_{2} \mathrm{O}$ ) in the region between the brewster windows and the end mirror and diffraction grating. It has been suggested that enclosing the entire laser cavity, including end mirror and grating in a box purged with dry $\mathrm{N}_{2}$ will improve output for these missing wavelengths [3]. The output power of the laser in the TEM $ळ$ mode varied from $1 \mathrm{~W}$ to a few tens of milliwatts depending on the frequency. With all transverse modes lasing (irises open) the maximum output was approximately 3 watts. The strongest lasing occurred between $1800 \mathrm{~cm}^{-1}$ and $2000 \mathrm{~cm}^{-1}$. This corresponds to lasing from $v=14$ to 13 to $v=4$ to 3 . Decreasing the helium and carbon monoxide pressures increased the power at frequencies $>1950 \mathrm{~cm}^{-1}$ (also allowed lasing above 2000 


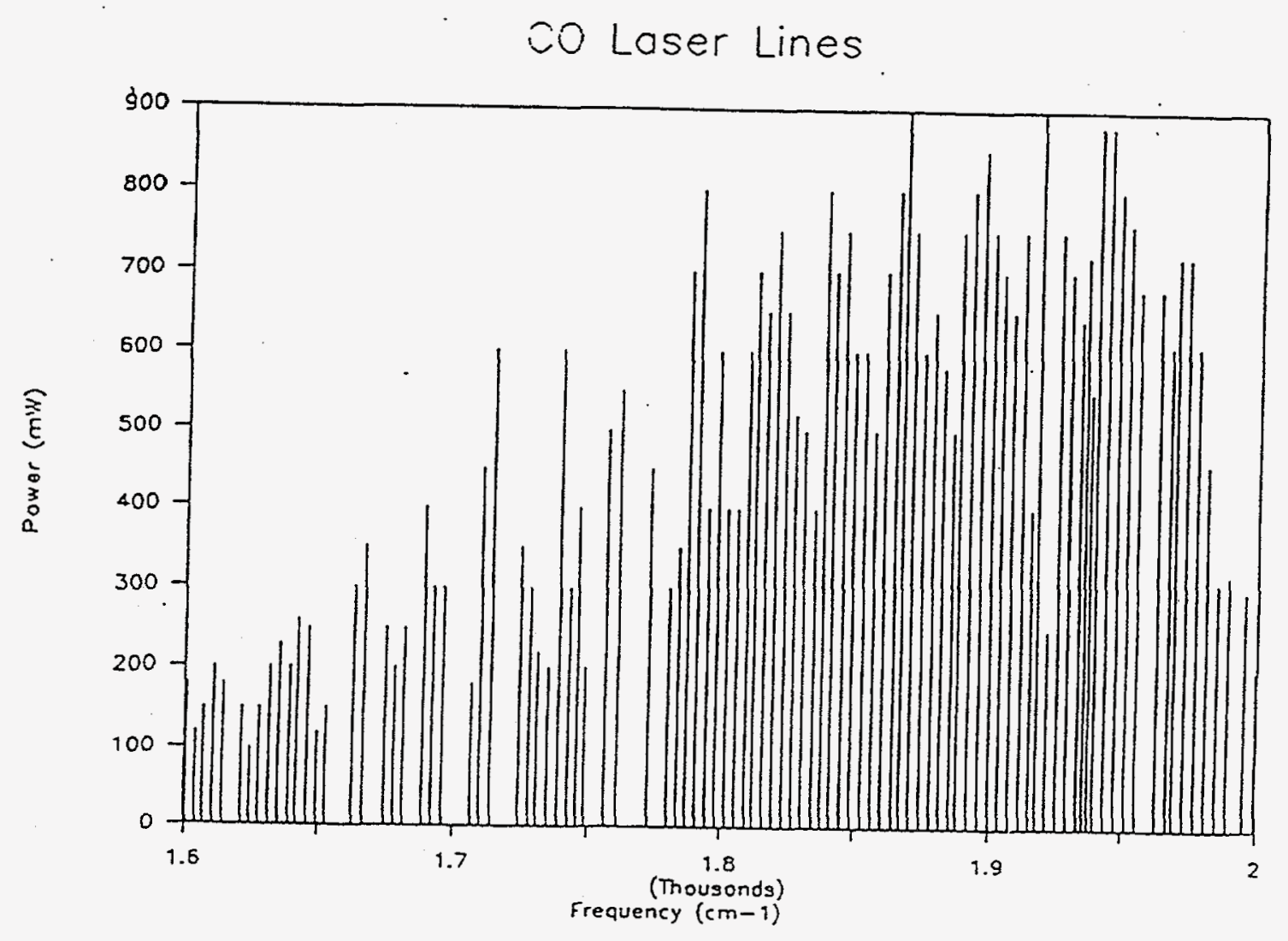

Figure 1.4 - Carbon Monoxide Laser Output. 
$\mathrm{cm}^{-1}$ ). Running the laser without liquid nitrogen caused an increase in power at frequencies below $1800 \mathrm{~cm}^{-1}$.

The start up and shutdown procedures for the laser are:

\section{CARBON MONOXIDE LASER TURN-ON PROCEDURE}

1. Check pressure in laser cavity to make sure it is pumped down to about 0.4 torr and the vacuum pump is working fine.

2. Fill liquid nitrogen tank and connect tubing for flowing the liquid nitrogen.

3. Fill laser tube cooling jacket with liquid nitrogen.

4. Turn on valves at gas tanks.

5. Fill laser tube with 6 torr helium.

6. Slowly turn high voltage up to $12 \mathrm{kV}$ (should see a pink discharge in laser tube).

7. Open air valve one small division ( -0.05 torr).

8. Open nitrogen gas valve just to full scale ( 0.5 torr).

9. Open carbon monoxide valve 2.5 big divisions ( 0.25 torr).

10. Laser should be lasing.

\section{CARBON MONOXIDE LASER SHUT-DOWN PROCEDURE}

(*including emergency shut-down)

*1. Turn off high voltage (most important).

*2. Turn off carbon monoxide gas valve (important).

*3. Discharge the electrode to ground.

*4. Remove clip from ground glass joint where gases exit the laser tube.

5. Turn off air and nitrogen gas valves.

6. Stop liquid nitrogen flow.

7. Let helium gas run for about 2-3 hours to evacuate the tube and then turn off. 
*Steps 1-4 should be taken in case of an emergency such as flood, fire, earthquake or for any power failure.

A recurring problem with this laser is that ozone is produced in the electrical discharge and condenses on the liquid nitrogen cooled interior surface of the laser tube. This caused two serious problems. First, the condensed $\mathrm{O}_{3}$ constituted an explosion hazard. It was probably safe as long as the system was liquid nitrogen cooled, but if the liquid nitrogen cooling quickly ceased, the condensed $\mathrm{O}_{3}$ could evaporate and produce dangerous concentrations of the gas in the tube. To keep this from happening, the liquid nitrogen level was always closely monitored and if the tube stopped being cooled (e.g. because the liquid nitrogen tank was empty) the discharge would not be restarted until the system was recooled and evacuated (although this was rarely effective, see below). In cases of emergency shutdown (see above) the procedure was to turnoff the high voltage (to prevent the ignition of ozone when power came back on), turn off carbon monoxide (a poisonous gas), discharge the electrode (to prevent $\mathrm{O}_{3}$ ignition), and remove the clip on the output line. This last step was to remove a clip holding a ground glass joint together that connected the laser tube to the vacuum pump. The joint would stay sealed as long as there was less than atmospheric pressure in the tube. When the pressure in the laser tube increased to atmospheric pressure (because of the evaporation of $\mathrm{O}_{3}$ and the in flowing helium) the joint would disengage allowing the gases to vent to the atmosphere and not allowing dangerous concentrations of $\mathrm{O}_{3}$ to buildup in the tube.

The other difficulty produced by the ozone was that if the liquid nitrogen level got low (presumably allowing the laser tube to heat up slightly) the pressure in the laser tube would go up to a level where lasing was not possible. There are two ways that the ozone 
could be responsible for this problem. First, the evaporation of the ozone could start a chemical reaction in the laser tube (with CO?) that would heat the tube, evaporating more ozone and causing the pressure to continually go up. However, it seems unlikely that this process would continue after the liquid nitrogen was refilled and the tube recooled. An alternate, and I believe more plausible, explanation is that when the ozone evaporated it is sucked out of the laser and into the pump. The ozone could then react with the pump oil to produce volatile compounds and thus reduce the efficiency of the pump. Several attempts were made to reduce the problem, including silver foil to catalyze the reaction of $\mathrm{O}_{3}$ to $\mathrm{O}_{2}$, but none were effective. The best solution would probably be to put a liquid nitrogen cold trap between the laser tube and the pump to condense and trap any ozone leaving the tube. This has the disadvantage of producing another explosive danger with the condensed ozone.

\section{Actual Performance}

The infrared upconversion experiment was a victory in principle, but a defeat in practice. The problem was fundamentally a signal-to-noise issue. The noise inherent in the system was large for several reasons. First the measurement of the infrared beam depended upon upconversion - a nonlinear optical process. Any fluctuation in spatial profile of either the infrared beam or the upcoming pulse or poynting instability in either caused noise on the signal that could not be easily subtracted. In addition the reference signal was produced strictly from a portion of the upconverting pulse and therefore did not reference out any noise due to the carbon monoxide laser or the upconversion process.

It is especially likely that the output of the carbon monoxide laser was noisy due to 
beating between longitudinal modes of the laser cavities. The difference in frequency between adjacent longitudinal modes is [4]:

$$
\begin{aligned}
& \qquad \Delta v=2 \pi(\mathrm{c} / 2 \mathrm{~L}) \\
& \Delta v=\text { difference in frequency between adjacent longitudinal modes } \\
& \mathrm{c}=\text { speed of light } \\
& \mathrm{L}=\text { laser cavity length. }
\end{aligned}
$$

The two meter carbon monoxide laser cavity has longitudinal mode spacings of approximately $0.015 \mathrm{~cm}^{-1}$. Therefore, in the $0.1 \mathrm{~cm}^{-1}$ gain profile of each rotational vibrational transition of the $\mathrm{CO}$ laser several (5-6) frequencies will lase simultaneously. Beating between these modes will cause fluctuations in the infrared output on the nanosecond time scale that are very difficult to measure as well as subtract out of the signal.

Another factor contributing to the noise was the use of a PMT to measure the upconverted light. In the visible pump-probe experiments discussed in this work, silicon photodiode detectors were used. However, the small number of photons in the upconverted pulse $\left(\sim 10^{5}\right)$ required amplification to produce the $10^{9}$ electrons needed for measurement. The only feasible way to get $10^{4}$ amplification (including internal inefficiencies) was a photomultiplier tube. However when two photomultiplier tubes were used to measure two portions of the gating pulse and the reading on each photodiode plotted and compared to two photodiodes measuring the same beams (see figure 1.5) the photomultiplier tubes were obviously much noisier. The fluctuation of the ratio of the two detectors shows a standard deviation of $4 \%$ shot-to-shot for the photomultiplier tubes and $0.2 \%$ for the photodiodes. The reason for the large noise in the PMT output was believed to be that the maximum currents of the last few dynodes of the PMT were being exceeded. 


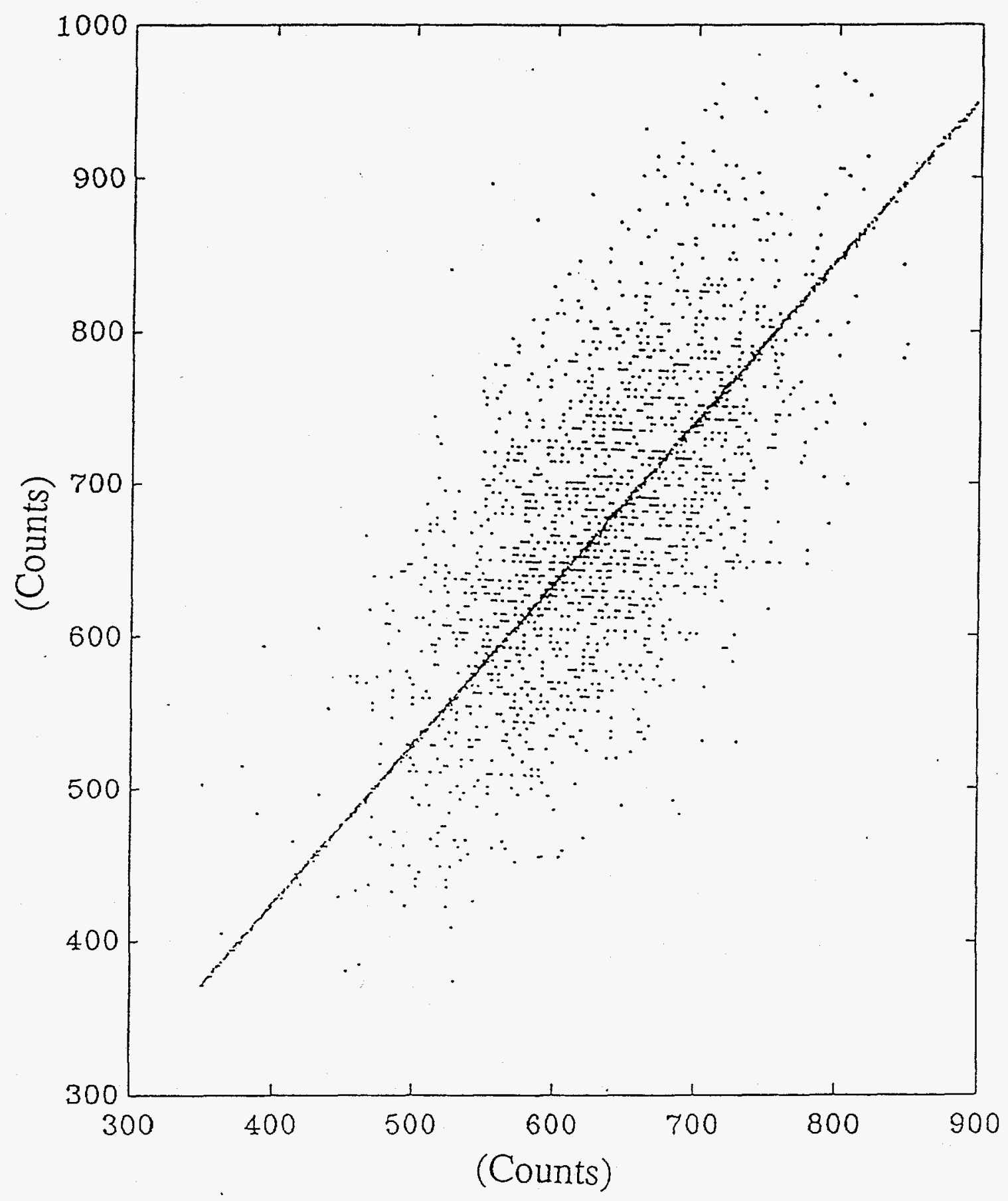

Figure 1.5 - The Readings from Two Photodiodes (narrow distribution) and Two Photomultiplier Tubes (scattered distribution). The Detectors Were Used to Measure Two Portions of the Upconverting Pulse. 
These large currents were due to the short input pulses and the comparatively large number of electrons required for measurement. Several custom built photomultiplier tubes were engineered by Hamamatsu Corp., but none produced significant improvement in the results shown in figure 1.5 .

The contribution to the noise that ultimately made our infrared upconversion setup impractical was the low repetition rate of the system. While other infrared upconversion apparatuses had similar noise sources, the ones that were successful operated at repetition rates of $10^{2}$ to $10^{3}[5,6]$. This allowed fluctuations of a few percent shot-to-shot to be averaged away at 10 to 30 times the rate possible with our apparatus, allowing signals of a few tenth's of a percent to be measured.

Despite the poor signal to noise characteristics of our apparatus, a few experiments with samples that produced very large signals were possible. Figure 1.6 shows the change in absorption at $1977 \mathrm{~cm}^{-1}$ for a thin silicon wafer following excitation at $295 \mathrm{~nm}$. The silicon wafer is originally transparent to the infrared because the valence band is full and the photon energy is less than the band gap. The excitation pulse excites electrons well above the bandgap for silicon $(1.2 \mathrm{eV})$ and into the conduction band where intraband excitations are possible, and the absorbance of the sample goes up. This can be seen as an increase in the absorption at $t=0$ in the data. This is followed by a decrease in absorption probably due to cooling of the electrons in the conductor band. This cooling occurs with an exponential time of $20 \mathrm{ps}$. There is then a much longer decay ( $>1 \mathrm{~ns}$ ) of the absorption as electrons and holes recombine. It is only the very large change in absorption for this sample $(\sim 15 \%)$ that allowed it to be studied. Signal sizes from chemical reactions in solution were estimated to be only $2-4 \%$ so in the end this apparatus was not able to study those processes for which it was intended. 
Infrared Upconversion

Silicon - Pump $295 \mathrm{~nm}$. Probe $1977 \mathrm{~cm}^{-1}$

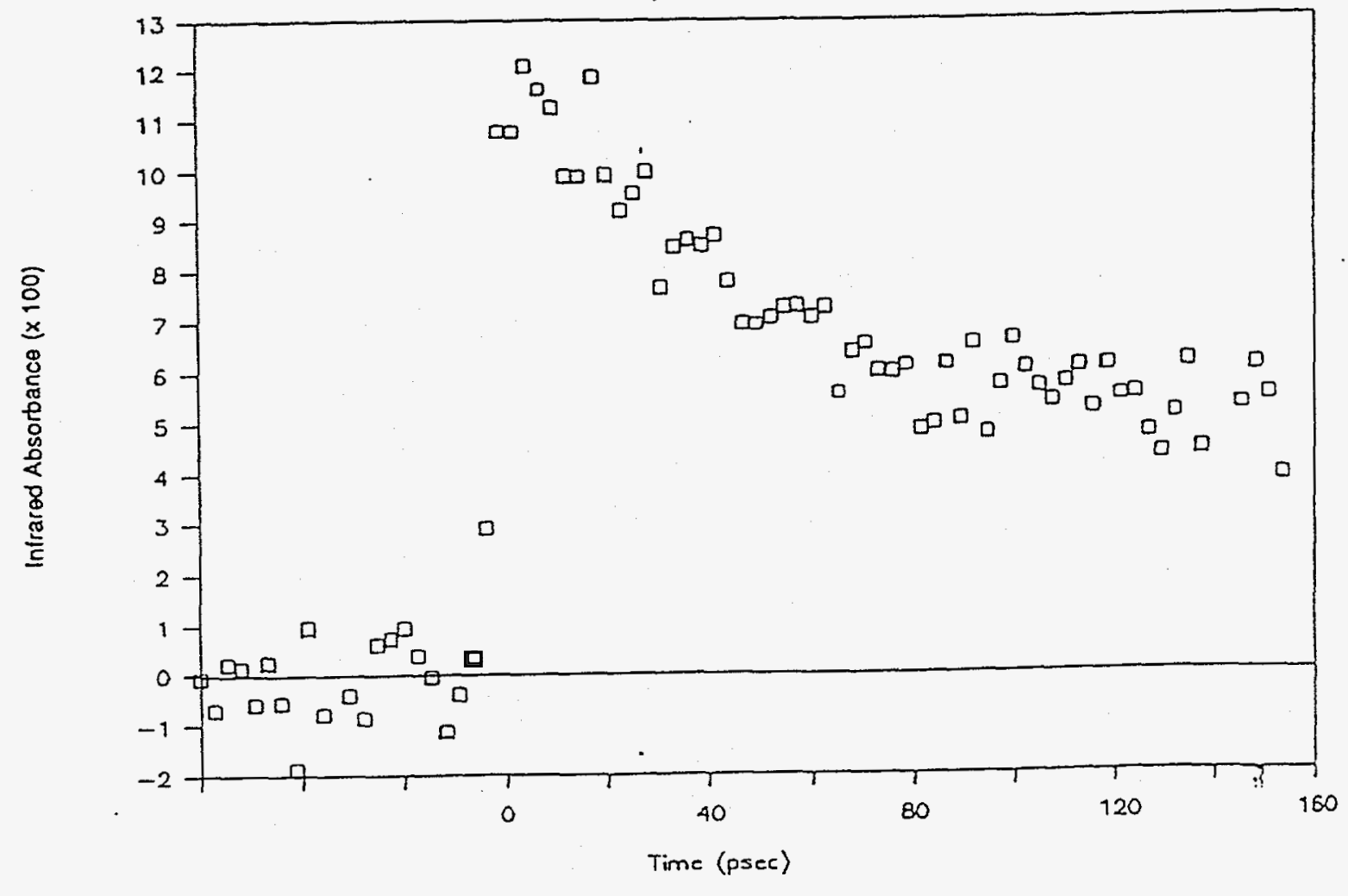

Figure 1.6 - Change in Infrared Absorption (1977 $\left.\mathrm{cm}^{-1}\right)$ Following Ultraviolet Excitation $(295 \mathrm{~nm})$ for a Thin Silicon Sample. Measured with an Infrared Upconversion Apparatus. 
For this system to have been successful, the effective noise needed to be significantly reduced. As mentioned previously, one way to reduce the noise was to combine the infrared with a higher repetition rate system. The two ultrafast systems available at the time for combining with the infrared were an $8 \mathrm{KHz}$ colliding pulse modelocked laser system and a $10 \mathrm{~Hz}$ dye laser system. The $10 \mathrm{~Hz}$ system was chosen because it was easier (longer pulse length, more power per pulse). However, the CPM based system probably would have been a better choice. Another solution to the extreme noise would have been a better normalization of the signal and reference. This might have been achieved through upconverting both the signal and the reference. Recent work in other groups has shown this to be beneficial [7]. Subsequent attempts to Q-switch the carbon monoxide laser, although aggressively pursued [8], probably were in vain because it still would not have reduced the noise sufficiently. Perhaps the lesson to be learned from this work is to quickly identify the weaknesses of a technique, decide whether the problems are fundamental, and if so, try a different approach. In the end the realization of the difficulties came too slow and attempts to correct them were not revolutionary enough. 


\section{Chapter II: Vibrational Energy Relaxation of Ions in Nonpolar and Moderately Polar Solvents}

\section{Introduction}

The formation of a chemical bond is one of the most fundamental events in chemistry. Despite the fact that bond formation occurs in nearly every chemical reaction, the process is still not well understood, especially in solution. Consequently, there has been a tremendous amount of work both theoretical and experimental to understand this process, however several factors make bond formation difficult to study. One difficulty in addressing this problem theoretically is that the process strongly depends on the interaction of the reacting species with their environment. In solution, this interaction is extremely complex, depending on how the internal degrees of freedom of the reacting species interact with the many-body intermolecular potentials of the solvent. This has made the process difficult to describe in an analytic form, although some progress has been made in smaller systems [9]. An experimental difficulty in studying chemical bond formation is the very short time scale on which the event occurs. Even for reactions that take days to complete, the individual bonds are broken and formed in $10^{-10}$ to $10^{-12}$ seconds. It is only recently, with the advent of ultrashort pulsed lasers that experimental tools capable of monitoring the formation of a chemical bond have been developed.

While there are many types of ultrafast spectroscopies $[10,11]$ (e.g. pump-probe, transient raman and four-wave mixing), all depend upon initiating a chemical event with an ultrashort $\left(<10^{-9}\right.$ seconds) pulse of light. This limits the types of chemistry that can be studied with these techniques in two ways. First, because the reaction must be initiated by a pulse of light, only photochemistry can be studied. Second, to study a very fast process 
such as bond formation, the process must occur soon after the initiating light pulse or the kinetics of the fast event will be swamped out by the longer time scale processes. For these two reasons, studies of bond formation in solution have focussed primarily on the reformation of the chemical bond between two reactive fragments produced by photodissociation.

The first system in which bond formation was thoroughly studied was the photodissociation and recombination of the $\mathrm{I}_{2}$ molecule [12]. Following photodissociation some of the iodine atoms are trapped by the solvent cage and recombine on the ground state potential. These molecules then reform the chemical bond. Eisenthal and coworkers conducted the first experiments probing bond reformation by single color pump-probe experiments [13]. In these experiments one pulse of light (pump) was used to initiate the chemical reaction and a second weaker pulse (probe) of the same wavelength was used to monitor the recovery of the $I_{2}$ absorbance. The absorbance of $I_{2}$ returned as the iodine atoms recombined with their geminate partners to reform the chemical bond and hence, $\mathrm{I}_{2}$. The chemical bond was found to reform in $70 \mathrm{ps}$ to $140 \mathrm{ps}$, depending on the solvent. The rate limiting step in this process was assigned to the diffusion of the photodissociated I atoms to find their original partners.

Several years later Hynes and coworkers challenged the assignment of diffusion as the rate limiting step [14]. Their simulations of the bond formation process showed that the recovery of the ground state absorption, studied by Eisenthal and coworkers, does not occur until the molecules are in the lowest vibrational levels of the ground state well. In addition, Hynes and coworkers determined that the time required for the two reactive iodine atoms at the top of the potential well to discard vibrational energy to the solvent and 
reach the lower vibrational levels is approximately 100 ps. This process, known as vibrational energy relaxation, was experimentally verified to be the rate limiting step in the formation the iodine bond by a subsequent series of studies. In particular, Harris and coworkers monitored the time dependent changes in the absorption spectrum of $I_{2}$ as the bond was reformed [15] and found that changes in the absorption spectrum agreed well with predictions from the simulations.

In later studies of many other chemical systems, vibrational energy relaxation was determined to be the rate limiting step in bond formation [15-18]. Vibrational energy relaxation was also studied in systems in which no chemical bonds were formed. This was done both by infrared pump-probe experiments in which a single quantum of vibrational energy was deposited in a bond and its subsequent relaxation was monitored, [19] and also in experiments where molecules were promoted to an excited electronic state which internally converted to the ground state with a large amount of excess vibrational energy [20]. In all cases the results were consistent. The rate of relaxation depends upon the coupling of the modes in the vibrationally excited species to modes of the solvent. The time scale for the process was similar for all systems, but varied from 10 ps for larger molecules with many modes capable of coupling to the solvent to $100 \mathrm{ps}$ for small molecules with fewer modes.

Several recent studies have shown that bond formation is dramatically different process in ions. In particular, work on the vibrational energy relaxation of the $I_{2}$ - ion has shown that the process is very different from that in the neutral $\mathrm{I}_{2}$ molecule. Barbara and coworkers studied the photodissociation and recombination of the $I_{2}$ - ion [21-23] as had been previously done for $\mathrm{I}_{2}$. Because $\mathrm{I}_{2}$ - is only stable on the nanosecond to microsecond 
time scale [24], it had to be produced via a photochemical process. Barbara and coworkers photodissociated the stable $I_{3}$ - ion to produce $I$ and $I_{2}$ - Then a several nanosecond delay allowed the $I_{2}$ ion to equilibrate with its environment. Just as with experiments on $I_{2}$, one pulse of light was used to dissociate the $\mathrm{I}_{2}$, and the reaction (bond formation) was then probed with a second pulse. Their work showed that the time required for the dissociation, recombination and vibrational relaxation varied from 3 to $5 \mathrm{ps}$ in water and a variety of alcohols, a factor of 20 to 30 times faster than the same process for $I_{2}$. The increased rate for vibrational energy relaxation of $\mathrm{I}_{2}$ - was postulated to occur because of charge hopping between the iodine nuclei during the relaxation [23]. The charge could couple very strongly to the polar solvent and provide an efficient route for energy transfer from the molecule to the solvent.

In a different series of studies, Banin and Ruhman examined the rate limiting step of vibrational energy relaxation in $I_{2}$ - bond formation via another route [25-28]. In their work the vibrationally excited $\mathrm{I}_{2}$ - was produced in the initial photodissociation of the stable $\mathrm{I}_{3}{ }^{-}$. From coherent oscillations in the absorption spectrum of the vibrationally excited $\mathrm{I}_{2}-$ $I_{2}$ - was found to be very vibrationally excited $(V=25)$ following the photodissociation of $I_{3}$. - The subsequent vibrational energy relaxation was monitored in water and a variety of alcohol solvents. In all cases the process was consistent with that of Barbara and coworkers with the vibrational energy relaxation occurring in 4-7 ps. These two series of studies both found that the vibrational energy relaxation was extremely fast for $I_{2}$ - in polar solvents.

The object of this study is to elucidate the mechanism of this very fast energy transfer in ions. This is done by thoroughly investigating the vibrational energy relaxation 
of $\mathrm{I}_{2}$ - in a nonpolar noncomplexing solvent, $\mathrm{CCl}_{4}$. There is the additional benefit that $\mathrm{I}_{2}$ has also been studied in this solvent, so that direct comparisons can be made between the relaxation of neutral and ionic species. The vibrational energy relaxation is also examined in increasingly polar $\mathrm{CHCl}_{3}$ and $\mathrm{CH}_{2} \mathrm{Cl}_{2}$ to determine the effect of the polarity of the solvent. The importance of the symmetry of $I_{2}$ is investigated by studying the dynamics of $\mathrm{IBr}^{-}$, and comparing them to the neutral IBr. Also, the importance of a variety of other factors, such as the effect of the counter ion, solvent impurities, and nonequilibrium electronic excitations are also addressed. Finally the longer time scale dynamics of $\mathrm{I}_{3^{-}}$and $\mathrm{IBr}_{2}-$ are addressed.

\section{Experimental Section}

The trihalides salts, $\mathrm{N}\left(\mathrm{C}_{3} \mathrm{H}_{8}\right)_{4} \mathrm{I}_{3}$ and $\mathrm{N}\left(\mathrm{C}_{3} \mathrm{H}_{8}\right)_{4} \mathrm{Br}_{2}$, were synthesized and purified by the method of Popov and Buckles [29]. It should be noted that the exothermicity of the reaction of $\mathrm{Br}_{2}$ and $\mathrm{N}\left(\mathrm{C}_{3} \mathrm{H}_{8}\right)_{4} \mathrm{I}$ is sufficient to boil the solvent and the $\mathrm{Br}_{2}$ should be added to the salt solution very slowly. The $\mathrm{CsI}_{3}$ was made by reacting an excess of CsI with $\mathrm{I}_{2}$ in 1-decanol. The IBr was purchased from Aldrich and used without further purification. The UV/Vis absorption spectra were found to be consistent with spectra from the literature for $\mathrm{N}\left(\mathrm{C}_{3} \mathrm{H}_{8}\right)_{4} \mathrm{I}_{3}$ [30], $\mathrm{N}\left(\mathrm{C}_{3} \mathrm{H}_{8}\right)_{4} \mathrm{Brr}_{2}$ [30], $\mathrm{CsI}_{3}$ [30] and $\mathrm{IBr}$ [31]. The solvents used were Fisher $\left(\mathrm{CH}_{2} \mathrm{Cl}_{2}\right.$ and $\left.\mathrm{CHCl}_{3}\right)$ and Aldrich (1-decanol, t-butyl alcohol and $\mathrm{CCl}_{4}$ ) spectroscopic grade.

The laser system used in these experiments has been described in chapter 1. The experiments are set up in a standard pump-probe configuration. In the experiments on $\mathrm{I}_{3}$ - 
and $\mathrm{IBr}_{2}$, a portion of the $590 \mathrm{~nm}$ light is frequency doubled to produce approximately 50 $\mu \mathrm{J}$ at $295 \mathrm{~nm}$, for the excitation pulse, while in the $\mathrm{IBr}$ experiment approximately $400 \mu \mathrm{J}$ of the $590 \mathrm{~nm}$ light is split off for the pump beam. The solution is flowed fast enough so that the sample is changed every laser shot. For the UV pump experiments, the pump and probe beams are aligned collinearly, and the UV is removed after the sample with longpass optical filters. For the experiments on $\mathrm{IBr}$ where visible light is used to excite the sample, the pump and probe beams are aligned off axis and overlapped in the sample. In all cases care was taken to attenuate the pump beam so that no signal was measured from the pure solvent. The pump power was reduced to $\leq 8 \mu \mathrm{J}$ for $295 \mathrm{~nm}$ excitation and $\leq 100 \mu \mathrm{J}$ for $590 \mathrm{~nm}$ excitation.

One of the primary difficulties to this work was to dissolve the ionic species, $\mathrm{I}_{3}$, in a nonpolar, noncomplexing solvent. In addition it was desirable to choose a solvent that $I_{2}$ had been studied in, so that a direct comparison of the vibrational relaxation $I_{2}$ and $I_{2}$ - could be made. Because many solvents such as benzene, alcohols and water form a charge transfer complex with either $I_{2}$ or the iodine atom, the choice of the solvents was limited to alkanes and chloromethanes. $I_{3}$ - was not stable in alkane solvents; it dissociated to form I$+I_{2}$. The solubility of the $I_{3}$ - in the chloromethanes was good for chloroform and methylene chloride presumably because of the polarity of these solvents $\left(\mu_{\mathrm{CHCl}}=1.0 \mathrm{D}\right.$, $\mu_{\mathrm{CH} 2 \mathrm{Cl} 2}=1.6 \mathrm{D}$ ), however the ion was found to be only very slightly soluble in carbon tetrachloride.

Several modifications were made to maximize the solubility. First a large nonpolar counter ion, tetra-n-propyl ammonium was used, to increase the solubility of the salt. Also, the solution was warmed to approximately $45^{\circ} \mathrm{C}$ to increase the solubility. Raising 
the temperature any higher or keeping it at this temperature for an extended period of time ( $>8$ hours) caused the $I_{3}-$ to dissociate into $I^{-}$and $I_{2}$ [32]. Care was taken to use fresh sample so that very little $I_{2}$ or $I^{-}$was present. With these modifications the maximum absorption of the sample at the peak of the UV absorbance centered at $295 \mathrm{~nm}$ using a 1 $\mathrm{cm}$ long cell was $0.4\left(\varepsilon_{295}=4 \times 10^{4}\right)$ [30] corresponding to a concentration of $1 \times 10^{-5}$ molar. The $1 \mathrm{~cm}$ long cell also reduced the time resolution of the experiment because of the difference in the speed of light in the sample at the wavelength of the pump (295 nm) and the probe (approximately $700 \mathrm{~nm}$ ). The instrument response function when using a 1 $\mathrm{cm}$ cell was approximately 4 ps. An additional difficulty was that the absorption maximum of the $\mathrm{I}_{2}$ - ion at $295 \mathrm{~nm}$ is near the tail of the $\mathrm{UV}$ absorption of the $\mathrm{CCl}_{4}$ solvent. This caused some signal from the solvent at high excitation energies. For this reason the UV excitation energy was always $\leq 5 \mu \mathrm{J}$ when $\mathrm{CCl}_{4}$ was used as the solvent. Because of the low energy used to excite the sample and the low solubility of $I_{3}$ - in carbon tetrachloride the maximum signal size was about $1 \times 10^{-3}$ change in absorption. To accurately determine the time scale of the absorption decays, measurements of changes in absorbance on the order of $1 \times 10^{-4}$ were necessary. This requires approximately 400 shots per point, so a total scan took approximately 2 hours.

\section{Results}

The data are all shown as a change in absorption at a particular wavelength as a function of time where $t=0$ corresponds to the pump pulse and probe pulse arriving at the sample at the same time. Data were taken at a single wavelength rather than as a change in the entire spectrum due to signal-to-noise considerations. The changes in absorption as a 
function of time were measured from the near UV to the near IR for most of the solute/solvent systems discussed. Only representative data illustrating the primary trends are shown here. The change in absorption at 620 and $800 \mathrm{~nm}$ is shown for the dissociation of $\mathrm{I}_{3}-$ to produce $\mathrm{I}$ and $\mathrm{I}_{2}$ - in $\mathrm{CCl}_{4}$ in figure 2.1. The rise in the absorption is instrument response limited at 600 . The rise time is clearly not instrument response limited at 800 $\mathrm{nm}$. The rise occurs on a time scale of $5 \mathrm{ps}$ at $800 \mathrm{~nm}$. The $600 \mathrm{~nm}$ has a fast decay component on the time scale of $5 \mathrm{ps.} \mathrm{This} \mathrm{component} \mathrm{is} \mathrm{large} \mathrm{at} \mathrm{shorter} \mathrm{wavelengths}(<$ $620 \mathrm{~nm}$ ) and is reduced in size in comparison to the total signal size at longer wavelengths until at approximately $700 \mathrm{~nm}$ no fast decay component is observed. At all wavelength where this fast decay component is observed, the decay time is the same, 5 ps. At all wavelengths measured there is a long decay component of approximately $100 \mathrm{ps}$. The long component decays to roughly $10 \%$ of the original signal size.

Figures 2.2 and 2.3 show data the photodissociation relaxation of $I_{2}$ in chloroform and methylene chloride, respectively. The dynamics in these solvents are the same as in carbon tetrachloride. Because of the increased solubility of $\mathrm{I}_{3}$ - in these solvents and the lack of solvent absorption near the excitation wavelength of $295 \mathrm{~nm}$, the signal size is increased by a factor of 3 . In addition the higher concentration of $\mathrm{I}_{3}\left(5 \times 10^{-4} \mathrm{M}\right)$ allows the use of a thinner sample cell, $1 \mathrm{~mm}$, which decreases the instrument response function to 2 ps. The only other obvious change is that the absorption maximum for the cooled $\mathrm{I}_{2}$ species is shifted to the blue in these polar solvents by $30-50 \mathrm{~nm}$ in comparison to $\mathrm{I}_{2}$ - in $\mathrm{CCl}_{4}$. This follows the trend seen in alcohols and water which shows a blue shift in the $\mathrm{I}_{2}$ absorption with increasing polarity of the solvent [33]. A ground state bleach recovery was measured in chloroform at $375 \mathrm{~nm}$ and is shown in figure 2.6. While both the $\mathrm{I}_{3}$ - and $\mathrm{I}_{2}$ - 
absorb at this wavelength, the $\mathrm{I}_{3}$ - cross section is much larger than $\mathrm{I}_{2}$ - so the absorption at this wavelength should be dominated by $I_{3}$ - dynamics [34]. In addition the dynamics of $I_{2}$ can be measured independently by monitoring its visible/near infrared absorption band to determine which components in the $375 \mathrm{~nm}$ absorption are due to $\mathrm{I}_{3^{-}}$and $\mathrm{I}_{2}{ }^{-}$. The absorption at $375 \mathrm{~nm}$ has a pulsewidth limited decay which then recovers with two time constants. A fast recovery component of $5 \mathrm{ps}$ is seen followed by a longer recovery of 100 ps. There is an offset of $10 \%$ which does not recover.

The photodissociation dynamics of $\mathrm{IBr}_{2}$ - and the vibrational energy relaxation of the $\mathrm{IBr}$ - ion were studied in chloroform. The absorption changes near the visible/near infrared absorption of IBr- are shown in figure 2.4. An absorption near $800 \mathrm{~nm}$ and 400 $\mathrm{nm}$ is expected for $\mathrm{IBr}-[35]$. The changes in absorption are similar to those found for $\mathrm{I}_{2}$. At all wavelengths studied there is a long component of 110 ps while at shorter wavelengths there is also a short decay of 4 ps.

To compare IBr- dynamics to its neutral equivalent, as has been done here for $\mathrm{I}_{2}$ and $\mathrm{I}_{2}$, the photodissociation and vibrational energy relaxation of $\mathrm{IBr}$ has also been studied in methylene chloride, chloroform and carbon tetrachloride. This molecule has a visible absorption similar to $I_{2}$, but with the maximum centered at $490 \mathrm{~nm}$ [31]. In these experiments the molecule is excited with the fundamental of the laser system at $590 \mathrm{~nm}$ and the changes in absorption in the visible and near infrared are measured and are shown for methylene chloride in figure 2.5. The transient absorptions at longer wavelengths show two decay times. The shorter decay times vary from approximately $10 \mathrm{ps}$ at $900 \mathrm{~nm}$ to $150 \mathrm{ps}$ at $670 \mathrm{~nm}$. The longer time scale decay is $2-4 \mathrm{~ns}$ depending upon the solvent. At shorter wavelengths the ground state bleach is monitored. The recovery of the ground state 
bleach also shows two components. The shorter component is $100-150$ ps in all solvents while the long component varies from $2 \mathrm{~ns}$ in methylene chloride to $4.4 \mathrm{~ns}$ in carbon tetrachloride.

The dissociation of $\mathrm{I}_{3}$ - and vibrational energy relaxation of $\mathrm{I}_{2}$ - was also studied 1decanol and t-butyl alcohol with cesium used as the counter ion. In both cases the trihalide salt was quite soluble and so a $1 \mathrm{~mm}$ thick sample cell was used. In both experiments the $\mathrm{I}_{3}$ - was formed in situ by adding iodine molecules to a solution containing an excess of

CsI. The iodide ion does not absorb until farther into the UV $(260 \mathrm{~nm})$. In both cases the dynamics of vibrational relaxation were the same within experimental error at all wavelengths studied to the vibrational relaxation of $\mathrm{I}_{2}$ - in the chloromethane solvents.

\section{Discussion}

The dynamics following the photodissociation of $\mathrm{I}_{3}$ - and $\mathrm{IBr}_{2}$ - can be split into two categories. There are fast components in the data which reflect changes due to vibrational relaxation of the diatomic anions and longer components due to the reformation of the triatomic anions. The majority of this work focuses on the vibrational relaxation of the dianions. First the vibrational relaxation of $\mathrm{I}_{2}$ - is discussed in nonpolar and increasingly polar solvents. Then the role of charge flow in the vibrational relaxation is studied using the asymmetric $\mathrm{IBr}^{-}$. The results for this ion are also compared to the polar $\mathrm{IBr}$ molecule to test the efficiency of a dipole at transferring energy to the solvent. Also, the possibility of some secondary agent, such as the counter ion or solvent impurities, acting as a conduit for energy transfer to the solvent is examined. Finally the longer time dynamics of $I_{3}$ and 
$\mathrm{IBr}_{2}-$ are examined.

\section{A. Vibrational Relaxation}

In a recent series of experiments, the vibrational energy relaxation of ions in polar solvents has been studied $[21-23,25-28,36]$. The results show that the vibrational energy relaxation rate is exceedingly fast for ions compared neutral species. In particular the vibrational relaxation of $\mathrm{I}_{2}$ - has been studied in a variety of polar solvents and occurs in 3-5 ps depending upon the solvent. By comparison, the vibrational relaxation of $I_{2}$ has been studied in a variety of solvents and occurs in $70-150 \mathrm{ps.} \mathrm{The} \mathrm{mechanism} \mathrm{for} \mathrm{the}$ acceleration of the energy transfer rate to the solvent is not clear. One mechanism that has been proposed for the acceleration of the vibrational energy relaxation rate in $I_{2}$ - versus $I_{2}$ is that the charge on the ion can have long range interactions with the polar solvent molecules [23]. It has been predicted that this long range charge/dipole interaction would provide a new and efficient channel for energy transfer to the solvent.

To test this hypothesis experimentally, it was necessary to study the two species, $I_{2}$ and $\mathrm{I}_{2}^{-}$, in the same nonpolar solvent. In this way, it was hoped, the charge on the ion would not have permanent dipoles in the solvent to couple to and therefore the effect of the charge/dipole interactions would be illustrated. The only nonpolar solvent we found which, one, does not form a complex with $\mathrm{I}, \mathrm{I}^{-}, \mathrm{I}_{2}-$ or $\mathrm{I}_{3^{-}}$, two, in which $\mathrm{I}_{2}$ had already been studied and three, in which $\mathrm{I}_{3}$ - was slightly soluble, was $\mathrm{CCl}_{4}$. The difficulties of dissolving the ionic salt $\mathrm{N}\left(\mathrm{C}_{3} \mathrm{H}_{8}\right)_{4} \mathrm{I}_{3}$ in $\mathrm{CCl}_{4}$ have been discussed in the experimental section.

Banin and Ruhman demonstrated that $\mathrm{UV}$ absorption by $\mathrm{I}_{3}$ - leads to dissociation to 
I (or $I^{*}$ ) and vibrationally excited $I_{2}-$ From coherent oscillations in the signal, they estimate the $I_{2}$ - to be excited to the $v=25$ level [28]. Their work showed that the relaxation process using this mechanism for producing vibrationally excited $\mathrm{I}_{2}$ is comparable to direct dissociation and recombination of the $\mathrm{I}_{2}{ }^{-}$as done by Barbara and coworkers [21-23].

In this study, $\mathrm{I}_{3}-$ is photodissociated to produce vibrationally excited $\mathrm{I}_{2}^{-}$, and its vibrational energy relaxation is monitored. Spectroscopic work on $\mathrm{I}_{2}$ - in matrices and liquids has shown a visible/near infrared absorption which corresponds to a $2 \Sigma+u$ ${ }^{2} \prod_{g 1 / 2}$ transition [21]. Its maximum is generally in the $700-800 \mathrm{~nm}$ region depending on the polarity of the environment. Spectral simulations have shown that vibrationally excited species should have enhanced absorption both at longer and shorter wavelengths than the room temperature thermally equilibrated species [23]. There are several important spectral changes at these wavelengths (figure $2.1,600 \mathrm{~nm}$ ). First there is an increase in the absorption that is faster than the time resolution of the experiment ( $3 \mathrm{ps})$. This corresponds to the very fast appearance of vibrationally excited species. Previous work showed that the appearance of these species occurs in $<300 \mathrm{fs}$ in polar solvents [23]. Next there is a nearly instrument limited disappearance in the absorption at this wavelength of $5 \mathrm{ps}$. This is similar to the spectral changes seen for the vibrational relaxation of $I_{2}$ - in polar solvents. An additional piece of information that was necessary for determining the dynamics of these vibrationally excited species is shown in the transient absorption at $800 \mathrm{~nm}$ in figure 2.1. This is the wavelength where the thermally equilibrated species has the highest absorption. The increase in absorption at $800 \mathrm{~nm}$ is not limited by the instrument response function and occurs in a time complementary to the disappearance of the vibrationally excited species. This disappearance of the vibrationally excited species with the 


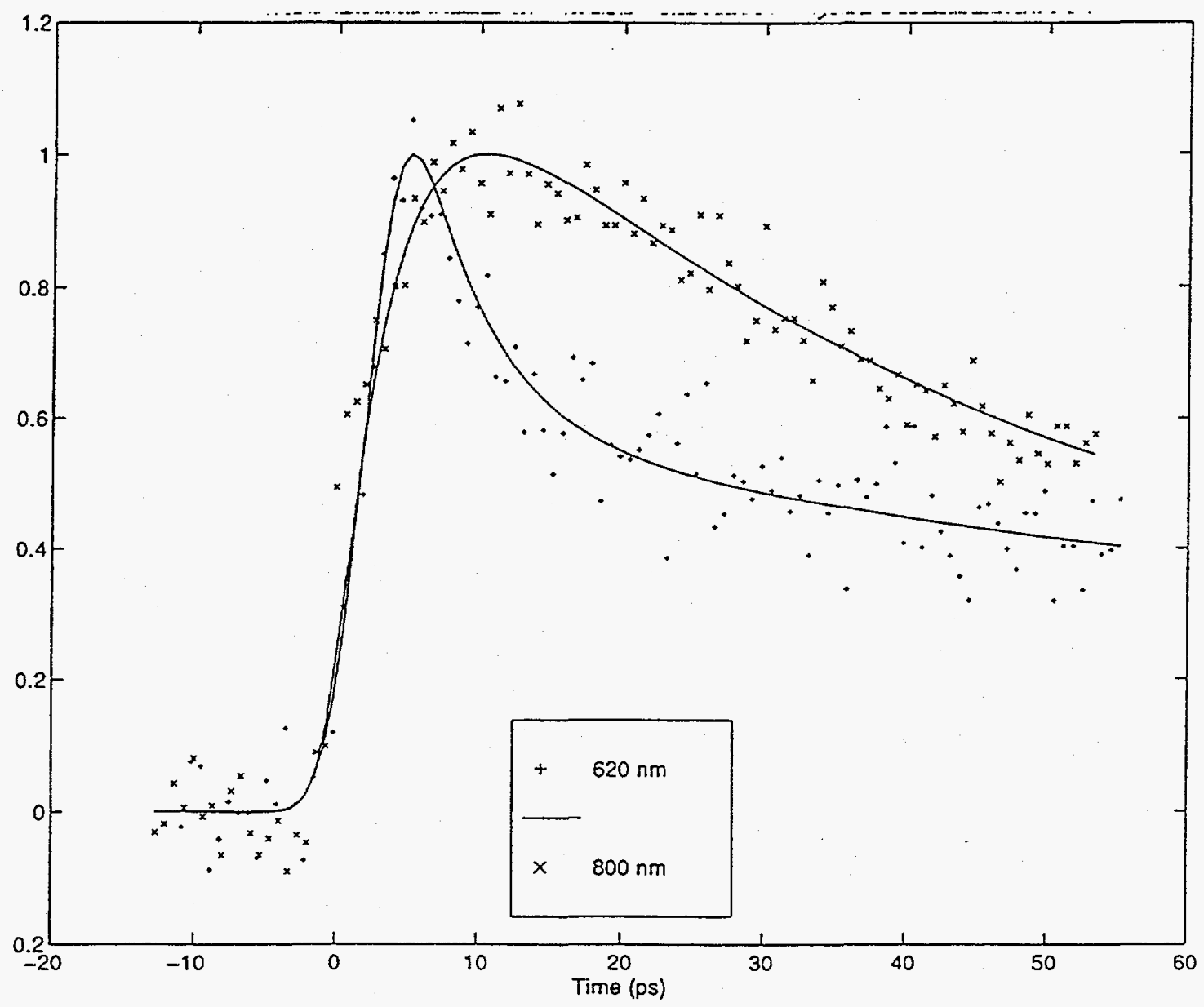

Figure 2.1 - The Change in Absorption at $620 \mathrm{~nm}$ and $800 \mathrm{~nm}$ Following the Photodissociation of $\mathrm{I}_{3}$ - in $\mathrm{CCl}_{4}$. 
complementary appearance of the vibrationally cool species is indicative of vibrational relaxation. It is the increase of the absorption at $800 \mathrm{~nm}$ that is necessary to indicate that this process is vibrational relaxation and has caused a reinterpretation of our data. The vibrational relaxation of $I_{2}$ has been found to occur just as fast in a nonpolar solvent, $\mathrm{CCl}_{4}$, as in very polar solvents. It indicates that there must be some unexpected mechanism, presumably involving the charge, that is responsible for the accelerated vibrational relaxation of $I_{2}$ - compared to $I_{2}$. The rest of this chapter is primarily concerned with determining the mechanism by which energy is transferred so quickly from the ion to the solvent, even if the solvent is nonpolar.

One way to test the importance of charge/dipole interactions on the vibrational relaxation process is to systematically increase the polarity of the solvent and monitor its effect on the rate of vibrational relaxation. The other chloromethanes make an ideal series of solvents to compare to $\mathrm{CCl}_{4}$ because the polarity is steadily increased from $\mu_{\mathrm{CCl} 4}=0.0$ to $\mu_{\mathrm{CHCl} 3}=1.0 \mathrm{D}$ to $\mu_{\mathrm{CH} 2 \mathrm{Cl} 2}=1.6 \mathrm{D}$. The dynamics of the photodissociation of $\mathrm{I}_{3^{-}}$and the subsequent vibration relaxation of $\mathrm{I}_{2}$ - were measured in $\mathrm{CHCl}_{3}$ and $\mathrm{CH}_{2} \mathrm{Cl}_{2}$ just as was done with $\mathrm{CCl}_{4}$ as the solvent. The changes in absorption for the reaction in $\mathrm{CHCl}_{3}$ and $\mathrm{CH}_{2} \mathrm{Cl}_{2}$ are shown in figures 2.2 and 2.3 respectively. Because of the higher solubility of $\mathrm{N}\left(\mathrm{C}_{3} \mathrm{H}_{8}\right)_{4} \mathrm{I}_{3}$ in these solvents (due to the increased polarity of the solvent), shorter path length cells $(1 \mathrm{~mm})$ could be used for these samples. This improved our time resolution to 2 ps and increased the signal size by a factor of approximately 3. The dynamics of the $I_{3}$ and $\mathrm{I}_{2}$ - are found to be nearly identical in the polar solvents, $\mathrm{CHCl}_{3}$ and $\mathrm{CH}_{2} \mathrm{Cl}_{2}$, as in the nonpolar $\mathrm{CCl}_{4}$. The disappearance of the vibrationally excited species at $600 \mathrm{~nm}$ takes 4 ps while the appearance of the vibrationally relaxed species happens on the same time 


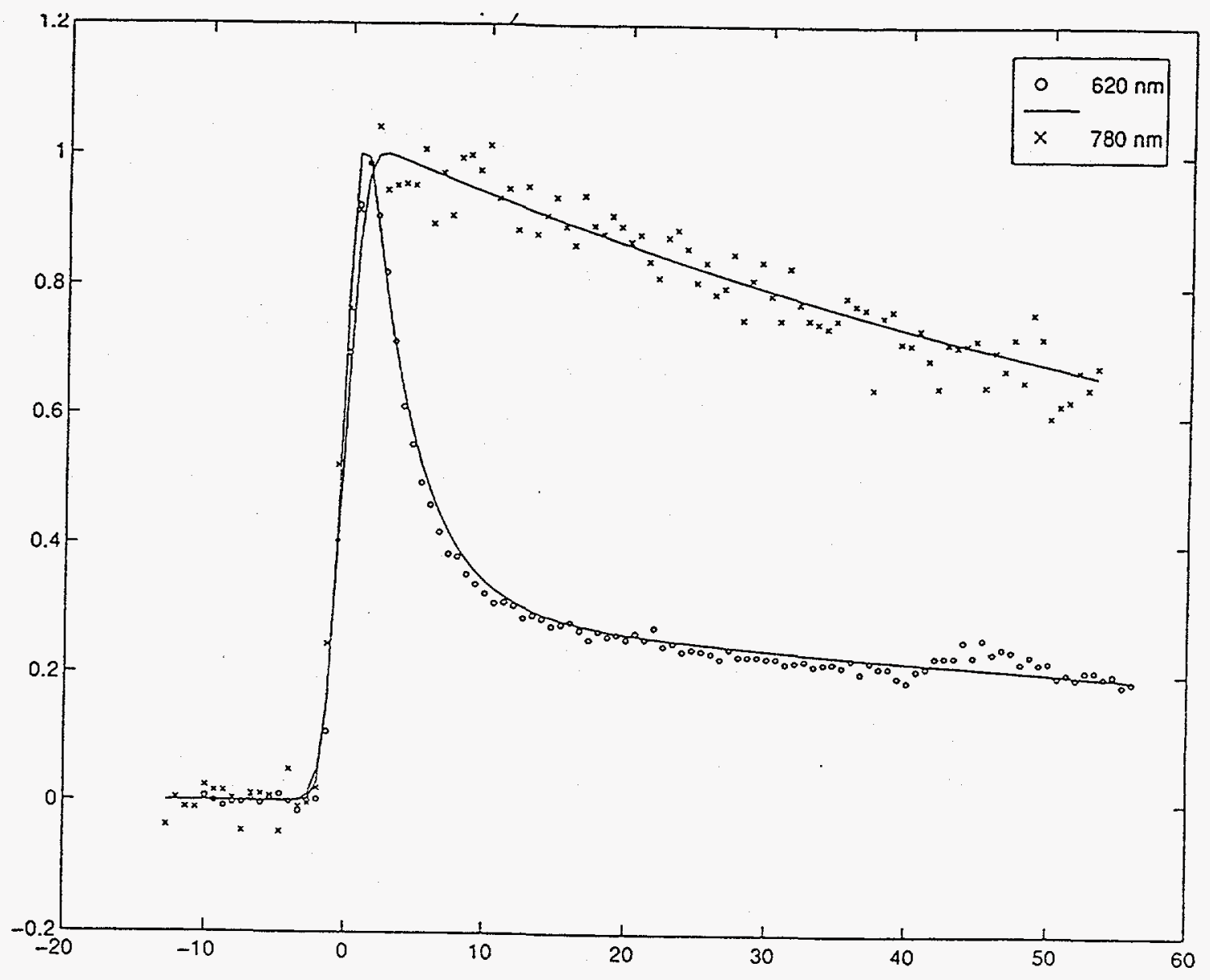

Figure 2.2 - The Change in Absorption at $620 \mathrm{~nm}$ and $780 \mathrm{~nm}$ Following the Photodissociation of $\mathrm{I}_{3}{ }^{-}$in $\mathrm{CHCl}_{3}$. 


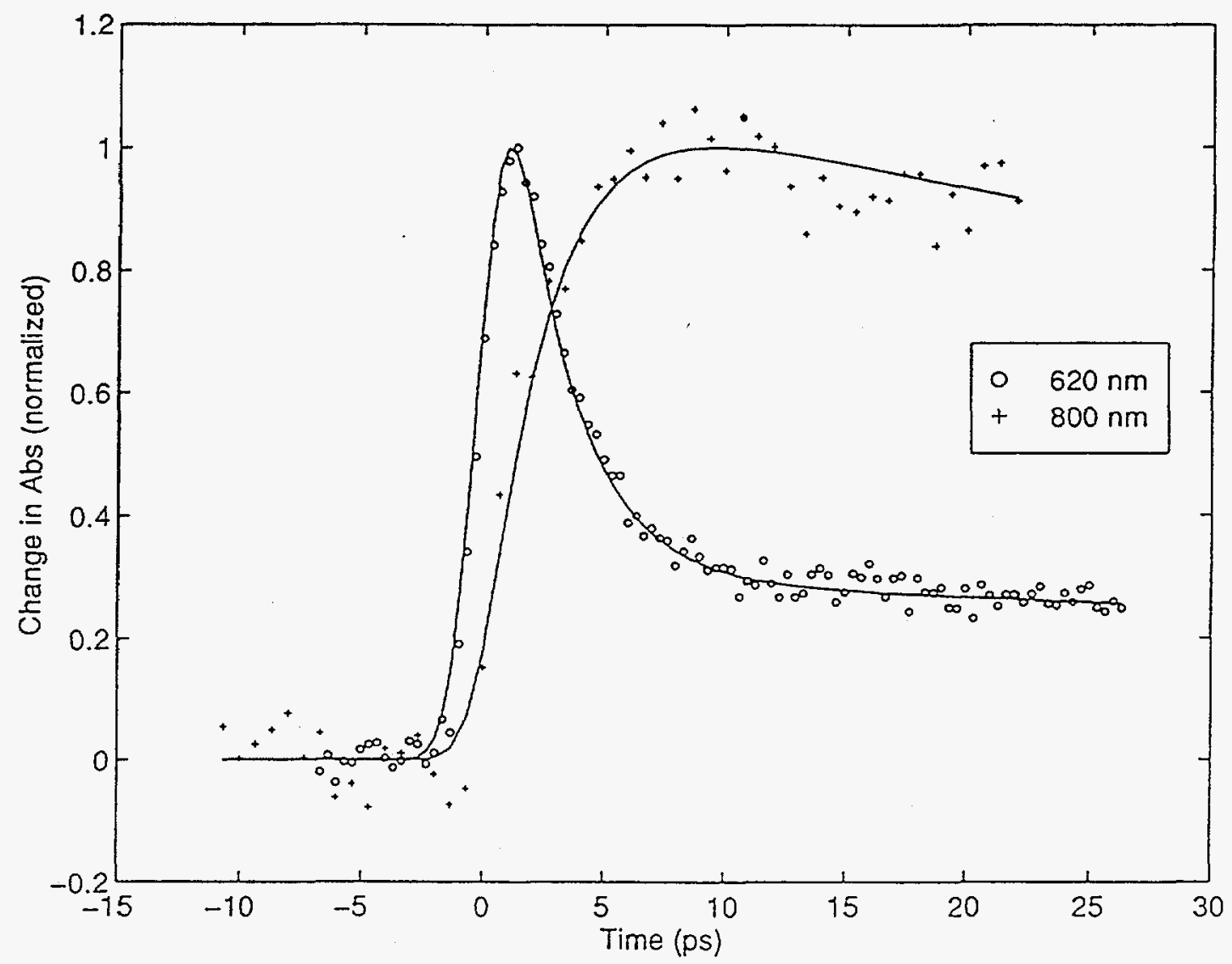

Figure 2.3 - The Change in Absorption at $620 \mathrm{~nm}$ and $800 \mathrm{~nm}$ Following the Photodissociation of $\mathrm{I}_{3}$ - in $\mathrm{CH}_{2} \mathrm{Cl}_{2}$. 
scale. The only changes between solvents is a slight blue shift in the absorption maximum with increasing polarity. The lack of an effect of the increasing polarity of the solvent on the relaxation rate is surprising because the increased solubility of the $\mathrm{I}_{3}$ in $\mathrm{CHCl}_{3}$ and $\mathrm{CH}_{2} \mathrm{Cl}_{2}$ indicates much stronger interaction between the ions and the solvent than in $\mathrm{CCl}_{4}$. These data again reemphasize the relative unimportance of the charge/dipole interaction in comparison to other mechanisms for transferring energy to the solvent.

Recent work by Barbara and coworkers has shown the vibrational relaxation rate of $\mathrm{I}_{2}$ - in polar and nonpolar solvents to be extremely fast and nonexponential especially in the upper part of the ground state well [23]. This fast relaxation is attributed to solvent induced charge flow between the iodine nuclei during the relaxation process. The charge is localized on one or the other iodine nuclei because solvent fluctuations create an asymmetric solvent shell which favors localization on one of the nuclei. As the solvent configuration fluctuates, the charge flows between the two nuclei. In our experiments, however, the solvent molecules either do not have a permanent dipole, as in the case of $\mathrm{CCl}_{4}$ or have a weak permanent dipole, as in $\mathrm{CHCl}_{3}$ and $\mathrm{CH}_{2} \mathrm{Cl}_{2}$. So fluctuations in the configuration of the solvent will not be able to localize the charge as efficiently as the polar solvents used by Barbara and coworkers. There is an additional mechanism for charge localization in $\mathrm{I}_{2}$. The ion dissociates to $\mathrm{I}+\mathrm{I}$. Therefore, at high vibrational levels, near the dissociation limit, the charge will be forced to localize on one of the iodine nuclei. Because of the symmetry of the ion, which nuclei the charge localizes on will be determined by the configuration of the solvent shell.

To test the importance of either of these charge localization mechanisms on the $\mathrm{I}_{2}-$ vibrational relaxation rate, the vibrational relaxation of $\mathrm{IBr}-$ was also studied. This ion is 
very similar to the $\mathrm{I}_{2}$ - ion except that the larger electron affinity of the $\mathrm{Br}$ atom breaks the symmetry of the ion preferentially localizing the charge on the $\mathrm{Br}$ atom. This means that fluctuations of the relatively nonpolar solvent shell configuration will be ineffective at localizing the charge on the iodine atom, and solvent induced charge localization should therefore be minimized. In addition, it is highly energetically favorable $(<12 \mathrm{kT})$ for the molecule to dissociate to $\mathrm{I}+\mathrm{Br}^{-}$. So at high vibrational levels the charge will always tend to localize on the $\mathrm{Br}$ atom. This results in an effective oscillating permanent dipole, but not charge flow between the nuclei. So both mechanisms of charge localization should be much reduced in $\mathrm{IBr}^{-}$compared to $\mathrm{I}_{2}^{-}$.

The experiment is done in the same manner as the $\mathrm{I}_{2}$ - experiment. The absorption spectra of $\mathrm{IBr}_{2}-$ was consistent with literature spectra with a strong $\mathrm{UV}$ absorption centered at $260 \mathrm{~nm}$ [30]. Because of the shift in the absorption maximum from $295 \mathrm{~nm}$ for $\mathrm{I}_{3}$ to $260 \mathrm{~nm}$ for $\mathrm{IBr}_{2}^{-}$, it was not possible to conduct the experiment in $\mathrm{CCl}_{4}$ because of its strong absorption centered at $260 \mathrm{~nm}$. So the photodissociation dynamics of $\mathrm{IBr}_{2}-$ and the vibrational relaxation of $\mathrm{IBr}$ - were investigated in $\mathrm{CHCl}_{3}$. The data for this system are shown in figure 2.4. The $\mathrm{IBr}$ - ion has absorptions in the visible/near infrared centered near $430 \mathrm{~nm}$ and $800 \mathrm{~nm}$ [35]. With the change in absorption maximum taken into account, the dynamics of IBrZ and IBr-are nearly identical to those of $I_{3}-$ and $I_{2}{ }^{-}$. The vibrational relaxation occurs on a time scale of $5 \mathrm{ps}$ and there is a longer time scale disappearance of the $\mathrm{IBr}-$ in $110 \mathrm{ps}$.

The equally fast cooling of $\mathrm{IBr}-$ and $\mathrm{I}_{2}-$ suggests that solvent-induced charge localization is not the primary mechanism for energy transfer. The solvent-induced charge localization depends upon the ability of charge to flow between the two nuclei. In $\mathrm{BBr}$ - the 


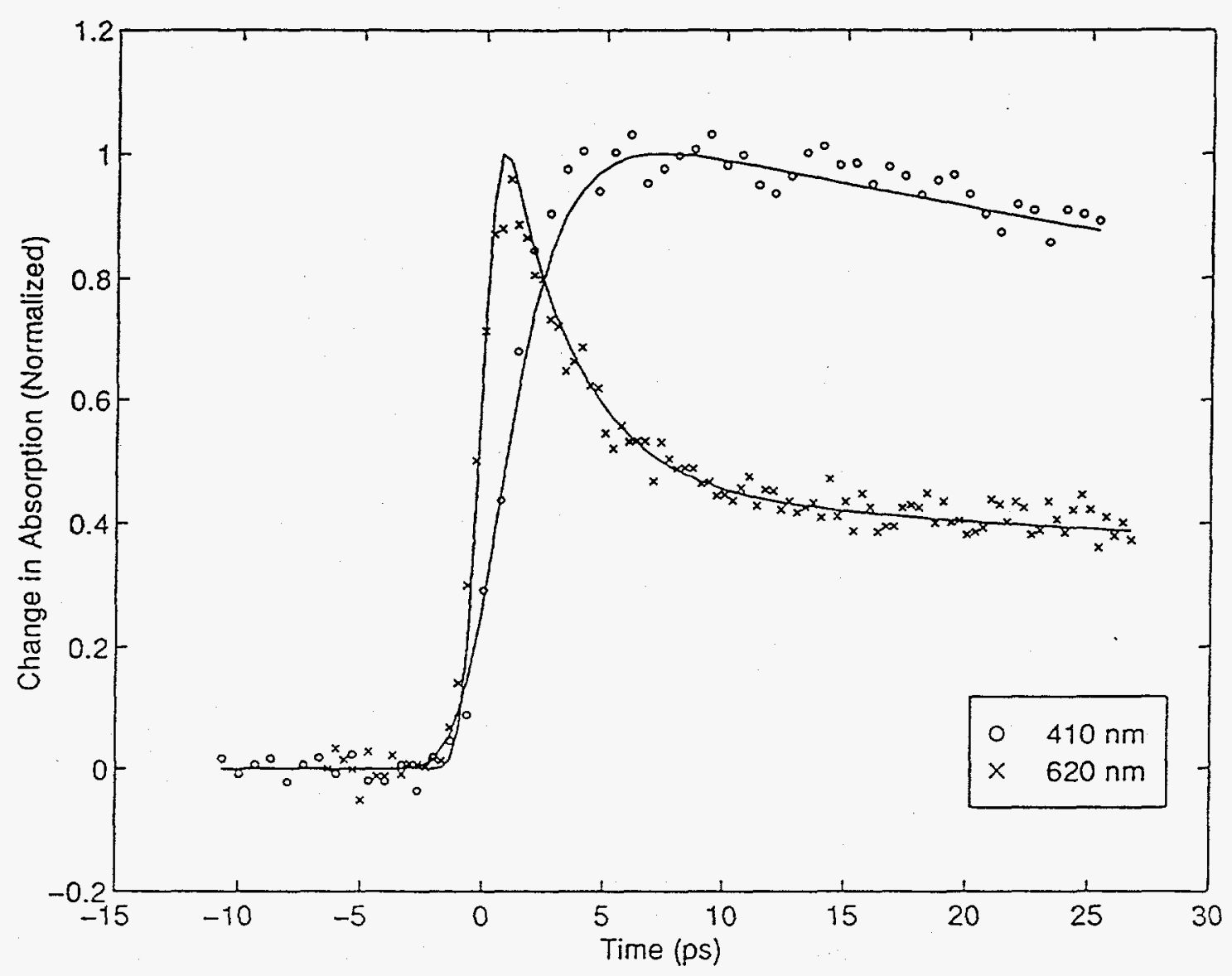

Figure 2.4 - The Change in Absorption at $410 \mathrm{~nm}$ and $620 \mathrm{~nm}$ Following the Photodissociation of $\mathrm{IBr}_{2}$ - in $\mathrm{CHCl}_{3}$. 
asymmetry tends to localize the charge on the $\mathrm{Br}$ nuclei. While it is difficult to predict the charge densities at bond lengths near the equilibrium bond length, the energetics at bond lengths near the dissociation limit, where charge flow is expected to be an important factor, is easier to approximate. The two dissociation channels available to $\mathrm{IBr}-$ are $\mathrm{I}+\mathrm{Br}$ and $\mathrm{I}$ $+\mathrm{Br}$. The difference in energy between these exit channels is roughly the difference in electron affinity of iodine versus bromine. The electron affinity of iodine is $70.5 \mathrm{kcal} / \mathrm{mol}$ while it is $77.6 \mathrm{kcal} / \mathrm{mol}$ for $\mathrm{Br}$ [37]. This large difference in energy (12kT) should effectively localize the charge on the $\mathrm{Br}$ portion of the ion, particularly because the solvent, chloroform, is fairly nonpolar. In addition, any solvation energy that can be provided by the fairly nonpolar solvent will favor localization on the smaller $\mathrm{Br}$ atom. Therefore, thermal fluctuations of the of the weak solvent dipoles should cause only small fluctuations on the energy levels of $\mathrm{IBr}-$. So it is unlikely that the solvent would force the charge to localize on the energetically unfavorable iodine portion of $\mathrm{IBr}-$. Once again these results suggest that for these ions in fairly nonpolar solvents, such as chloroform, solvent induced charge localization is not the primary mechanism for energy transfer to the solvent.

To test the efficiency of a dipole at transferring energy to the solvent, the vibrational relaxation of $\mathrm{IBr}$ was studied in the chloromethane solvents. The data for $\mathrm{IBr}$ in methylene chloride is shown in figure 2.5. The decay of the transient absorption at the longer wavelengths and the recovery of the ground state bleach show two time components. These components can be interpreted in the same manner as has been done for $I_{2}$ because the electronic surfaces are only slightly shifted in $\operatorname{IBr}[31]$. As with $I_{2}$, following photodissociation recombination of $\mathrm{IBr}$ can occur on two surfaces, the excited A-state (and nearly degenerate $\mathrm{A}^{\prime}$-state) and the ground state (X-state). The $>1$ ns component at longer wavelengths (transient absorption) and shorter wavelengths (ground state bleach) are due to 


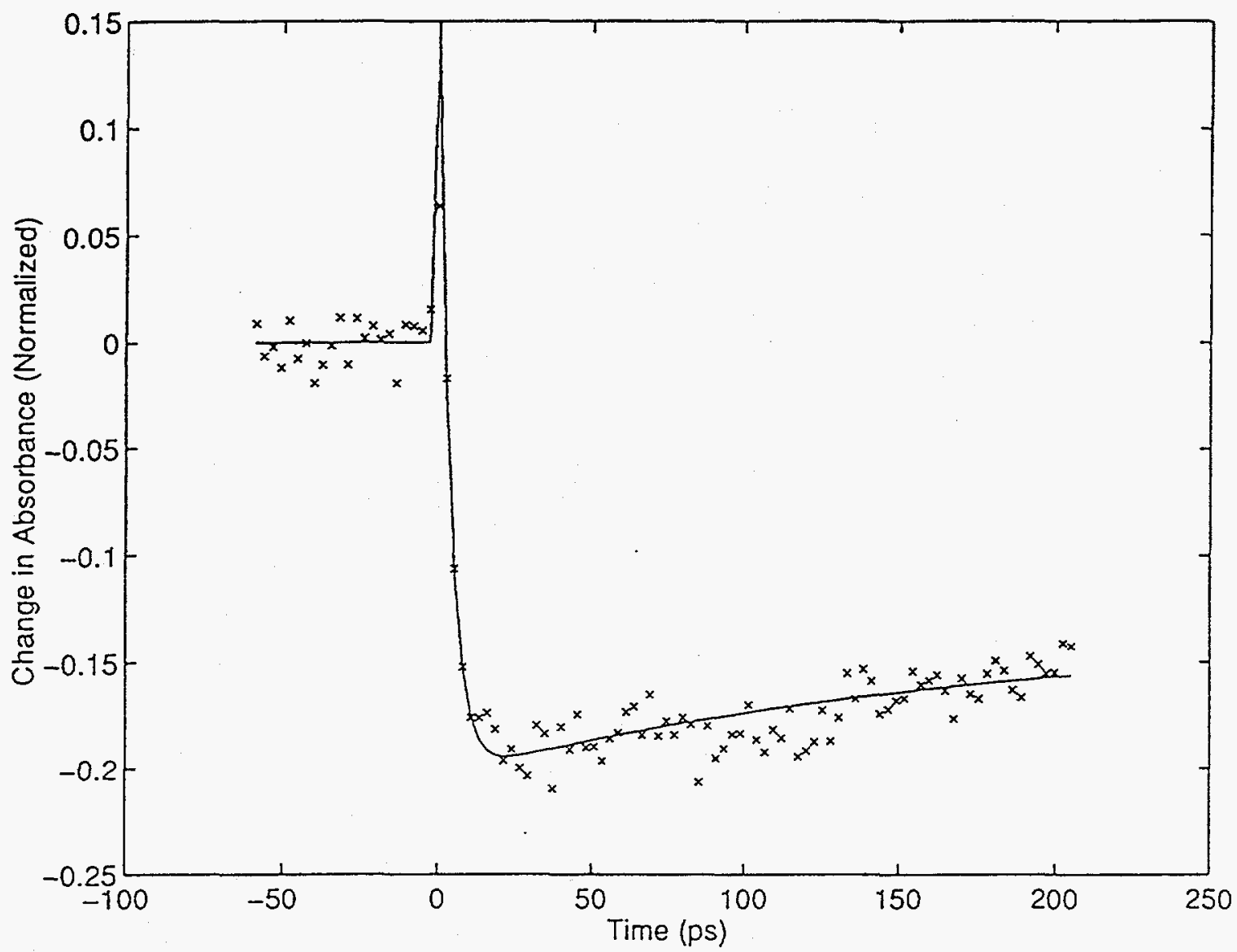

Figure 2.5 - The Change in Absorption at $490 \mathrm{~nm}$ Following the Photodissociation of $\mathrm{IBr}$ in $\mathrm{CH}_{2} \mathrm{Cl}_{2}$. 
molecules that initially recombine on the A-state and must cross over to the ground state surface before vibrationally relaxing. The rate of this curve crossing has been found to be solvent dependent for $I_{2}$ [12], and a similar trend is seen for IBr. The faster components are due to molecules that recombine on the ground state potential and then vibrationally relax to form cooled $\mathrm{IBr}$. The time scale for the complete vibrational relaxation are all approximately 100 ps. There are two important conclusions that can be drawn from these results. First, the polar $\mathrm{IBr}$ has a relaxation rate much more like $\mathrm{I}_{2}$ than $\mathrm{IBr}-$ or $\mathrm{I}_{2}$. This suggests that this dipole is not sufficient to considerably accelerate the relaxation and that a charge is the crucial feature in the fast relaxation of the anions. This is also supported by the other conclusion, that going from a solvent with no dipole, $\mathrm{CCl}_{4}$, to solvents with increasing polarity, $\mathrm{CHCl}_{3}$ and $\mathrm{CH}_{2} \mathrm{Cl}_{2}$, produces no systematic trend in the vibrational relaxation rate of this polar diatomic. Even for a weak dipole such as $\mathrm{IBr}$, the relaxation rate should be affected by changing from a nonpolar solvent to a polar solvent if dipole/dipole interactions are effective in coupling energy to the solvent.

Another possible explanation for the invariance of the vibrational relaxation rate to the nature of the solvent is that the energy could be going from the anion through an intermediate and finally to the solvent. If this is the case the vibrational relaxation of the ion would not depend upon the solvent environment, but only the intermediate. Two possibilities for intermediates that could accept energy directly from the ion were examined - the counter ion and solvent impurities.

One possible explanation for the very fast vibrational relaxation regardless of the solvent environment is that the anion is paired with its counter ion in solution. This counter ion could couple strongly to the vibrationally excited anion and act as a conduit for energy 
transfer to the solvent. From simple theory $\mathrm{I}_{3}$ is expected to be predominately paired with the cation in all three chloromethane solvents [38]. The pairing is strongest in $\mathrm{CCl}_{4}$ where virtually all of the ions should be paired and slightly weaker in $\mathrm{CHCl}_{3}$ and in $\mathrm{CH}_{2} \mathrm{Cl}_{2}$ (approximately 5\% unpaired in $\mathrm{CH}_{2} \mathrm{Cl}_{2}$ ). To test the effect of the counter ion, it would be ideal to study the vibrational relaxation rate in two nonpolar solvents, one in which ion pairing occurs, and one in which it does not. But the degree of ion pairing is fundamentally dependent upon the polarity of the solvent. It is therefore impossible to study the vibrationally relaxation in a nonpolar solvent without ion pairing.

An alternative means of testing the effect of ion pairing on the vibrational relaxation rate is to use a monatomic cation, such as an alkali metal ion, as the counter ion. The monatomic cation would be limited in its ability to accept energy from the anion and transfer it to the solvent because it lacks internal degrees of freedom. The rate of relaxation with the monatomic cation could then be compared to relaxation with the much larger polyatomic cations. Again however there is a fundamental difficulty in testing this hypothesis. The only way to do the experiment in nonpolar solvents was to use large polyatomic cations. $\mathrm{Cs}^{+}$was chosen as the most likely monatomic cation to work because it has the largest diameter of the alkali metal cations. However $\mathrm{CsI}_{3}$ was found to be insoluble or unstable in all the chloromethane solvents and a variety of other nonpolar solvents. The only solvent found that is nonpolar enough for ion pairing to occur in and in which the $\mathrm{CsI}_{3}$ was soluble and still stable is 1-decanol $(\varepsilon=8.1)$. From a simple description [38], approximately $97 \%$ of the ions would be expected to be paired in the conditions used. The dynamics were once again found to be the same - vibrational relaxation in $5 \mathrm{ps}$ - as when the larger counter ion tetra n-propyl ammonium was used. 
There are several ways to interpret this indifference of the relaxation rate to changes in the counter ion. One is just that the counter ion is not involved in the vibrational relaxation, so changing the counter ion has no effect. Another possible reason for the vibrational relaxation rate being the same with different cations is that the 1-decanol solvent may be better at solvating the ions than simple theory would predict (i.e. $97 \%$ of the ions are not paired). This could occur because of the ions ability to polarize the solvent, so that the local environment of the ion would be similar to that for much shorter alcohols where ion pairing is not predicted. This effect could be important because the dielectric constant of 1-decanol is near the transition for ions pairing and not pairing. This increased solvating power for 1-decanol could cause the vibrational relaxation rate to be same when different counter ions are used in two ways. First, by reducing the ion pairing it would eliminate any affect of changing the counter ion. Second this increased solvation would provide a very polar environment for the ion to interact with and could cause the very fast vibrational relaxation despite the inability of the counter ion to efficiently accept and transfer energy. Because of this uncertainty in the microenvironment of the ions, it is impossible to determine if the lack of change in the relaxation rate indicates that the counter ion is unimportant in the vibrational relaxation process. We are continuing to search for solvents that are more isotropic and less polar than 1-decanol in which $\mathrm{CsI}_{3}$ is stable and soluble so that the microenvironment of the ions can be better determined and the role of the counter ion addressed more definitively. Another route we are pursuing to determine the role of the counter ion is to find a cation whose internal energy can be independently spectroscopically probed. A cation with only a few internal degrees of freedom, so that energy transfer to it from the anion will have a measurable effect, and with a transition that can be spectroscopically probed is required. 
Several other mechanisms were considered to explain fast vibrational relaxation of the anions, $\mathrm{I}_{2}-$ and $\mathrm{IBr}^{-}$, in nonpolar and moderately polar solvents. One mechanism that was tested was that ionic and polar impurities in the solvent may be "solvating" the anions, giving them a very polar environment with which to interact. The $\mathrm{CCl}_{4}$ used was reported to be $99.9 \%$ pure. This $0.1 \%$ impurity level corresponds to an impurity concentration of $10 \mathrm{mM}$, corresponding to an impurity: $\mathrm{I}_{2}$ ratio of $1000: 1$. This could easily provide the polar environment that might be expected to cause very fast vibrational relaxation. The ability of these impurities to solvate the $I_{2}$ - ion was tested using saturated solutions of $I_{3}$ - in $\mathrm{CCl}_{4}$. Impurities, that were miscible with $\mathrm{CCl}_{4}$, were intentionally added to saturated solutions containing excess $\mathrm{N}\left(\mathrm{C}_{3} \mathrm{H}_{8}\right)_{4} \mathrm{I}_{3}$. If these impurities solvate the $\mathrm{I}_{3}$ - ion then the added impurity molecules should solvate the ions and the solubility of the ion should increase. This would cause the UV absorption to correspondingly increase. The concentration of saturated solutions were compared using: 1) pure spectroscopic grade $\mathrm{CCl}_{4}$ 2) pure spectroscopic grade $\mathrm{CCl}_{4}$ with several drops of water added 3) pure spectroscopic grade $\mathrm{CCl}_{4}$ with several drops of $\mathrm{CHCl}_{3}$ added and 4) reagent grade $\mathrm{CCl}_{4}$. In all cases the saturated concentrations were the same, indicating that the impurities do not effectively solvate the ion. This indicates that the ion is experiencing the nonpolar environment of the solvent, and not a microenvironment caused by impurities.

Another possible reason for an apparent fast vibrational relaxation could be due to incorrect spectroscopic assignments. It is known that both $\mathrm{I}_{2}$ - and $\mathrm{I}_{3}$ - have absorptions in the 500-600 nm region that are allowed when symmetry of the ions is broken [33]. The $\mathrm{I}_{2}$ has a strong absorption centered at $585 \mathrm{~nm}$ when its center of symmetry is broken, which is postulated to occur during the vibrational relaxation. $I_{3}$ - also has an allowed absorption 
at $585 \mathrm{~nm}$ that is allowed when the ion becomes bent [33]. This bent geometry might be expected during vibrational relaxation. These absorptions may be contributing to data at wavelengths in the $550-650 \mathrm{~nm}$ region and may contribute to the exceptionally fast rise time seen in the transient absorptions at these wavelengths [23]. However, the grow in of the absorption seen near $800 \mathrm{~nm}$ is strong and independent evidence that the cooled $\mathrm{I}_{2}$ and $\mathrm{IBr}$ are appearing very quickly. So regardless of possible overlapping absorption at some wavelengths, the vibrational relaxation can be confidently determined to be about 5 ps in all the chloromethane solvents.

\section{B. The Long Component}

In addition to the fast dynamics of the $\mathrm{I}_{2}^{-}$and $\mathrm{IBr}^{-}$vibrational relaxation, the photodissociation of $\mathrm{I}_{3}$ - and $\mathrm{IBr}_{2}$ - show dynamics on a longer time scale. At all wavelengths where $\mathrm{I}_{2}$ - and $\mathrm{IBr}^{-}$absorb there is a decay in the absorption on the order of 100 ps. The time for this decay in the absorption is amazingly consistent in very different solvents. The decay occurs in 80 ps in $\mathrm{CCl}_{4}, 90 \mathrm{ps}$ in $\mathrm{CHCl}_{3}$ and 100 ps in $\mathrm{CH}_{2} \mathrm{Cl}_{2}$. For other solvents the decay is $80 \mathrm{ps}$ in 1-decanol, $90 \mathrm{ps}$ in t-butyl alcohol and has been found to be 75 ps in ethanol by Banin and Ruhman [27]. The absorption of the IBr- fragment shows a similar decay on a 100 ps time scale in $\mathrm{CHCl}_{3}$. These decays reduce the absorption to approximately $10 \%$ of its initial value (disregarding the transient absorption due to vibrational relaxation) for $\mathrm{I}_{3} \cdot$ and $5 \%$ for $\mathrm{IBr}_{2}$. The assignment of these decays is possible when these transient absorptions are compared to the ground state bleach of $\mathrm{I}_{3}$. In figure 2.6 the ground state bleach of $\mathrm{N}\left(\mathrm{C}_{3} \mathrm{H}_{8}\right)_{4} \mathrm{I}_{3}$ in $\mathrm{CHCl}_{3}$ at $375 \mathrm{~nm}$ is shown. While 


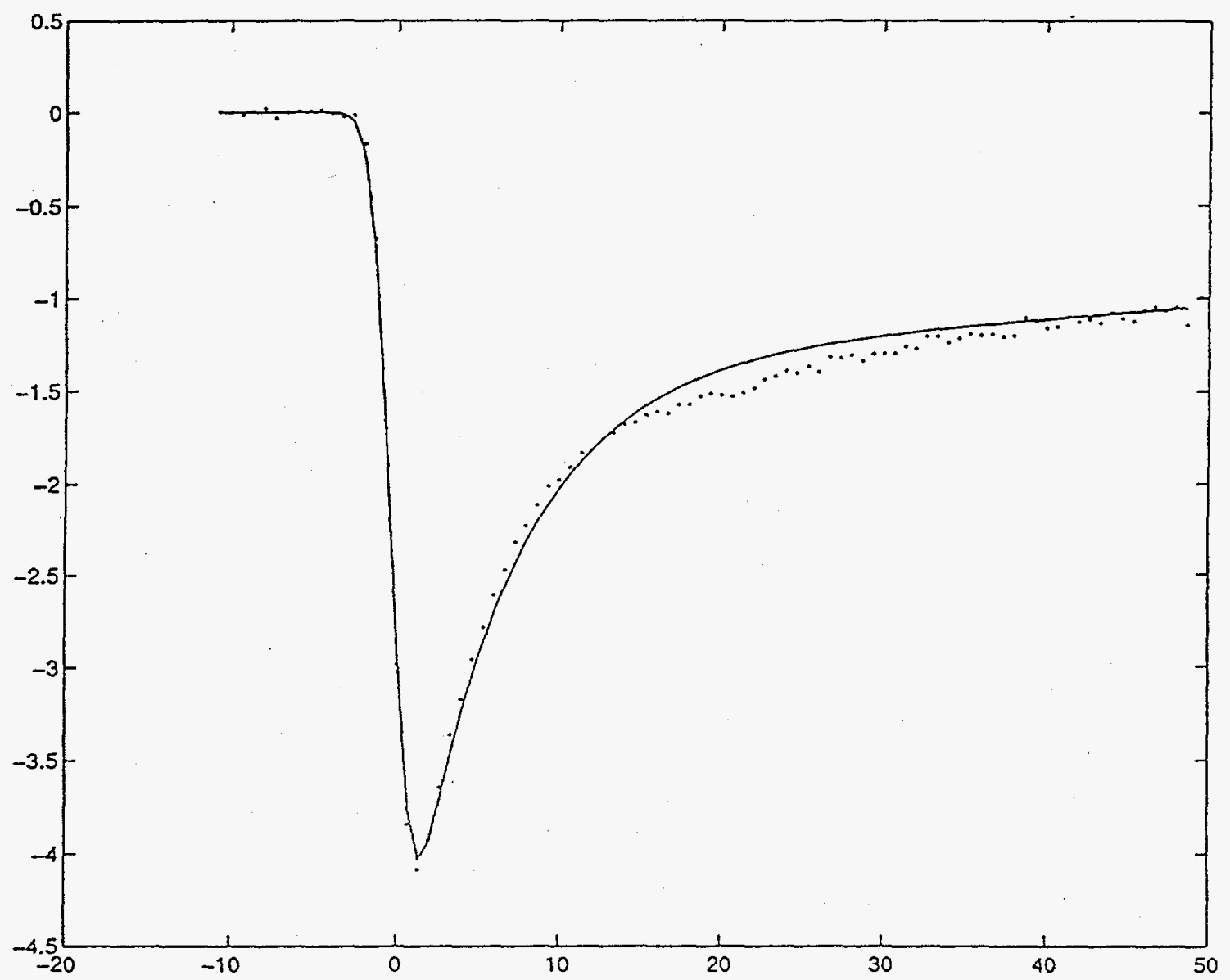

Figure 2.6 - The Change in Absorption at $380 \mathrm{~nm}$ Following the Photodissociation of $\mathrm{I}_{3}$ - in $\mathrm{CHCl}_{3}$. 
both the $\mathrm{I}_{3}$ and $\mathrm{I}_{2}{ }^{-}$have absorption at this wavelength, the $\mathrm{I}_{3}$ - cross section is considerably larger [34]. The data show an instrument limited decrease in absorption due to the disappearance of $I_{3}$ following photodissociation. A fast recovery (increase) of the absorption with a time constant of 5 ps follows. This recovery could be due to either the vibrational relaxation of $I_{2}-$ which does have an absorption at this wavelength or the vibrational relaxation of $\mathrm{I}_{3}$. From this single wavelength it is impossible to differentiate between these two possibilities.

The most important feature of this data, however, is the long time scale recovery of the absorption. It recovers in approximately $100 \mathrm{ps.} \mathrm{If} \mathrm{the} \mathrm{increase} \mathrm{in} \mathrm{absorption} \mathrm{were}$ from an increase in the population of the $I_{2}$ - ion then there would be an increase in the absorption at longer wavelengths where only $\mathrm{I}_{2}{ }^{-}$absorbs. Instead at these longer wavelengths a decrease in the absorption is seen on the same time scale. This is strong evidence that the $\mathrm{I}_{2}$ - is recombining with iodine atoms thus decreasing the absorption a longer wavelengths and reforming $\mathrm{I}_{3}$ - which causes the increase in absorption at $375 \mathrm{~nm}$.

This time scale for recombination has not been seen in any other system. Recombination without leaving the solvent cage, primary geminate recombination, has been observed in many systems, including $I_{2}$ and $I_{2}-$, and occurs in $<1$ ps [39]. Diffusional recombination should take $>1$ microsecond at the concentrations used (concentration had no effect on this 100 ps component). While some fragments may initially escape the solvent cage, but recombine with their geminate fragments in secondary geminate recombination, it is unlikely that $90-95 \%$ of the fragments are recombining in this manner. Once the dissociated fragments are separated by a solvent molecule or two, the probability of recombination should be dramatically reduced. Because no secondary 
geminate recombination has been observed in neutral species and no long time recovery occurs for $\mathrm{I}_{2}$ in these same solvents, it is unlikely that the recovery of the trihalides on a $100 \mathrm{ps}$ time scale is due to secondary geminate recombination. Instead this time scale for recombination implies a chemically significant barrier to both recombination and escape of the fragments - implying a metastable complex.

From an Arrhenius description the barrier heights can be estimated. Using a preexponential factor of $1 \times 10^{13}$ and a rate constant of $1 \times 10^{10}(1 / 100 \mathrm{ps})$ the barrier for recombination is calculated to be $4.2 \mathrm{kcal} / \mathrm{mol}$ and the barrier to "dissociation" of the complex is at least $5.5 \mathrm{kcal} / \mathrm{mol}$ [40]. There are several possible reasons for why the fragments might form a metastable complex. First, when dissociating $\mathrm{I}_{3}$ - with $295 \mathrm{~nm}$ light the species produced are $\mathrm{I}_{2}$ - and $\mathrm{I}^{*}$. This change in the electron spin could cause a barrier to direct recombination and thus a reason for the metastable intermediate. However, work on $\mathrm{I}_{3}$ excited at $308 \mathrm{~nm}$ where a mixture of $\mathrm{I}$ and $\mathrm{I}^{*}$ is produced [25-28], and at 390 $\mathrm{nm}$ where only I is produced [41], shows the same long time scale recombination of the $I_{2}$ and $\mathrm{I}$, indicating that the $\mathrm{I}^{*}$ is not the reason for the intermediate complex. Another possible cause of the metastable complex is that the dissociation products, $\mathrm{I}_{2}$ - and $\mathrm{I}$, do not correspond to the ground state dissociation limit of $\mathrm{I}_{3}$ [42]. The $\mathrm{I}_{3}$ ground state dissociates to $\mathrm{I}_{2}$ and $\mathrm{I}$. These product channels are separated by approximately $1 \mathrm{eV}$. This difference in energy could cause a significant barrier to curve crossing down to the ground state potential. The nature of the complex produced by $\mathrm{I}_{2}$ - and I which can convert to the ground state $\mathrm{I}_{2}$ and $\mathrm{I}$ - potential and reform $\mathrm{I}_{3}$ - is not known.

The photodissociation of $I_{3}$ - was also studied in t-butyl alcohol to be sure that the $I$ produced during the photodissociation was not undergoing an $S_{N} 2$ type reaction with the 
halogenated solvents. This reaction should be energetically favorable, but no evidence for it was seen in the ultrafast dynamics.

\section{Conclusion}

The ultrafast dynamics following the photodissociation of $\mathrm{I}_{3}$ - in solution have been studied in a variety of polar and nonpolar solvents. Even in a completely nonpolar, noncomplexing solvent, $\mathrm{CCl}_{4}$, the vibrational relaxation occurs in only $5 \mathrm{ps}$. This is very similar to the rate of relaxation of $\mathrm{I}_{2}$ - in water and alcohols, but much faster (approximately 30 times) than that for $I_{2}$ in these same solvents. The effect of the polarity of the solvent was measured by increasing the polarity using $\mathrm{CHCl}_{3}$ and $\mathrm{CH}_{2} \mathrm{Cl}_{2}$ as solvents. No increase in relaxation rate was measured for the more polar solvents. The dynamics following the photodissociation of $\mathrm{IBr}_{2}-$ were also investigated. In particular, the vibrational relaxation of $\mathrm{Br}^{-}$was found to be just as fast as for $\mathrm{I}_{2}^{-}$.

Both the fast vibrational relaxation of $I_{2}$ - regardless of the polarity of the solvent and the very fast cooling of the asymmetric $\mathrm{IBr}$ - ion suggest that solvent induced charge localization is not the mechanisms for energy transfer from the ions to the solvents. The more polar solvents would be expected to localize the charge more effectively and hence produce faster cooling, however this is not observed. Also the asymmetry of the $\mathrm{IBr}$ - ion should localize the charge on the $\mathrm{Br}$ portion of the ion and therefore shut off the solvent induced charge transfer, however the vibrational relaxation is just as fast for $\mathrm{IBr}$ - as for the symmetric $\mathrm{I}_{2}$. Both of these results suggest that some other mechanism must be responsible for the acceleration of the vibrational relaxation rate in these ions. 
The vibrational relaxation of the neutral IBr was also studied to examine the cooling of a dipole in nonpolar and slightly polar solvents for comparison to the relaxation of $\mathrm{IBr}$ The vibrational relaxation rate was found to be much more similar to $I_{2}$ than $I B r-$ or $I_{2}$. The relaxation rate showed no trend with increasing polarity of the solvent.

The effects of the counter ion and ion pairing were investigated, but because of the inability to prepare the appropriate conditions, these results were inconclusive. Experiments were performed to see if polar impurities in the solvent were affecting the local environment of the ion. No indication of "solvation" by polar impurities was found.

Finally, the longer time dynamics of $\mathrm{I}_{3}^{-}$and $\mathrm{IBr}_{2}$ - were investigated. In both cases there is an efficient recombination of the dissociation products to reform the trihalide anion on a $100 \mathrm{ps}$ time scale. This implies that a metastable intermediate is formed which can dissociate or decay back to the starting material. The size of the barrier for recombination is estimated to be $4.2 \mathrm{kcal} / \mathrm{mol}$ and the barrier to dissociation at least $5.5 \mathrm{kcal} / \mathrm{mol}$. The reason for this intermediate may be a barrier to the recombination because electron transfer and curve crossing are required to go from products back to reactants. 


\section{Chapter III: Vibrational Relaxation of $\mathrm{M}(\mathrm{CO})_{6}(\mathrm{M}=$ Cr, Mo, W): Effect of Metal Mass on Vibrational Cooling Dynamics and NonBoltzmann Internal Energy Distributions}

\section{Introduction}

There has been a great deal of interest in the study of photodissociation, solvation and vibrational relaxation of transition metal carbonyls in solution using ultrafast timeresolved laser techniques $(6,16,17,43-50)$. The metal carbonyls are ideally suited for study of these processes for several reasons. First, the metal carbonyls provide a rich diversity of chemical structures and reactions, so that they can serve as model systems for the study of a variety of fundamental processes including isomerization, dissociation, and curve-crossing (51). Also, transition metal carbonyls have strong electronic transitions in the visible and ultraviolet, making them experimentally attractive. In addition, synthetic and spectroscopic studies of transition metal carbonyls have provided extensive information about the bonding and stability of these compounds (51). Finally, many studies have been performed on the reaction kinetics of these compounds on the nanosecond and microsecond time scales (52-54) which provide important information for identifying transient species and ultrafast processes.

Some of the most thorough ultrafast work done on metal carbonyls is a series of studies conducted on $\mathrm{Cr}(\mathrm{CO})_{6}$ using transient visible spectroscopic techniques $(16,17,43-$ 45). In these experiments, excitation across a strong, broad absorption band with a maximum near $290 \mathrm{~nm}$, assigned to a $\mathrm{M} \longrightarrow \pi * \mathrm{C} \equiv \mathrm{O}$ charge transfer transition, causes 
efficient ( $\phi_{\text {dis. }}=0.7$ in alkane solution) cleavage of the $\mathrm{Cr}-\mathrm{CO}$ bond (55). These studies determined that the molecule dissociates in $<500$ fs (1), and that the pentacarbonyl fragment begins to associate with a solvent molecule (S) to form a vibrationally excited $\mathrm{Cr}(\mathrm{CO})_{5} \cdot \mathrm{S}$ complex in about $1.5 \mathrm{ps}(16,17,43,44)$. The solvated species then cools in cyclohexane in 17 ps (45a). Finally, long time scale studies have shown the cool, solvated $\mathrm{M}(\mathrm{CO})_{5} \cdot \mathrm{S}$ complex is stable out to the microsecond regime (54) (and longer depending on the electron donating ability of the solvent).

There is still, however, one important part of the dynamics of $\mathrm{Cr}(\mathrm{CO})_{6}$ dissociation that remains ambiguous. Some studies have indicated that additional cooling takes place on a time scale longer than 17 ps (49). In a recent study using transient raman spectroscopy, Hopkins and coworkers suggested that cooling in some modes of the solvated complex, including the $\mathrm{C} \equiv \mathrm{O}$ stretch, may take as long as $150 \mathrm{ps}$ (49). This is consistent with another study by Heilweil and coworkers who directly excited the $\mathrm{C} \equiv \mathrm{O}$ stretching mode of the ground electronic state $\mathrm{Cr}(\mathrm{CO})_{6}$ with picosecond infrared pulses and found that cooling from this mode takes place on the $150 \mathrm{ps}$ time scale (47b). This longer cooling process has not been observed in any visible ultrafast spectroscopic studies done on $\operatorname{Cr}(\mathrm{CO})_{5} \cdot \mathrm{S}$. In this chapter, we present evidence for the presence of dual cooling rates in the vibrational relaxation of $\mathrm{Cr}(\mathrm{CO})_{5} \cdot \mathrm{S}$ through a quantitative examination of the transient electronic absorption spectrum. In addition, we will be addressing the generality of the $\mathrm{Cr}(\mathrm{CO})_{6}$ results to $\mathrm{Mo}(\mathrm{CO})_{6}$ and $\mathrm{W}(\mathrm{CO})_{6}$ in this study. A similar study performed by Joly and Nelson found that all three $\mathrm{M}(\mathrm{CO})_{6}(\mathrm{M}=\mathrm{Cr}, \mathrm{Mo}, \mathrm{W})$ compounds are dissociated in $<500 \mathrm{fs}$, that solvent complexation occurs in a $0.5-5 \mathrm{ps}$ interval and that vibrational relaxation happens in the 5-50 ps regime. No qualitative differences in the 
reaction dynamics of $\mathrm{M}(\mathrm{CO})_{6}$ were found upon changing the identity of $\mathrm{M}$ from $\mathrm{Cr}$ to $\mathrm{Mo}$ to W. Joly and Nelson focussed their attention on making a careful comparison of the dissociation process for the three complexes; however, a quantitative comparison of the dynamics on longer times scale was not performed.

In this study, the important parameters involved in the vibrational relaxation dynamics after dissociation are established by quantitatively comparing the dynamics of $\mathrm{M}(\mathrm{CO})_{6}$ on the $1 \mathrm{ps}$ to $1 \mathrm{~ns}$ time scale. Transient visible spectroscopy is used to monitor the reaction products after dissociation of a $\mathrm{C} \equiv \mathrm{O}$. While these results are in agreement with those of Joly and Nelson, in that there are similarities in the vibrational relaxation dynamics of these species, important differences have also been found in the cooling dynamics of each of the solvated pentacarbonyl complexes especially on the longer time scales.

Section II will discuss the materials, experimental procedure and apparatus used for these experiments. In section III the results will be presented, and in section IV a discussion on several important differences in the vibrational relaxation of the solvated species will be given. Finally, the results will be summarized in section V.

\section{Experimental}

\section{A. Experimental Procedures}

The $295 \mathrm{~nm}$ pump and the probe beams are focussed collinearly into the sample with a $10 \mathrm{~cm}$ focal length lens, giving an estimated spot size of $200 \mu \mathrm{m}$ at the sample. Typical signal sizes are changes in absorption on the order of $0.2 \%$. The UV pump power 
intensity is attenuated to $3-8 \mu \mathrm{J}$ so that no transient signal is observed from the neat solvent; large uv pump intensities can result in multiphotonionization of the pure solvents, resulting in large transient absorption signals from the radical cations. The observed signals are found to vary linearly with pump intensity and are independent of probe intensity, indicating that the signals are not due to multiphoton processes.

\section{B. Materials:}

The transition metal carbonyls, $\mathrm{Cr}(\mathrm{CO})_{6}, \mathrm{Mo}(\mathrm{CO})_{6}$ and $\mathrm{W}(\mathrm{CO})_{6}$, were obtained from Pressure Chemical Company and used without further purification. Spectrograde cyclohexane from Aldrich was used as received for all of the solutions. Samples of 3-5 $\mathrm{mM} \mathrm{M}(\mathrm{CO})_{6}$ in cyclohexane were flowed through a dye laser nozzle (Spectra-Physics) to

produce an optically flat, $100 \mu \mathrm{m}$ thick sample at the laser focus. A jet was used, instead of a flow cell, to prevent photoproduct from building up on cell walls. The flow rate was more than sufficient to ensure that a fresh sample volume was being probed every laser shot at $10 \mathrm{~Hz}$.

\section{Results}

Picosecond transient absorption spectroscopy was used to monitor the photodissociation of $\mathrm{C} \equiv \mathrm{O}$ from $\mathrm{M}(\mathrm{CO})_{6}(\mathrm{M}=\mathrm{Cr}, \mathrm{Mo}, \mathrm{W})$. The metal carbonyls were excited at $295 \mathrm{~nm}$, near the center of an absorption band assigned to a $\mathrm{M} \longrightarrow \pi^{*} \mathrm{C} \equiv \mathrm{O}$ charge transfer transition in $\mathrm{M}(\mathrm{CO})_{6}(51)$. The absorption of the photoproducts was measured at a variety of wavelengths in the visible region of the spectrum on the time scale 
of $1 \mathrm{ps}$ to $1 \mathrm{~ns}$. In figures 3.1 and 3.2 the transient absorption at a variety of probe wavelengths produced over the first $60 \mathrm{ps}$ after excitation of $\mathrm{W}(\mathrm{CO})_{6}$ is shown. The fitting parameters for all the data are shown in table 3.1. All data are fit to a convoluted $1 \mathrm{ps}$ Gaussian pulse. The components used to fit the data may include an exponential rise, a single or double exponential decay and an offset as noted in table 3.1. The first species observed after photodissociation of $\mathrm{W}(\mathrm{CO})_{6}$ absorbs at $560 \mathrm{~nm}$. This absorption has a pulse-width limited rise ( $\leq 1 \mathrm{ps)}$ ). After the rise the absorption at $560 \mathrm{~nm}$ decays in a double exponential manner; the first and larger component decaying in about $3 \mathrm{ps,}$, and the second, minor component decaying in about 29 ps. At $520 \mathrm{~nm}$ a similar absorption profile is observed. In this case, however, the initial rise is not quite pulse-width limited (1-2 ps), and the fast decay has slowed to about $6 \mathrm{ps}$. No slow component is present, but an offset due to the absorption of the cooled, solvated species is present. These trends continue further to the blue. At $480 \mathrm{~nm}$ the rise of the absorption has slowed to 2-3 ps and the decay is about $16 \mathrm{ps}$. To the blue of $480 \mathrm{~nm}$ the profile of the transient absorption changes markedly. At $450 \mathrm{~nm}$ the absorption rises in about 3-4 ps and then remains constant. For transient absorptions to the blue of $450 \mathrm{~nm}$ the absorption continues to rise throughout the first $60 \mathrm{ps}$ as shown in figure 3.2. At $430 \mathrm{~nm}$ there is a $3 \mathrm{ps}$ rise in the absorption and then a slower rise of about $30 \mathrm{ps}$. At $410 \mathrm{~nm}$ the fast rise becomes pulse-width limited and the slow rise is about $42 \mathrm{ps}$.

As mentioned earlier, there are similarities in the dynamics of all three of these species. For $\mathrm{Cr}(\mathrm{CO})_{6}$ and $\mathrm{Mo}(\mathrm{CO})_{6}$, figures 3.3 and 3.4 and figures 3.5 and 3.6, respectively, the same general trends hold. In all cases there is an initial absorption at redder wavelengths that blue shifts as a function of time. At a particular wavelength the 
absorption rises quickly and then remains constant. While at bluer wavelengths the absorption rises throughout the first $60 \mathrm{ps.} \mathrm{Although} \mathrm{these} \mathrm{general} \mathrm{trends} \mathrm{hold} \mathrm{for} \mathrm{all} \mathrm{three}$ compounds, the actual rates vary by as much as a factor of two at analogous wavelengths for the different compounds. Furthermore, there is one component that was found to be qualitatively different for one compound. In the scans at redder wavelengths for $\mathrm{Cr}(\mathrm{CO})_{6}$ a very slow decay, about $150 \mathrm{ps}$, was observed, as shown in figure 3.7 .

\section{Discussion}

The photolysis of $\mathrm{M}(\mathrm{CO})_{6}(\mathrm{M}=\mathrm{Cr}, \mathrm{Mo}, \mathrm{W})$ has been studied previously on the pico- and femtosecond time scales. It was found that dissociation occurs in $<500 \mathrm{fs}$, complexation of a solvent molecule begins between 0.5 and 5 ps and that vibrational relaxation occurs in the first $50 \mathrm{ps}$ for all three species (16). Our experimental results are in agreement with those observations. The emphasis of this work, however, is on comparing the vibrational relaxations of $\mathrm{M}(\mathrm{CO})_{5} \cdot \mathrm{S}$ to determine the effect of different metal atoms. To compare the data for the vibrational relaxation of these three compounds, it is first necessary to identify the trends in the transient absorptions that correspond to vibrational relaxation. From matrix $(52,53)$ and longer time scale $(51,54)$ studies, it has been determined that the cooled, solvated, pentacarbonyl species has an absorption centered in the visible region of the spectrum which is not present for the parent hexacarbonyl species. The $\lambda_{\max }$ for these species is dependent on the solvating species (the more electron donating ability, the bluer the absorption) and the identity of the metal center $\left(\lambda_{\max }\left(\mathrm{W}(\mathrm{CO})_{5} \bullet \mathrm{S}\right) \approx \lambda_{\max }\left(\mathrm{Mo}(\mathrm{CO})_{5} \bullet \mathrm{S}\right)<\lambda_{\max }\left(\mathrm{Cr}(\mathrm{CO})_{5} \cdot \mathrm{S}\right)\right)$. For the cyclohexane solvated species, the absorption peaks are $\lambda_{\max }\left(\mathrm{W}(\mathrm{CO})_{5} \cdot \mathrm{S}\right)=415 \mathrm{~nm}, \lambda_{\max }\left(\mathrm{Mo}(\mathrm{CO})_{5} \cdot \mathrm{S}\right)$ 
$=415 \mathrm{~nm}$ and $\lambda_{\max }\left(\mathrm{Cr}(\mathrm{CO})_{5} \cdot \mathrm{S}\right)=500 \mathrm{~nm}$ (56). To accurately compare the relaxation dynamics of these three species it is necessary to compare wavelengths relative to the absorption maximum of the cool, solvated species. In previous studies, a common transient spectroscopic signature has been identified for the process of vibrational relaxation. It has been found $(15,56)$ that a vibrationally excited species, in this case the solvating pentacarbonyl species, often absorbs to the red of its cool $\lambda_{\max }$ because the species is high in the potential energy well, and therefore closer to the excited electronic state. For $\mathrm{W}(\mathrm{CO})_{5}{ }^{\circ}$ cyclohexane, the absorption of the highly vibrationally excited species is centered at $560 \mathrm{~nm}$. As the species starts to cool and relax down the well, the absorption at these reddest wavelengths disappears quickly while the absorption of cooler species, more to the blue, increases $\left(520 \mathrm{~nm}\right.$ and $480 \mathrm{~nm}$ for $\mathrm{W}(\mathrm{CO})_{5}{ }^{*}$ cyclohexane). As the species cools, the rate of cooling slows down. This slowing is due to two factors. First, as the internal temperature of the solvating pentacarbonyl decreases, the difference in temperature between the metal carbonyl and the solvent becomes smaller and the rate of cooling slows. Also the anharmonicity of the potential will assist cooling near the top of the well. At the top of the well the spacing between the energy levels is smaller. This allows better coupling between the vibrational modes of the metal carbonyl and the low energy rotational and translational modes of the solvent which have been shown to be important modes for accepting energy in vibrational relaxation (15). This slowing can be seen in $\mathrm{W}(\mathrm{CO})_{5} \cdot$ cyclohexane at $520 \mathrm{~nm}$ and $480 \mathrm{~nm}$. In both cases the cooler species (absorbing at $520 \mathrm{~nm}$ and $480 \mathrm{~nm}$ ) do not appear as fast as the hotter species (absorbing at $560 \mathrm{~nm}$ ), and the disappearance of these cooler species is slower. At bluer wavelengths there may be a region where the changes in population due to vibrational relaxation, and the 


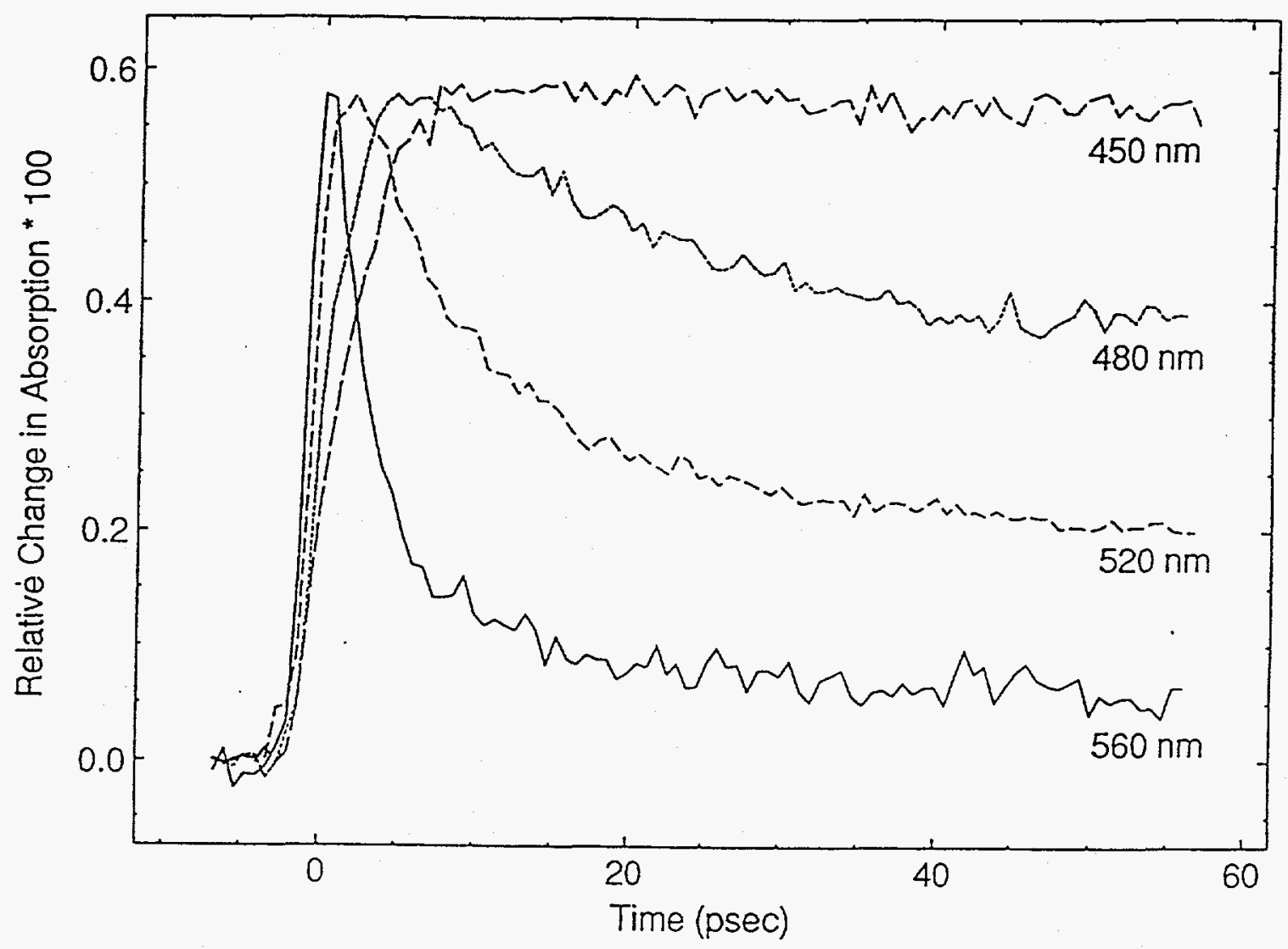

Figure 3.1 - The Changes in Absorption at $560 \mathrm{~nm}, 520 \mathrm{~nm}, 480 \mathrm{~nm}$ and $450 \mathrm{~nm}$ Following Photodissociation of $\mathrm{W}(\mathrm{CO})_{6}$ in Cyclohexane. 


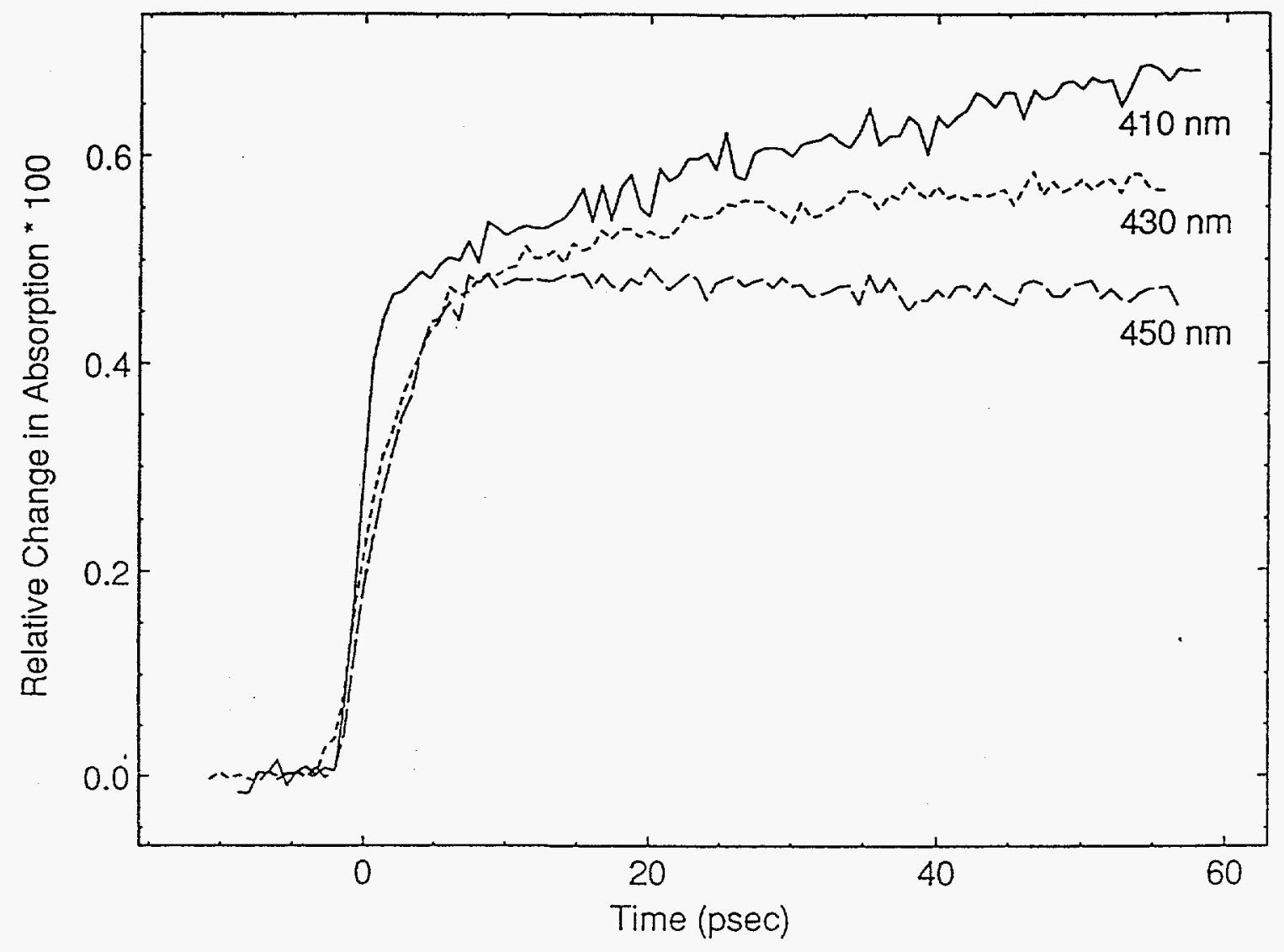

Figure 3.2 - The Changes in Absorption at $450 \mathrm{~nm}, 430 \mathrm{~nm}$, and $410 \mathrm{~nm}$ Following Photodissociation of $\mathrm{W}(\mathrm{CO})_{6}$ in Cyclohexane. 


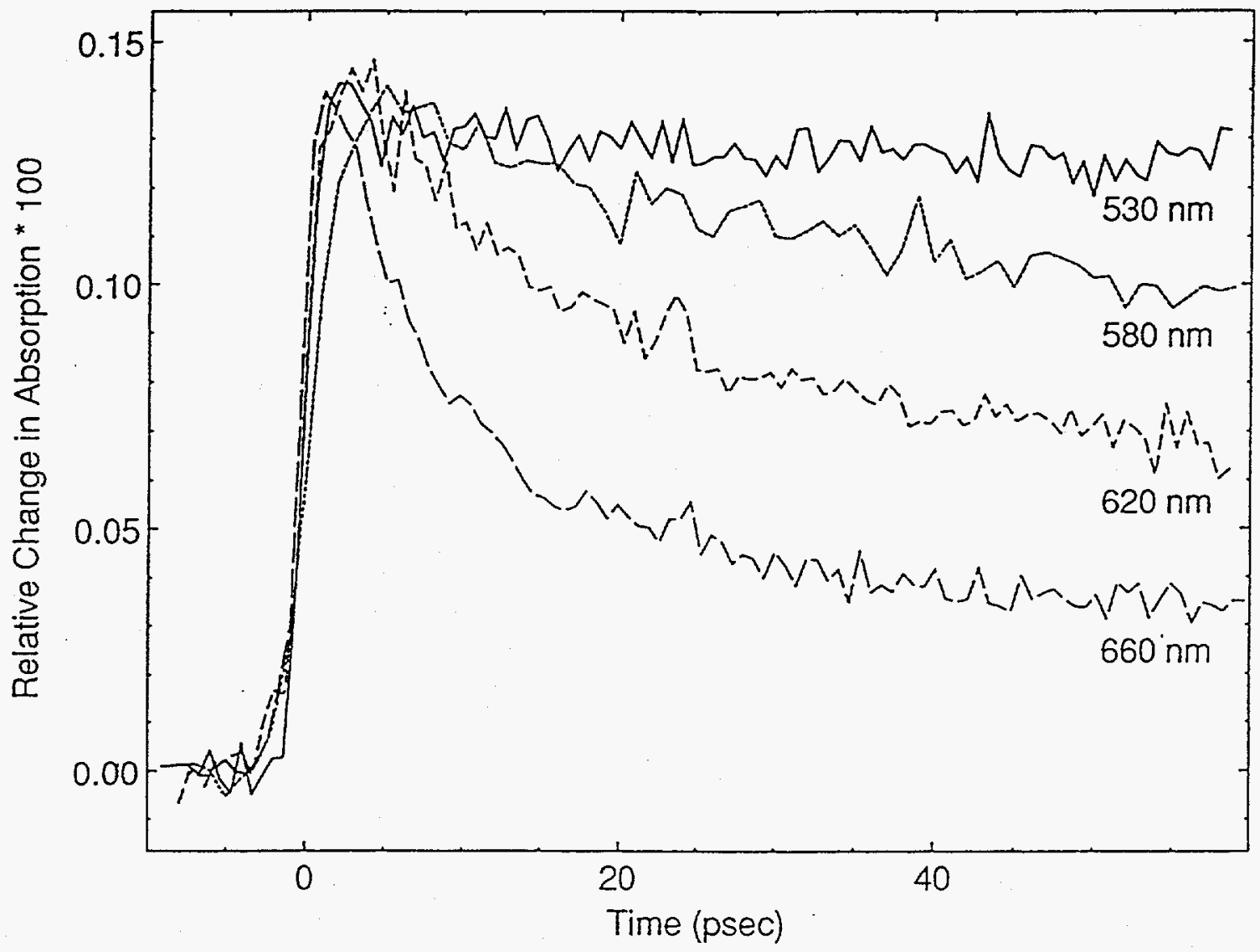

Figure 3.3 - The Changes in Absorption at $660 \mathrm{~nm}, 620 \mathrm{~nm}, 580 \mathrm{~nm}$ and $530 \mathrm{~nm}$ Following Photodissociation of $\mathrm{Cr}(\mathrm{CO})_{6}$ in Cyclohexane. 


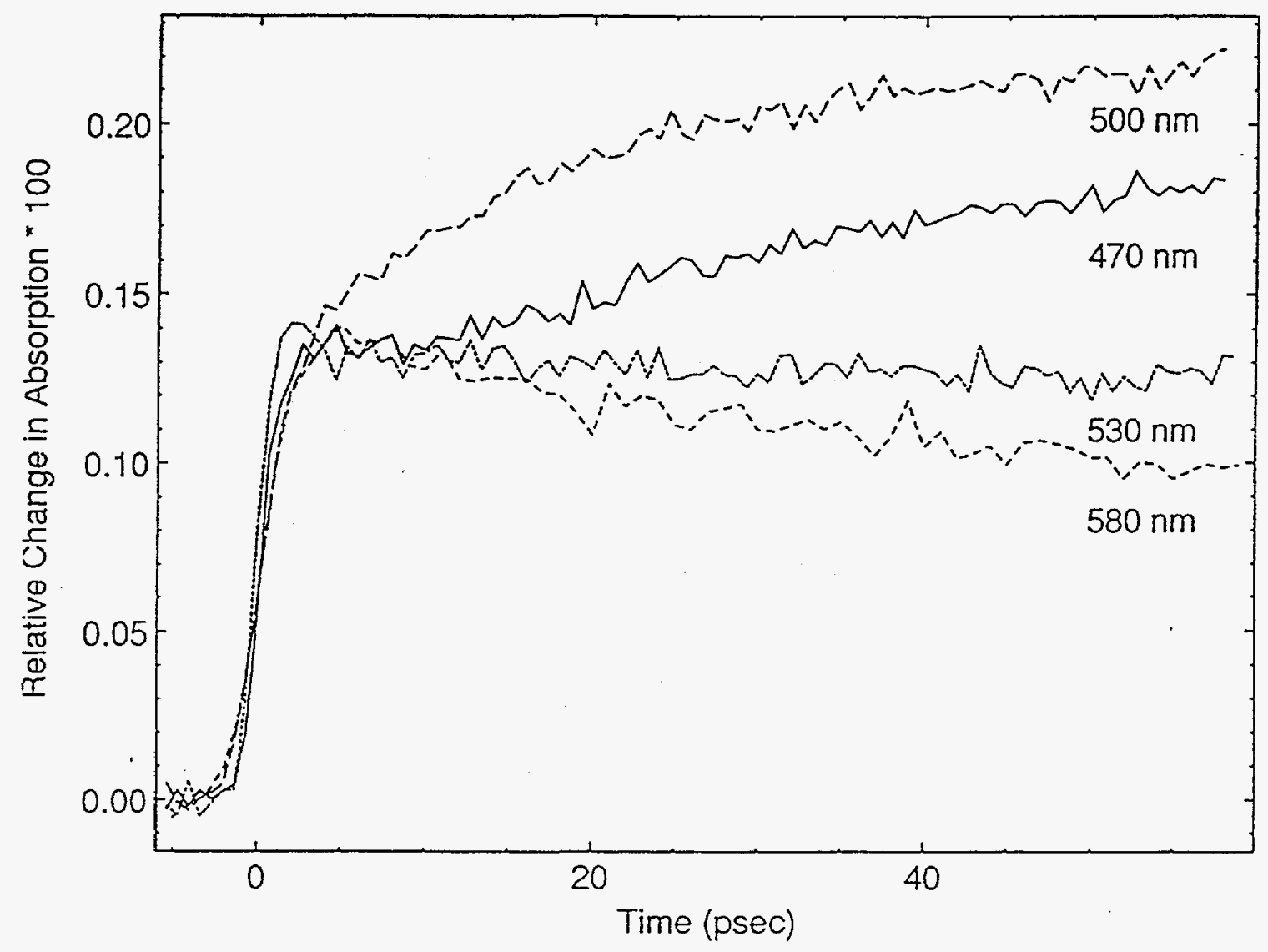

Figure 3.4 - The Changes in Absorption at $580 \mathrm{~nm}, 530 \mathrm{~nm}, 500 \mathrm{~nm}$ and $470 \mathrm{~nm}$ Following Photodissociation of $\mathrm{Cr}(\mathrm{CO})_{6}$ in Cyclohexane. 


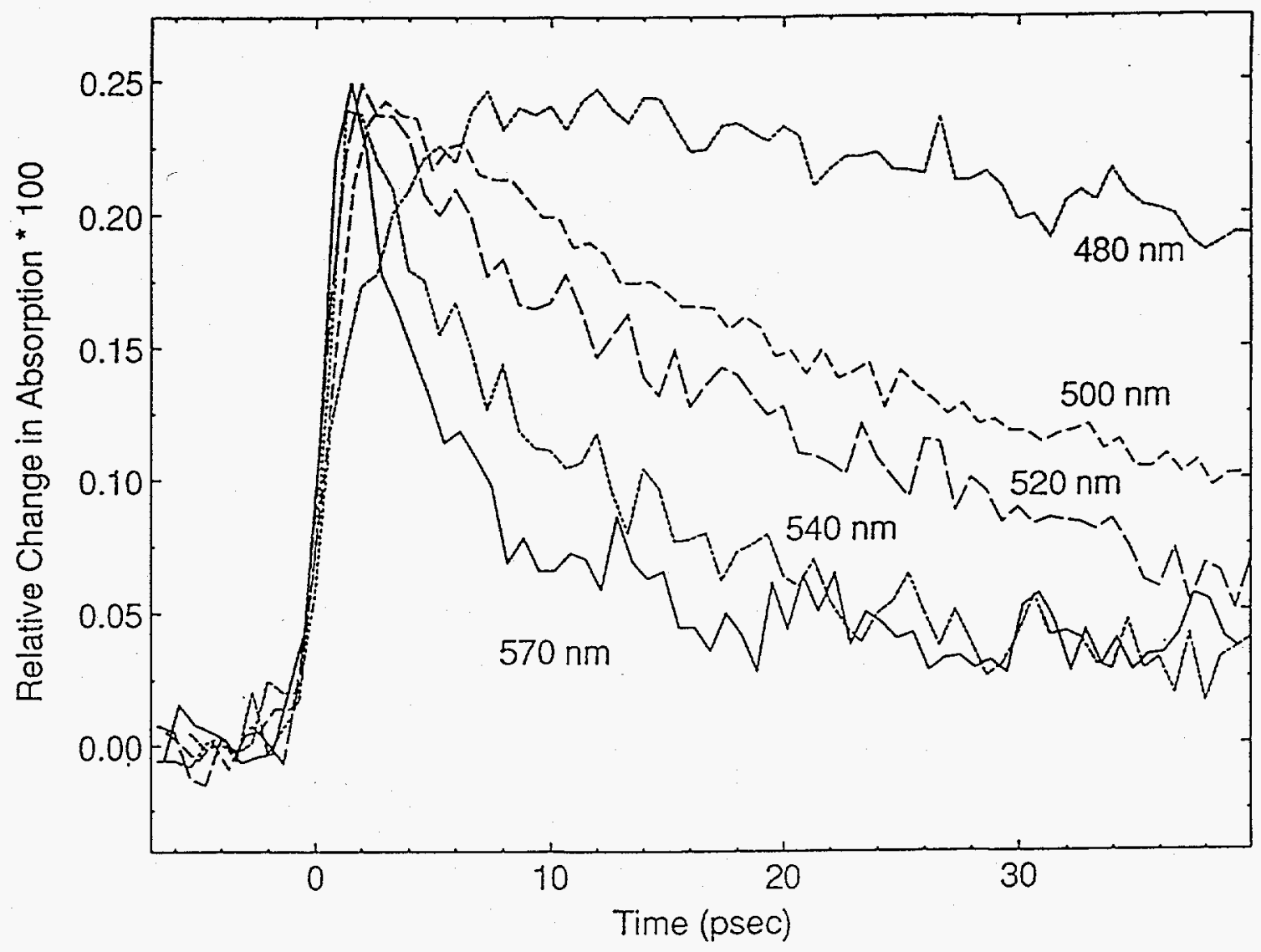

Figure 3.5 - The Changes in Absorption at $570 \mathrm{~nm}, 540 \mathrm{~nm}, 520 \mathrm{~nm}, 500 \mathrm{~nm}$ and $480 \mathrm{~nm}$ Following Photodissociation of $\mathrm{Mo}(\mathrm{CO})_{6}$ in Cyclohexane. 


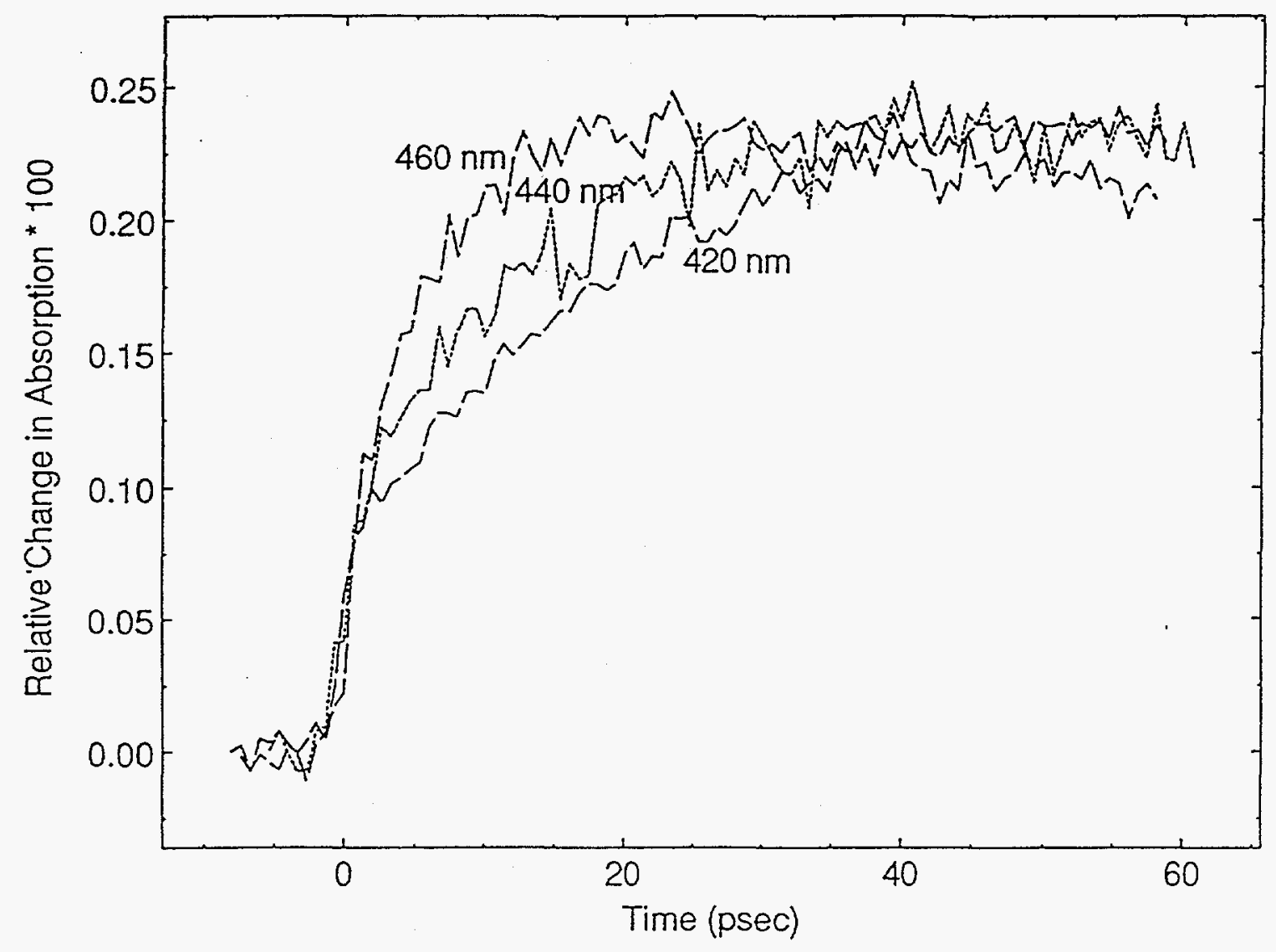

Figure 3.6 - The Changes in Absorption at $460 \mathrm{~nm}, 440 \mathrm{~nm}$ and $420 \mathrm{~nm}$ Following Photodissociation of $\mathrm{Mo}(\mathrm{CO})_{6}$ in Cyclohexane. 
TABLE I.

\begin{tabular}{|c|c|c|c|}
\hline Molecule & Wavelength (nm) & $\begin{array}{c}\text { Time } \\
\text { Constants (ps) }\end{array}$ & $\begin{array}{l}\text { Preexponential } \\
\text { Factor }\end{array}$ \\
\hline $\mathrm{W}(\mathrm{CO})_{6}$ & $\begin{array}{l}410 \\
430 \\
450 \\
480 \\
520 \\
560\end{array}$ & $\begin{array}{r}<1 \\
42 \\
3 \\
30 \\
3 \\
2 \\
16 \\
\text { offset } \\
6 \\
\text { offset } \\
3 \\
29 \\
\text { offset }\end{array}$ & $\begin{array}{c}-0.24 \\
-0.17 \\
-0.84 \\
-0.31 \\
-0.49 \\
-0.59 \\
0.26 \\
0.33 \\
0.48 \\
0.21 \\
0.29 \\
0.04 \\
0.02\end{array}$ \\
\hline $\mathrm{Cr}(\mathrm{CO})_{6}$ & $\begin{array}{l}470 \\
500 \\
530 \\
580 \\
620 \\
660\end{array}$ & $\begin{array}{r}<1 \\
9 \\
25 \\
<1 \\
18 \\
140 \\
\text { offset } \\
20 \\
\text { offset } \\
12 \\
150 \\
\text { offset } \\
8 \\
170 \\
\text { offset }\end{array}$ & $\begin{array}{c}-0.13 \\
0.02 \\
-0.09 \\
-0.20 \\
-0.17 \\
0.03 \\
0.13 \\
0.18 \\
0.35 \\
0.23 \\
0.09 \\
0.13 \\
0.30 \\
0.11 \\
0.06\end{array}$ \\
\hline $\mathrm{MO}(\mathrm{CO})_{6}$ & $\begin{array}{l}420 \\
440 \\
460 \\
480 \\
\\
500 \\
520 \\
540 \\
570\end{array}$ & $\begin{array}{r}<1 \\
18 \\
<1 \\
10 \\
8 \\
35 \\
\text { offset } \\
5 \\
28 \\
\text { offset } \\
22 \\
\text { offset } \\
20 \\
4 \\
18 \\
3 \\
23\end{array}$ & $\begin{array}{r}-0.10 \\
-0.25 \\
-0.04 \\
-0.13 \\
-0.15 \\
0.08 \\
0.15 \\
-0.15 \\
0.15 \\
0.13 \\
0.19 \\
0.07 \\
0.17 \\
0.09 \\
0.10 \\
0.15 \\
0.04\end{array}$ \\
\hline
\end{tabular}

a. Negitive preexponential factors correspond to a increase in absorption; positive correspond to a decrease in absorption

Table 3.1 - Parameters for the best fits to the data for $\mathrm{Cr}(\mathrm{CO})_{6}, \mathrm{Mo}(\mathrm{CO})_{6}$ and $\mathrm{W}(\mathrm{CO})_{6}$ at a variety of probe wavelengths. 
changes in absorption of the different species roughly balance each other and after the initial rise at these wavelengths the absorption remains essentially constant. This corresponds to $450 \mathrm{~nm}$ for $\mathrm{W}(\mathrm{CO})_{5}{ }^{\bullet}$ cyclohexane. Finally, as the species relaxes to the bottom of the potential well and comes into equilibrium with the solvent, its absorption increases at wavelengths that have been found to be the $\lambda_{\max }$ for the cool, solvated species. For $\mathrm{W}(\mathrm{CO})_{5}{ }^{\circ}$ cyclohexane this corresponds to the absorption near $415 \mathrm{~nm}$. All three compounds show this trend in their transient absorption spectrum, and in each case it is assigned to vibrational relaxation.

Although these similarities exist, important differences between the dynamics of the vibrational relaxation of these complexes are also observed. One difference is a very long (>100 ps) component in the decay of vibrationally excited $\mathrm{Cr}(\mathrm{CO})_{5} \cdot$ cyclohexane. Figure 3.7 shows the transient absorption of this complex at 530,620 and $660 \mathrm{~nm}$. At all three wavelengths the long component was measured to be about $150 \mathrm{ps.} \mathrm{The} \mathrm{relaxations}$ of the tungsten and molybdenum complexes show no corresponding long component in those systems. This long component was first observed in our group in the initial studies of $\mathrm{Cr}(\mathrm{CO})_{6}(58)$, but was not assigned until subsequent vibrational work was completed. Hopkins and coworkers used transient raman spectroscopy to study the vibrational relaxation of $\mathrm{Cr}(\mathrm{CO})_{5}{ }^{*}$ cyclohexane and found a relaxation time similar to this long component for the vibrationally excited $\mathrm{C} \equiv \mathrm{O}$ stretch in $\mathrm{Cr}(\mathrm{CO})_{5}{ }^{*}$ cyclohexane (49). This is also the time scale for relaxation of vibrationally excited $\mathrm{C} \equiv \mathrm{O}$ on $\mathrm{Cr}(\mathrm{CO})_{6}$ measured by Heilweil and coworkers(47b). Based on the similarity in time scale with these studies, we assign this long component in the transient absorption of $\mathrm{Cr}(\mathrm{CO})_{5} \cdot$ cyclohexane to relaxation of the vibrationally excited $\mathrm{C} \equiv \mathrm{O}$ stretch. 


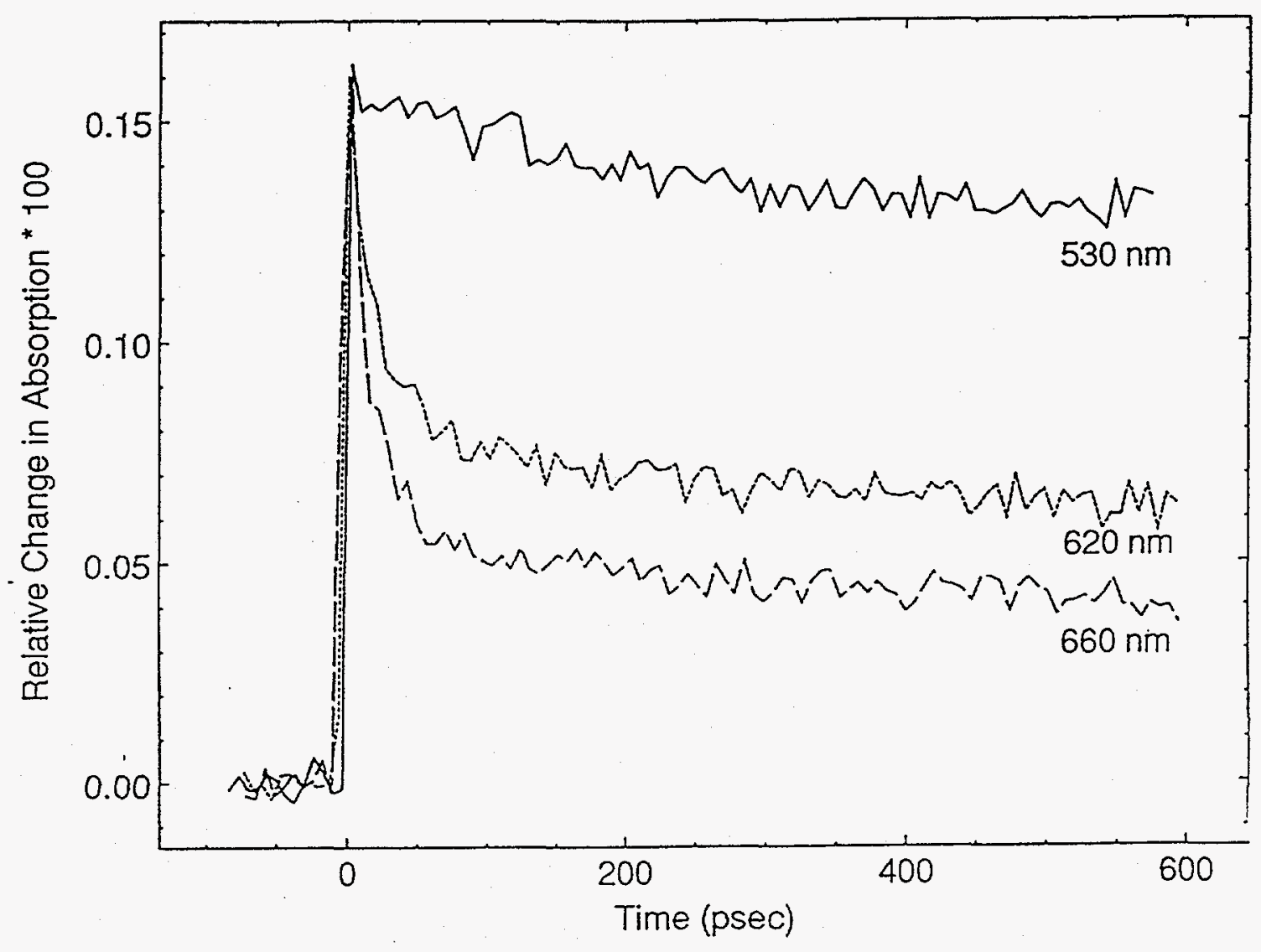

Figure 3.7 - The Changes in Absorption at $660 \mathrm{~nm}, 620 \mathrm{~nm}$ and $530 \mathrm{~nm}$ Following Photodissociation of $\mathrm{Cr}(\mathrm{CO})_{6}$ in Cyclohexane. 
When probed to the blue of $620 \mathrm{~nm}$, closer to the absorption maximum of the cooled product $(500 \mathrm{~nm})$, the long component is absent over the region $570-610 \mathrm{~nm}$, but reappears again near $530 \mathrm{~nm}$. There are two possible explanations for the reappearance of the long component at $530 \mathrm{~nm}$. First, the absorption spectrum of the species with a $\mathrm{C} \equiv \mathrm{O}$ vibrationally excited is not known. It could be that this species has a larger absorption cross section at $530 \mathrm{~nm}$ than the completely cooled complex. If this is the case then we are just monitoring the disappearance of the same species at three different wavelengths (530, 620 and $660 \mathrm{~nm}$ ). Another possibility is that increased absorption at $530 \mathrm{~nm}$ is due to population in low energy modes of the $\mathrm{Cr}(\mathrm{CO})_{5}{ }^{*}$ cyclohexane. The similarity of the time scales for these two features could then be interpreted as vibrational energy from the high frequency modes (absorbing at $620 \mathrm{~nm}$ ) being transferred to lower frequency modes (absorbing at $530 \mathrm{~nm}$ ) which then transfer the energy to the solvent. If the energy transfer to the solvent (intermolecular) was faster than high frequency to low frequency energy transfer (intramolecular), then a small component with the same decay rate as the high frequency to low frequency transfer rate should be seen when probing the low frequency modes at $530 \mathrm{~nm}$. The long component is not seen at intermediate wavelengths (570-610 $\mathrm{nm}$ ) because the $\sim 2000 \mathrm{~cm}^{-1}$ of energy that is transferred from the high frequency $\mathrm{C} \equiv O$ stretch mode to the low frequency modes is quickly distributed over the entire complex via efficient intramolecular vibrational energy redistribution so that the internal temperature of the complex is never high enough to absorb above $530 \mathrm{~nm}$. This scheme is also in agreement with the previously mentioned transient Raman work (49). In that study it was found that the $\mathrm{M}-\mathrm{CO}$ bond relaxed with the same rate as the high frequency $\mathrm{C} \equiv \mathrm{O}$ stretch mode, with a time constant of approximately $150 \mathrm{ps}$. 
In an earlier study of a similar molecule, $\mathrm{Mn}_{2}(\mathrm{CO})_{10}$, it was found that the relaxation of $\mathrm{Mn}_{2}(\mathrm{CO})_{9}$ also had a component $>100 \mathrm{ps}(45 \mathrm{~b})$. It was also attributed to vibrational relaxation through the $\mathrm{C} \equiv \mathrm{O}$ stretch mode. Other work completed in this laboratory on the third row transition metal complexes has shown that there is no long component in the relaxation dynamics of $\operatorname{Re}_{2}(\mathrm{CO})_{9}$. As discussed above, we have found no long component in the relaxation of either the molybdenum or the tungsten carbonyl complexes. So, of the five compounds studied, $\mathrm{Cr}(\mathrm{CO})_{6}, \mathrm{Mo}(\mathrm{CO})_{6}, \mathrm{~W}(\mathrm{CO})_{6}, \operatorname{Re}_{2}(\mathrm{CO})_{10}$ and $\mathrm{Mn}_{2}(\mathrm{CO})_{10}$, the only two which show anomolously long relaxation times are the ones with first row transition metals, $\mathrm{Cr}(\mathrm{CO})_{6}$ and $\mathrm{Mn}_{2}(\mathrm{CO})_{10}$. There are several possible explanations why these lighter transition metal carbonyls might show the long component in their dynamics. First, the $\mathrm{C} \equiv \mathrm{O}$ stretch may not be significantly excited in the dissociation of the heavier metal carbonyls. The additional metal mass could affect the partitioning of the available energy from photodissociation among the different degrees of freedom. The heavier mass would lead to less coupling between the $C \equiv O$ stretch mode in $\mathrm{M}(\mathrm{CO})_{5}$ and the $\mathrm{M}-\mathrm{CO}$ dissociation coordinate and thus less $\mathrm{C} \equiv \mathrm{O}$ stretch excitation. Another possible explanation for the absence of a slow component in the heavier transition metal carbonyls is that the energy deposited in the $\mathrm{C} \equiv \mathrm{O}$ stretch of these species is transferred more quickly to other modes of the molecule or solvent. However, it was found by Heilweil and coworkers that energy generally took longer to transfer from the $\mathrm{C} \equiv \mathrm{O}$ stretch to the low energy modes in $\mathrm{W}(\mathrm{CO})_{6}$ than in $\mathrm{Cr}(\mathrm{CO})_{6}(47 \mathrm{~b})$. Based on this finding, it is likely that the amount of energy initially deposited in the $\mathrm{C} \equiv \mathrm{O}$ stretch is the most important factor, and the stronger coupling of the $\mathrm{C} \equiv \mathrm{O}$ stretch mode to the 
dissociation coordinate in $\mathrm{Cr}(\mathrm{CO})_{6}$ causes this larger deposit of energy.

Another important difference in the dynamics of these compounds is the amount of time needed to reach thermal equilibrium with the solvent. The absorption of these solvated pentacarbonyl species near their maximum is plotted in figure 3.2, 3.4 and 3.6. All three show a fast rise, which is attributed to the initial formation of a bond with a solvent molecule, followed by a slow rise which is assigned to relaxation of the vibrationally excited species. For both $\mathrm{Cr}(\mathrm{CO})_{5} \cdot$ cyclohexane and $\mathrm{Mo}(\mathrm{CO})_{5}{ }^{*}$ cyclohexane the initial fast rise is pulse-width limited, and the slow rise is approximately $18 \mathrm{ps.} \mathrm{For} \mathrm{the}$ tungsten complex, however, the fast rise is not pulse-width limited, $3 \mathrm{ps,} \mathrm{and} \mathrm{the} \mathrm{slower}$ rise is approximately $42 \mathrm{ps}$. Both of these slower rises in the tungsten data point to slower vibrational relaxation in the tungsten complex than either the molybdenum or chromium complexes. The slower fast component implies that it takes longer for the naked pentacarbonyl species to lose enough energy to begin to form a bond with a solvent molecule, and the slower long rise implies that it takes longer for the solvated species to relax to thermal equilibrium with the solvent. This is a surprising result because one might expect a species with a higher density of states such as $\mathrm{W}(\mathrm{CO})_{5} \cdot$ cyclohexane to have modes which match those of the solvent better and therefore, have a faster cooling rate. A similar effect has been noted for the vibrational relaxation of asymmetric mixed-valent transition metal dimers (59). In these studies it was noted that energy transfer rates are significantly decreased upon substituting osmium for ruthenium. The reason for the slower cooling in the heavier metal systems is not apparent at this time. Perhaps the lighter species have resonances that fortuitously match the resonances in the solvent better or the internal modes of the lighter species are better coupled to allow a more even and faster 
cooling.

Regardless of the causes, both the 150 ps component in the vibrational relaxation of $\mathrm{Cr}(\mathrm{CO})_{5}{ }^{\circ}$ cyclohexane and the longer primary cooling of $\mathrm{W}(\mathrm{CO})_{5}{ }^{\circ}$ cyclohexane show that some simple ideas about energy distribution and dissipation do not apply even in these moderately sized molecules. For example, the concept of internal temperature is often used when considering the intramolecular vibrational energy redistribution after absorption of a photon. However, in cases such as $\mathrm{Cr}(\mathrm{CO})_{5}{ }^{\star}$ cyclohexane where different modes of the molecule are only weakly coupled, a single internal temperature, calculated as a Boltzmann distribution of the available energy over all the modes of the molecule (60), is clearly insufficient. Instead, a nonBoltzmann type of description of the individual modes is necessary to accurately describe the internal energy distribution in these systems.

\section{Conclusion}

The photodissociation dynamics of $\mathrm{Cr}(\mathrm{CO})_{6}, \mathrm{Mo}(\mathrm{CO})_{6}$ and $\mathrm{W}(\mathrm{CO})_{6}$ have been studied and the vibrational relaxation rates of their photoproducts in cyclohexane have been determined. All the molecules dissociate in $<1$ ps. $\mathrm{Cr}(\mathrm{CO})_{5}$ and $\mathrm{Mo}(\mathrm{CO})_{5}$ are found to associate with a solvent in $\leq 1$ ps. $\mathrm{W}(\mathrm{CO})_{5}$ takes $\sim 3$ ps to associate with a solvent molecule. The cooling of the solvated species, $\mathrm{Cr}(\mathrm{CO})_{5} \cdot \mathrm{S}$ and $\mathrm{Mo}(\mathrm{CO})_{5} \cdot \mathrm{S}$ ( $S=$ cyclohexane), occurs with a time constant of $18 \mathrm{ps,} \mathrm{while} \mathrm{W}(\mathrm{CO})_{5} \cdot \mathrm{S}$ takes twice as long, 42 ps. A slow decay component observed in $\mathrm{Cr}(\mathrm{CO})_{5}{ }^{\circ}$ cyclohexane is assigned to relaxation of the high frequency $\mathrm{C} \equiv \mathrm{O}$ stretch to low frequency modes in the molecule. This slow component is not present in the heavier transition metal carbonyls, 
$\mathrm{Mo}(\mathrm{CO})_{5}{ }^{\circ}$ cyclohexane and $\mathrm{W}(\mathrm{CO})_{5} \cdot \mathrm{cyclohexane}$. This anomalously long component is also reported in the relaxation of $\mathrm{Mn}_{2}(\mathrm{CO})_{9}$, another first row metal carbonyl, but not in $\mathrm{Re}_{2}(\mathrm{CO})_{10}$, a second row metal carbonyl. One possible explanation for the trend of first row transition metal//ong vibrational relaxation is that the $\mathrm{C} \equiv \mathrm{O}$ stretch mode in $\mathrm{M}(\mathrm{CO})_{5}$ is more likely to be excited during the dissociation in the lighter first row transition metals. A $\mathrm{C} \equiv \mathrm{O}$ stretch mode is more likely to be excited in the lighter $\mathrm{Cr}(\mathrm{CO})_{5}$ fragment because its lighter mass increases the amount of kinetic energy deposited in the fragment. This higher kinetic energy increases the probability of energy being transferred into the high frequency $\mathrm{C} \equiv \mathrm{O}$ stretch. More generally these results begin to address the important issue of the effect of the internal structure on the reaction dynamics of moderately sized molecules. This is a fundamental issue that must be addressed to advance our understanding from the dynamics of diatomics to the more chemically relevant moderate and large sized molecules. These results have important implications in understanding the role of internal structure in the energy relaxation dynamics of moderately sized molecules in solution. 


\section{Chapter IV: The Ultrafast Photochemistry of $\mathrm{Fe}_{3}(\mathrm{CO})_{12}$ and $\mathrm{Ru}_{3}(\mathrm{CO})_{12}$}

\section{Introduction}

Metal carbonyl complexes are an important class of compounds both because of their technological importance and as prototypes for investigating a variety of chemical reactions. Their versatility as prototypes comes from a variety of factors. First, their chemical reactivity and structures differ widely depending upon the number and type of transition metals in the complex. In addition, the absorptions of complexes in both the ultraviolet/visible region and infrared region of the spectrum are strong, well studied and diagnostic of the structure of the complex.

The structure and photochemistry of the mono and dinuclear metal carbonyls have been studied extensively in both long time scale studies and to a lesser extent on the ultrafast time scale. An example of work on the ultrafast time scale is the study of the dynamics of $\mathrm{M}(\mathrm{CO})_{6}(\mathrm{M}=\mathrm{Cr}, \mathrm{Mo}, \mathrm{W})$ in Chapter 3. However a much less studied class of complexes is the trinuclear metal carbonyls, $\mathrm{M}_{3}(\mathrm{CO})_{12}(\mathrm{M}=\mathrm{Fe}, \mathrm{Ru}, \mathrm{Os})$. These species undergo a wide variety of chemical reactions, some of which are technologically useful. The molecules also show some novel chemical behavior, such as dynamic structure, quantum yields exceeding 100 for photocatalyzed reactions and semi-stable isomeric structures. Also these trinuclear carbonyls have several types of ultraviolet/visible absorptions that lead to distinctly different chemistry. The longer wavelength absorptions generally involve metal-metal bond excitations, while shorter wavelength absorptions are 
metal-ligand bond excitations. This variety of chemistry and structures make these very interesting, but complex systems to study.

\section{Ultrafast Studies of Metal-Metal Bond Cleavage in $\mathrm{Fe}_{3}(\mathrm{CO})_{12}$ in Solution}

The structure and dynamics of $\mathrm{Fe}_{3}(\mathrm{CO})_{12}$ have been under investigation for over 60 years. The solid state structure was intensely investigated by many groups throughout the 1950 's, 60 's and early 70 's [61], but proved difficult to determine because of disorder in the crystal caused by intramolecular rearrangement. In 1967, Wei and Dahl showed that in the solid state, the three iron centers form an isosceles triangle [62] (see figure 4.1a). At the apex of this triangle is an iron atom with four terminal carbonyl ligands just as all the metal centers in $\mathrm{Ru}_{3}(\mathrm{CO})_{12}$ and $\mathrm{Os}_{3}(\mathrm{CO})_{12}$ contain. However in $\mathrm{Fe}_{3}(\mathrm{CO})_{12}$, two carbonyl ligands bridge across the asymmetric side of the triangle (see figure 4.1a). In 1974, Cotton and Troupe [63] refined the structure originally proposed by Wei and Dahl and showed the two $\mathrm{CO}$ bridges to be highly asymmetric, and based on this, they proposed that the barrier between an all terminal $\mathrm{CO}$ configuration and a $\mathrm{CO}$ bridging configuration is low and nearly flat. The structure of $\mathrm{Fe}_{3}(\mathrm{CO})_{12}$ in solution has also been a subject of much investigation. It is clear from the infrared spectrum that the bridging character of $\mathrm{Fe}_{3}(\mathrm{CO})_{12}$ is much reduced in solution as compared to the solid state [64]. This is also supported by more recent extended X-ray absorption fine structure (EXAFS) studies [65] which showed the primary structure in nonpolar solution is an all terminal CO structure (figure 4.1b) with a small contribution from a possible bridging isomer (figure 4.1a or 4.1c). Additionally, ${ }^{13} \mathrm{C}$ NMR studies by Cotton and Hunter on $\mathrm{Fe}_{3}(\mathrm{CO})_{12}$ in solution 


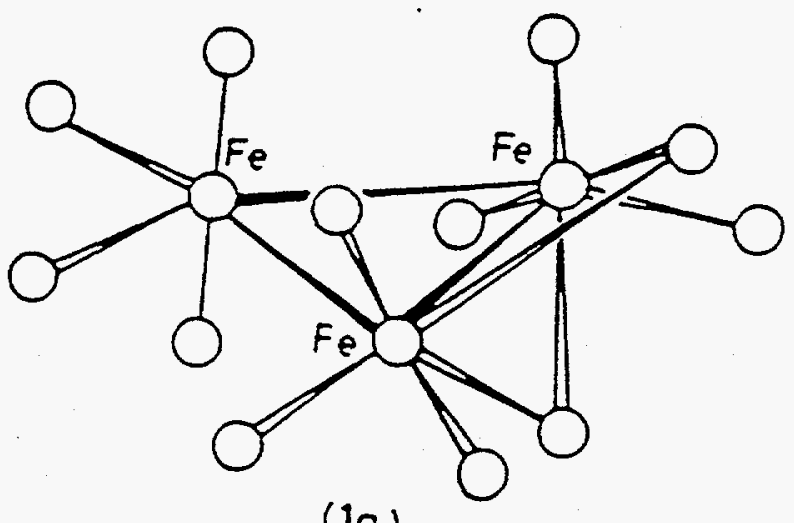

(1a)

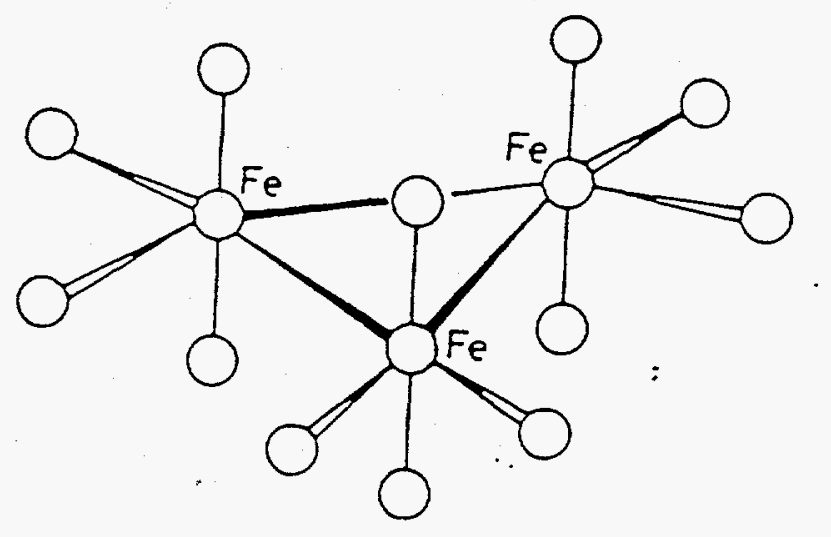

(1b)

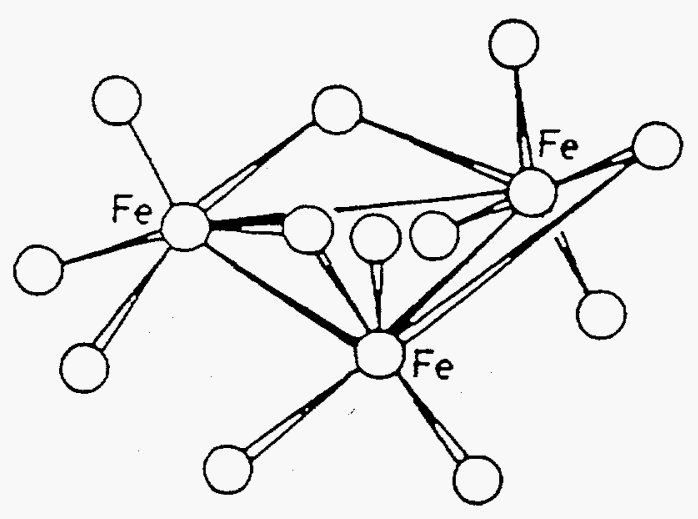

(ic)

Figure 4.1 - The Structures of $\mathrm{Fe}_{3}(\mathrm{CO})_{12}$ (1a - solid-state structure; $1 \mathrm{~b}$ - all terminal structure; ic - $\mathrm{CO}$ exchange structure). 
[64] showed that there is rapid exchange of CO's between the iron atoms, indicating some type of transient bridging species. Based on low temperature studies they determined that the barrier between an all terminal structure and a bridging intermediate must be $\leq 6$ $\mathrm{kcal} / \mathrm{mol}$. In this section the long wavelength $\left(>560 \mathrm{~nm}\right.$ ) photochemistry of $\mathrm{Fe}_{3}(\mathrm{CO})_{12}$ in cyclohexane is investigated. Results indicate that this bridging to terminal process, first investigated by Cotton and Hunter, may play an important role in the long wavelength photochemistry of $\mathrm{Fe}_{3}(\mathrm{CO})_{12}$.

Triiron dodecacarbonyl undergoes cleavage of a metal-metal bond upon absorption of visible light $[51,66]$. The bond cleavage is a result of a direct $\sigma \rightarrow \sigma^{*}$ absorption which is centered at $600 \mathrm{~nm}$, figure 4.2. Spectroscopic studies in low temperature matrices have shown that isomerization occurs following absorption [66]. Following cleavage of the iron-iron bond, both metal atoms have a 17 -electron configuration. The isomerization involves shifting one of the terminal carbonyl groups into a bridging position between the two iron atoms where the bond had just been broken. This gives one of the iron atoms a stable 18-electron configuration, but leaves the other iron atom (whose carbonyl has just gone from terminal to bridging) coordinatively unsaturated with only 16 electrons. The coordinatively unsaturated intermediate $\mathrm{Fe}_{3}(\mathrm{CO})_{12}$ (unsat) can, upon heating, convert back to ground state $\mathrm{Fe}_{3}(\mathrm{CO})_{12}$ or fragment to produce mono and dinuclear species. This conversion back to ground state $\mathrm{Fe}_{3}(\mathrm{CO})_{12}$ accounts for the low quantum yield observed at this wavelength for the fragmentation of $\mathrm{Fe}_{3}(\mathrm{CO})_{12}[66]$.

To understand the dynamics of the long wavelength excitation of $\mathrm{Fe}_{3}(\mathrm{CO})_{12}$ in solution, picosecond pump-probe experiments have been carried out with 1 ps time resolution. The experimental details have been described in chapter 1 [15]. Briefly, $1 \mathrm{ps,}$ 

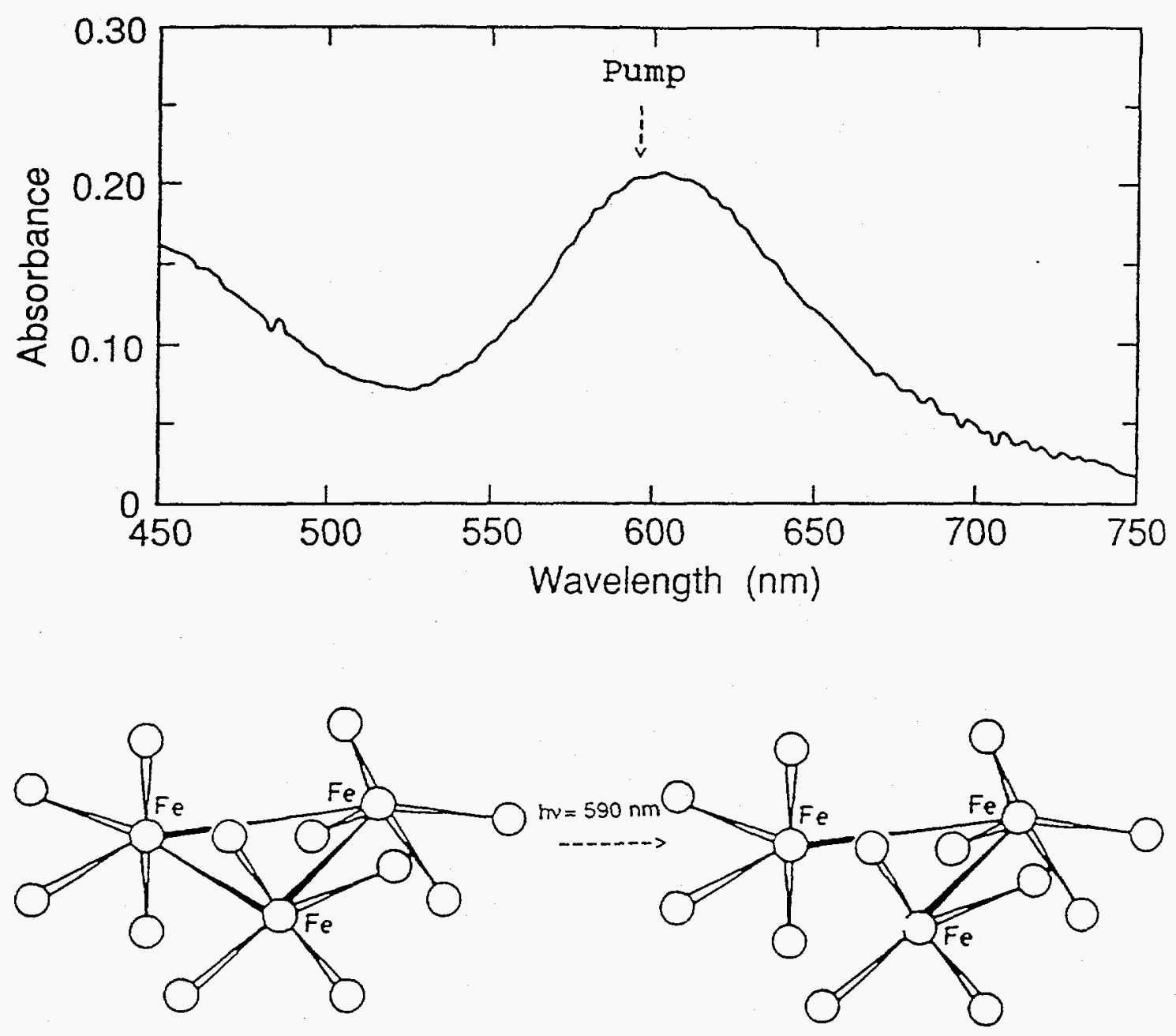

Figure 4.2 - Absorption Spectrum of $\mathrm{Fe}_{3}(\mathrm{CO})_{12}$. The $600 \mathrm{~nm}$ Absorption Causes Metal-Metal Bond Cleavage 
$0.5 \mathrm{~mJ}$ pulses at $590 \mathrm{~nm}$ were used to excite the sample and transient absorption signals were measured using a continuum probe. The continuum was generated in a water cell and $10 \mathrm{~nm}$ FWHM bandpass filters were used for wavelength selection. The sample concentration was $1 \times 10^{-3} \mathrm{M} \mathrm{Fe}_{3}(\mathrm{CO})_{12}$ in deoxygenated cyclohexane. This solution was continuously flowed through an optical cell with a path length of $1 \mathrm{~mm}$.

$\mathrm{Fe}_{3}(\mathrm{CO})_{12}$ has a broad absorption centered at $600 \mathrm{~nm}$ which is attributed to a metal-metal $\sigma \rightarrow \sigma^{*}$ transition. Figure 4.3 displays the absorbance change at $560 \mathrm{~nm}$ near the center of the $\mathrm{Fe}_{3}(\mathrm{CO})_{12}$ absorption following excitation at $590 \mathrm{~nm}$. The data show an instrument response-limited decrease (note the negative y-axis) in the absorption of the sample followed by a recovery of the absorption which fits a single exponential decay with a time of $150 \pm 20$ ps. The bleach does not recover to the initial value, but exhibits an offset of approximately $20 \%$.

Figure 4.4 shows the absorbance change at $720 \mathrm{~nm}, 760 \mathrm{~nm}$ and $800 \mathrm{~nm}$ following excitation at $590 \mathrm{~nm}$. At all wavelengths the data show a transient absorption with a two component decay. The rise time of the absorbance is instrument response limited. The long component of the decay is $150 \pm 15$ ps and is independent of wavelength. The fast component is wavelength dependent with values of $14 \pm 2 \mathrm{ps}, 9 \pm 2$ ps and $5.5 \pm 2 \mathrm{ps}$ at 720,760 and $800 \mathrm{~nm}$, respectively.

In low temperature matrices the bridging isomer, $\mathrm{Fe}_{3}(\mathrm{CO})_{12}$ (unsat), has been shown to have a broad featureless absorption to the red of the ground state $\mathrm{Fe}_{3}(\mathrm{CO})_{12}[66]$. Based on this work we assign the broad transient absorption to the red of the ground state absorption to the formation of $\mathrm{Fe}_{3}(\mathrm{CO})_{12}$ (unsat). Therefore, the instrument response limited rise time in both the bleach and the red-shifted transient absorption indicate that 


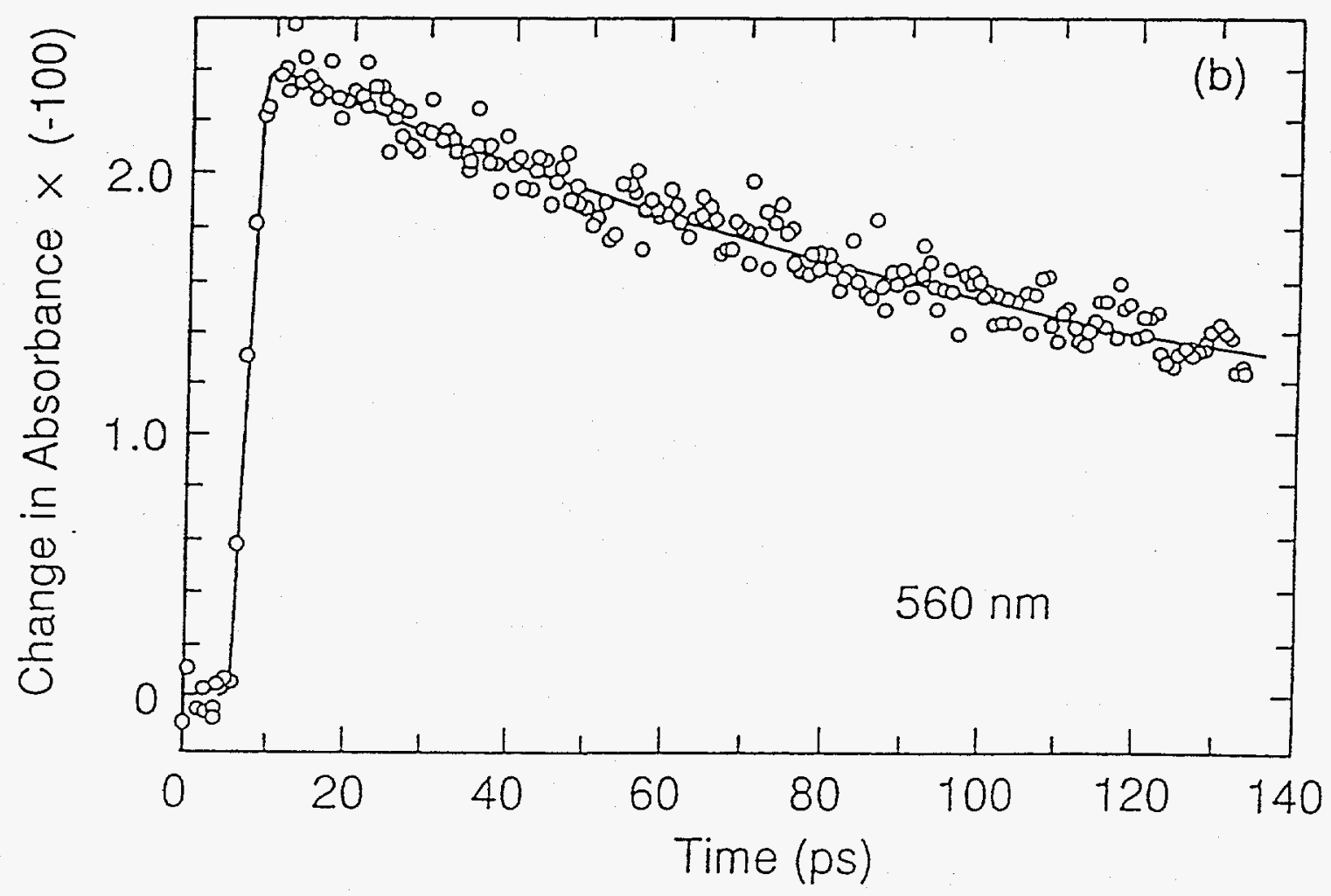

Harris/70.10(6790)

Figure 4.3 - The Change in Absorption at $560 \mathrm{~nm}$ following excitation at $590 \mathrm{~nm}$. 
$\mathrm{Fe}_{3}(\mathrm{CO})_{12}$ (unsat) is formed in $\leq 1 \mathrm{ps}$ after excitation. The $150 \mathrm{ps}$ component present in both the recovery of the ground state absorption at $560 \mathrm{~nm}$ and in the decay of the absorption of $\mathrm{Fe}_{3}(\mathrm{CO})_{12}$ (unsat) at $720 \mathrm{~nm}, 760 \mathrm{~nm}$ and $800 \mathrm{~nm}$ is attributed to the conversion of $\mathrm{Fe}_{3}(\mathrm{CO})_{12}$ (unsat) back to ground state $\mathrm{Fe}_{3}(\mathrm{CO})_{12}$.

From a simple Arrhenius description, the size of the barrier in going from the bridging isomer, $\mathrm{Fe}_{3}(\mathrm{CO})_{12}$ (unsat), to the all terminal ground state can be estimated. Assuming a preexponential of $1 \times 10^{13}$ ( same as used by Cotton et. al.[64]) and a rate of isomerization of $6.67 \times 10^{9} \mathrm{~s}^{-1}(1 / 150 \mathrm{ps})$ at $300 \mathrm{~K}$, the height of the barrier is approximately $4.3 \mathrm{kcal} / \mathrm{mol}$. This is well under the upper limit placed by Cotton and Hunter $(6 \mathrm{kcal} / \mathrm{mol})$ from NMR studies, but still chemically reasonable. Temperature dependent studies would provide further evidence for this process.

The decay of the transient absorption at $720 \mathrm{~nm}, 760 \mathrm{~nm}$ and $800 \mathrm{~nm}$ shows two components. The wavelength independent long component of $150 \mathrm{ps}$, as mentioned above, is assigned to isomerization of $\mathrm{Fe}_{3}(\mathrm{CO})_{12}$ (unsat) back to ground state $\mathrm{Fe}_{3}(\mathrm{CO})_{12}$. The fast component is wavelength dependent and does not appear in the ground state bleach at $560 \mathrm{~nm}$. This indicates that a fraction of the coordinatively unsaturated species, $\mathrm{Fe}_{3}(\mathrm{CO})_{12}$ (unsat), are not returning to ground state $\mathrm{Fe}_{3}(\mathrm{CO})_{12}$. Previous studies have shown that $\mathrm{Fe}_{3}(\mathrm{CO})_{12}$ (unsat) can fragment to produce mono and dinuclear species [66]. In light of this, the fast component is attributed to the fragmentation of $\mathrm{Fe}_{3}(\mathrm{CO})_{12}$ (unsat) which also accounts for the observed incomplete recovery of the bleach at $560 \mathrm{~nm}$.

The wavelength dependence of the fast component can be interpreted as probing $\mathrm{Fe}_{3}(\mathrm{CO})_{12}$ (unsat) molecules with excess vibrational energy. It has been found in previous studies $[18,60]$ that following excitation vibrationally excited molecules absorb to the red 

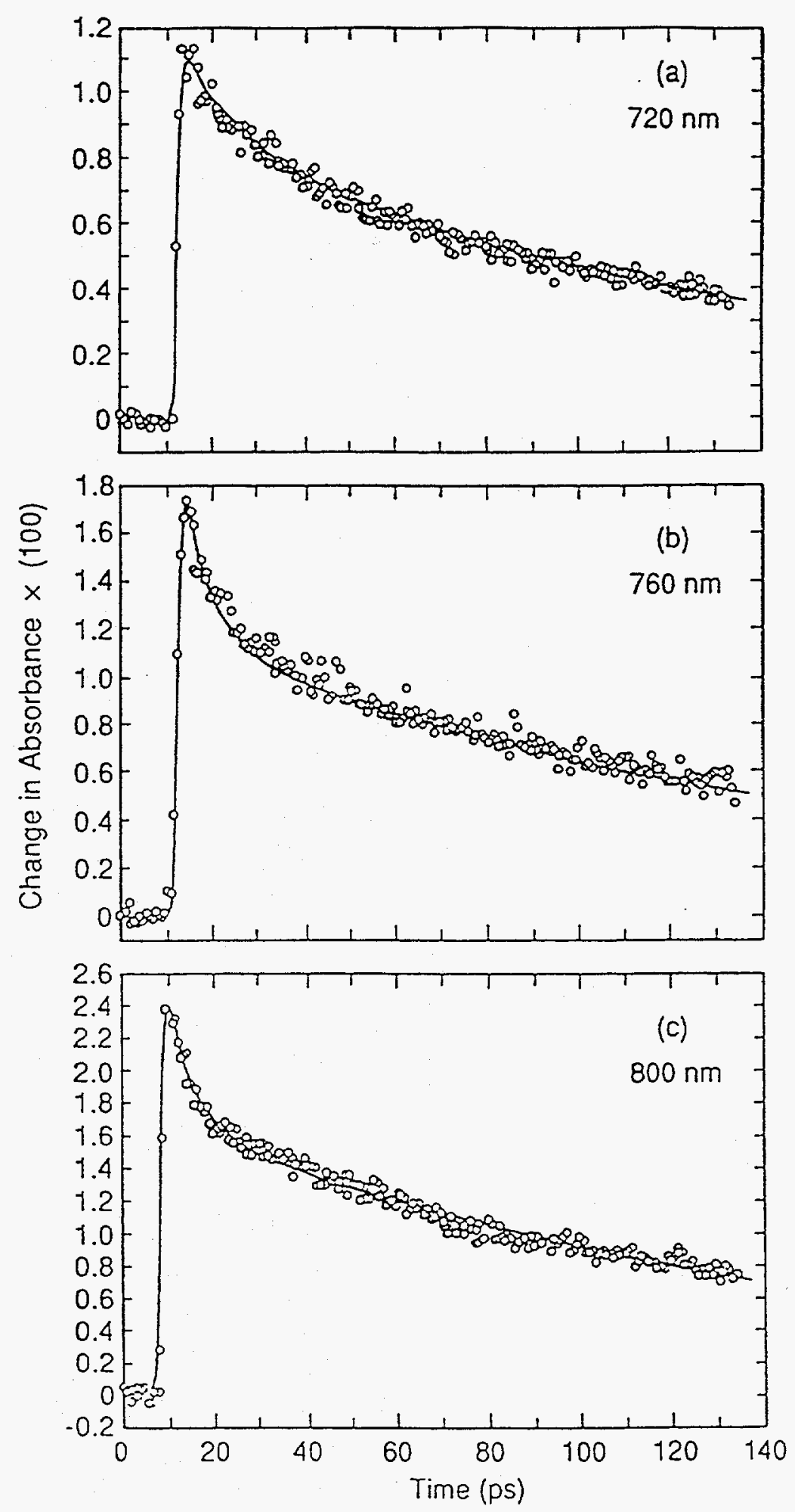

Figure 4.4 - The Change in Absorption at (a) $720 \mathrm{~nm}$, (b) $760 \mathrm{~nm}$ and (c) $800 \mathrm{~nm}$ Following Excitation at $590 \mathrm{~nm}$. 
of the cooled species. Therefore, the faster decays at longer wavelengths correspond to species with more excess vibrational energy fragmenting faster than species with less vibrational energy.

Figure 5 summarizes our results for the dynamics following metal-metal bond cleavage in $\mathrm{Fe}_{3}(\mathrm{CO})_{12}$. A coordinatively unsaturated, carbonyl bridging intermediate, $\mathrm{Fe}_{3}(\mathrm{CO})_{12}$ (unsat), which results from metal-metal bond cleavage and carbonyl rearrangement is formed within 1 ps. This intermediate can either fragment or convert back to ground state $\mathrm{Fe}_{3}(\mathrm{CO})_{12}$. The fragmentation is promoted by excess vibrational energy and occurs in 5 to $15 \mathrm{ps}$. The isomerization back to the all terminal ground state structure occurs on a time scale of 150 ps which implies a barrier of $4.3 \mathrm{kcal} / \mathrm{mol}$. Transient infrared experiments which can probe the bridging carbonyl group in $\mathrm{Fe}_{3}(\mathrm{CO})_{12}$ (unsat) will help to better understand the details of the carbonyl rearrangement.

\section{Ultrafast Dynamics of Trinuclear Metal Carbonyl Complexes Following Ligand Dissociation}

\section{A. Introduction}

While the longer wavelength excitations of trimetal carbonyl clusters are associated with breaking metal-metal bonds (as discussed in the previous section), the shorter wavelength excitations of the clusters are primarily metal-ligand charge transfer bands and therefore promote dissociation of the carbonyl ligand $[66,67]$. To study the dynamics of these metal-carbonyl clusters following ligand dissociation, experiments using $295 \mathrm{~nm}$ pulses to initiate the photochemistry (as opposed to the $590 \mathrm{~nm}$ excitation in the previous 


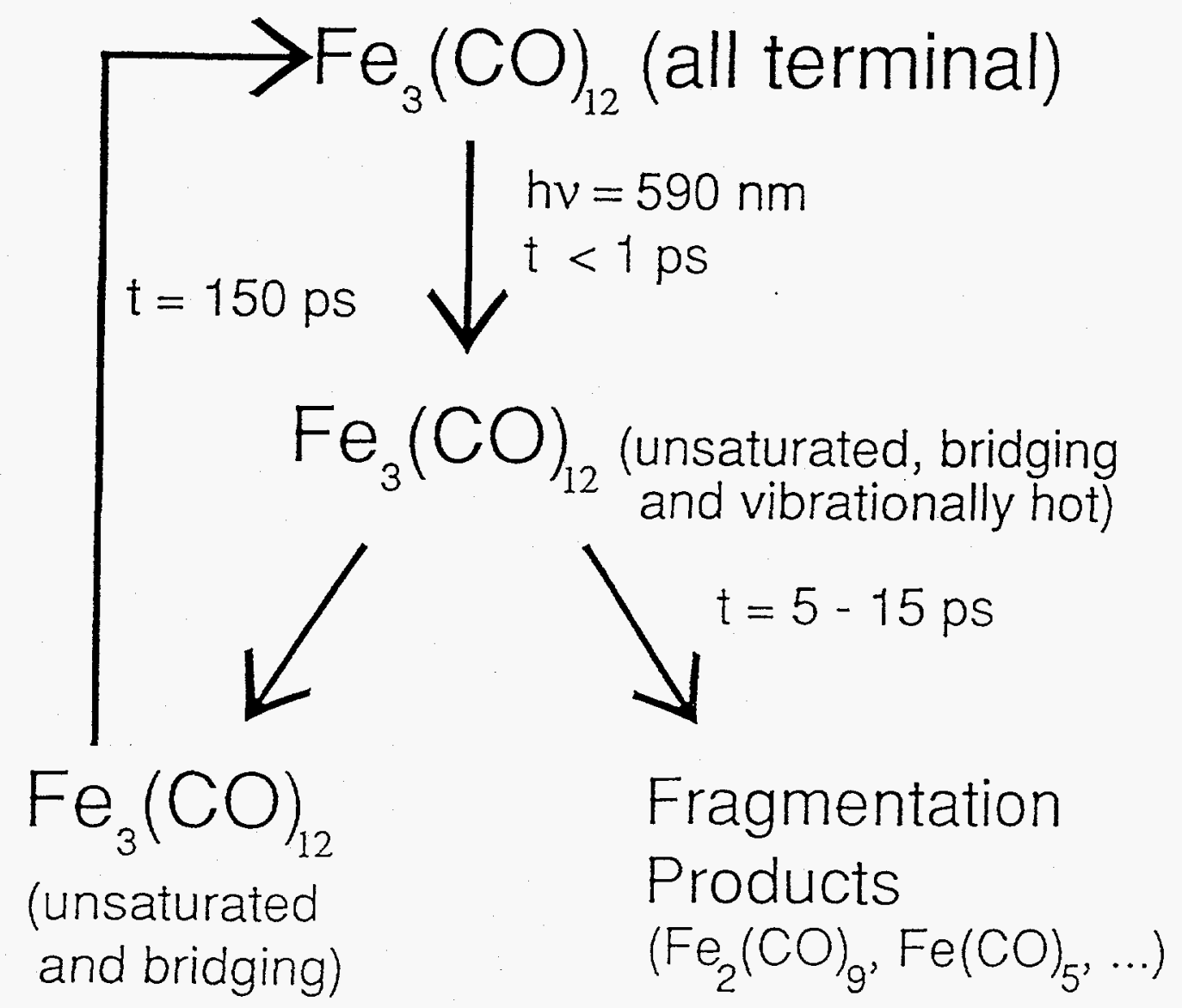

Figure 4.5 - Reaction Scheme for the Long Wavelength Excitation of $\mathrm{Fe}_{3}(\mathrm{CO})_{12}$. 
section) have been performed on both $\mathrm{Fe}_{3}(\mathrm{CO})_{12}$ and $\mathrm{Ru}_{3}(\mathrm{CO})_{12}$.

The laser system used in these experiments is the same as in the previous section except that a portion of the $590 \mathrm{~nm}$ light is frequency doubled to excite the samples at 295 $\mathrm{nm}$. Less than $10 \mu \mathrm{J}$ pulse of $295 \mathrm{~nm}$ light were used to excite the sample to remove any signal due to the solvent. The solvent used was hexane. This solvent may have been a poor choice because of the difficulty in obtaining pure $n$-hexane. The solvent was usually Aldrich spectrophotometric grade hexane, $95+\%$, but experiments were also performed with Fisher spectroanalyzed hexanes. The specifications for this solvent (Fisher) state "This reagent is generally a mixture of several isomers of hexane $\left(\mathrm{C}_{6} \mathrm{H}_{14}\right)$, predominately n-hexane and methyl cyclopentane." While the saturated isomers of hexane may not affect the reaction dynamics, any unsaturated species and the variability of their concentration from solvent to solvent could significantly affect the dynamics. This is because the unsaturated alkenes could form strong bonds with any unsaturated transition metal complexes. In fact one of the primary uses of these compounds is to catalyze the movement of double bonds within such alkenes. This change in the purity of the solvent may account for the irreproducibility of some of the longer time scale dynamics. I would suggest in future experiments on these compounds using a different solvent, such as pentane or heptane, which can be obtained with greater purity and with greater quantitative knowledge of the impurities. In addition it would be advisable in general to use hplc grade solvents as opposed to spectroscopic grade solvents, because of the exclusion of isomers from the hplc grade solvents. The samples were saturated with solute implying a concentration of $10^{-3} \mathrm{M}$ to $10^{-4} \mathrm{M}$. The sample was flowed at a rate sufficient to provide fresh sample with every laser shot. For both compounds photoproduct built up on the window of the flow cell. To keep this buildup from having an effect on the signal, the 
solution was flowed quickly, the position of the cell moved frequently and the translation stage scanned alternatively in the forward and backward directions.

Because the products and reactants in the photochemistry of $\mathrm{M}_{3}(\mathrm{CO})_{12}$ often have overlapping and complex absorptions in the visible and near UV, it is difficult to assign an absorption to an intermediate with a particular structure. The only option is to look at the photochemistry of these compounds in low temperature matrices where the kinetics are slowed and identify intermediates and products based on these assignments. However the chemistry in the low temperature matrix can be different as well as simply slower than solution phase dynamics, so caution is necessary in comparing results in these two environments.

\section{B. The Ultraviolet Excitation of $\mathrm{Ru}_{3}(\mathrm{CO})_{12}$}

Work in both low temperature matrices and in solution have shown that ultraviolet excitation of both $\mathrm{Fe}_{3}(\mathrm{CO})_{12}$ and $\mathrm{Ru}_{3}(\mathrm{CO})_{12}$ lead to dissociation of one $\mathrm{CO}$ ligand [66, 67]. For $\mathrm{Ru}_{3}(\mathrm{CO})_{12}$ the disappearance in the ground state absorption measured at $410 \mathrm{~nm}$ (figure 4.6) shows that this process occurs faster than our instrument resolution. At the same time there is a pulse width limited increase in the absorption of the sample between 450 and $740 \mathrm{~nm}$ (see figure 4.7 and 4.8 ). At $430 \mathrm{~nm}$ no change in absorbance is seen indicating a quasi-isosbestic point. Following the disappearance of the starting material and the appearance of products which absorb at longer wavelengths there appear to be two separate processes occurring.

First, there is the recovery of the ground state absorption at $410 \mathrm{~nm}$, figure 4.6. This recovery occurs in $25 \mathrm{ps}$, and the bleach has an offset of $25 \%$. This time scale for the 


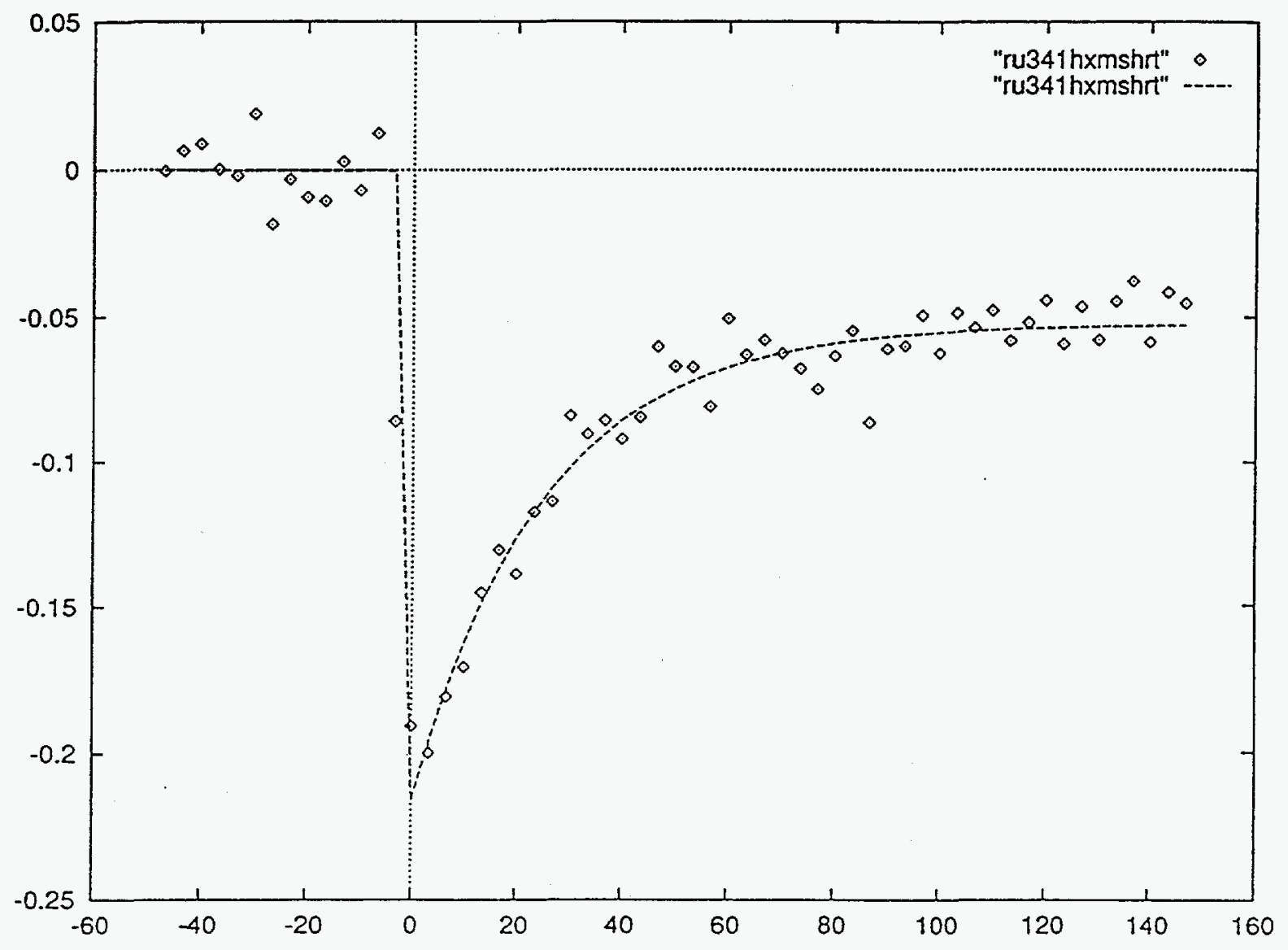

Figure 4.6 - The Change in Absorption at $410 \mathrm{~nm}$ Following Photodissociation of $\mathrm{Ru}_{3}(\mathrm{CO})_{12}$ in Hexane. 
recovery and the size of the offset are consistent with the $\mathrm{Ru}_{3}(\mathrm{CO})_{11}$ undergoing geminate recombination with the dissociated $\mathrm{CO}$ and vibrational relaxation to reform the starting material. Vibrational relaxation of other metal carbonyl complexes with similar amounts of excess energy have measured to be $20-40 \mathrm{ps}$ [18]. In addition, the quantum yield for some type of chemical reaction, either fragmentation or substitution, following excitation near $300 \mathrm{~nm}$ is approximately $15 \%$ [67]. The offset shows that all but about $25 \%$ of the molecules return to the ground state consistent with the quantum yield measurement. The $10 \%$ discrepancy could be due to some reformation of $\mathrm{Ru}_{3}(\mathrm{CO})_{12}$ on a longer time scale or because the wavelength used in this experiment is slightly different from that in the quantum yield measurements.

Additional evidence for the geminate recombination of approximately $75 \%$ of the photodissociated $\mathrm{Ru}_{3}(\mathrm{CO})_{12}$ is a wavelength dependent component from 500 to $660 \mathrm{~nm}$. The component is fastest at longer wavelengths $(610 \mathrm{~nm}, 4 \mathrm{ps})$ and slower at shorter wavelengths $(560 \mathrm{~nm}, 10 \mathrm{ps}$, see figure 4.7). This trend for vibrational relaxation has been seen in many systems $[15,18]$. It occurs because vibrationally excited species are higher in the vibrational well so that the absorption is red-shifted from the ground state. The component corresponding to vibrational relaxation becomes progressively smaller at shorter wavelengths ( $500 \mathrm{~nm}$ and $528 \mathrm{~nm}$, see figures 4.9 and 4.10 ) because the difference in the cross section of the vibrationally excited species and the cooled species is small, so the vibrational relaxation does not cause significant changes in absorption at these wavelengths. The decay constants for these vibrationally excited species (4-10 ps) is consistent with the complete recovery of the cooled ground state species in $25 \mathrm{ps}$.

Besides the recovery of the ground state and the vibrational relaxation of 


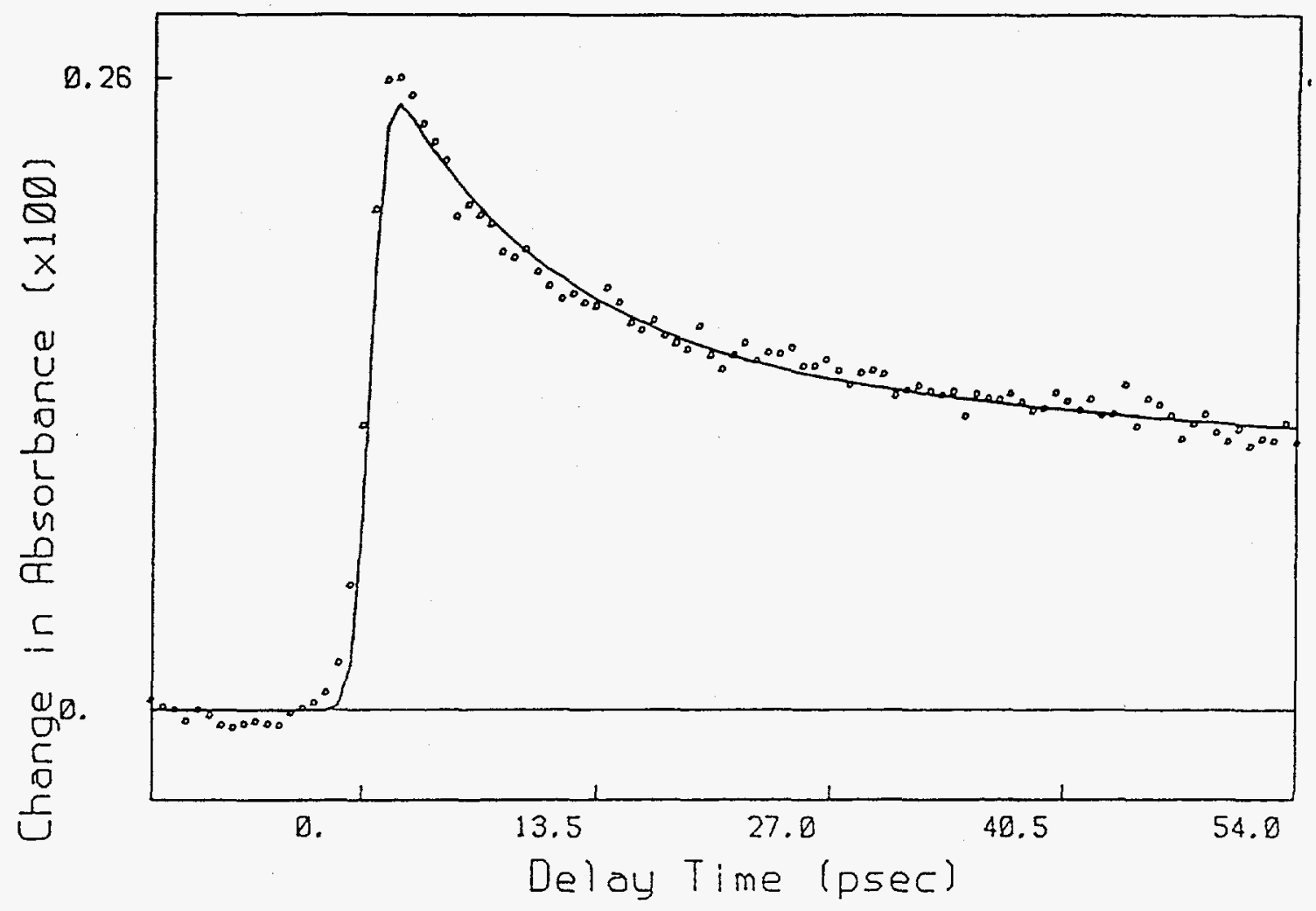

Figure 4.7 - The Change in Absorption at $560 \mathrm{~nm}$ Following Photodissociation of $\mathrm{Ru}_{3}(\mathrm{CO})_{12}$ in Hexane. 


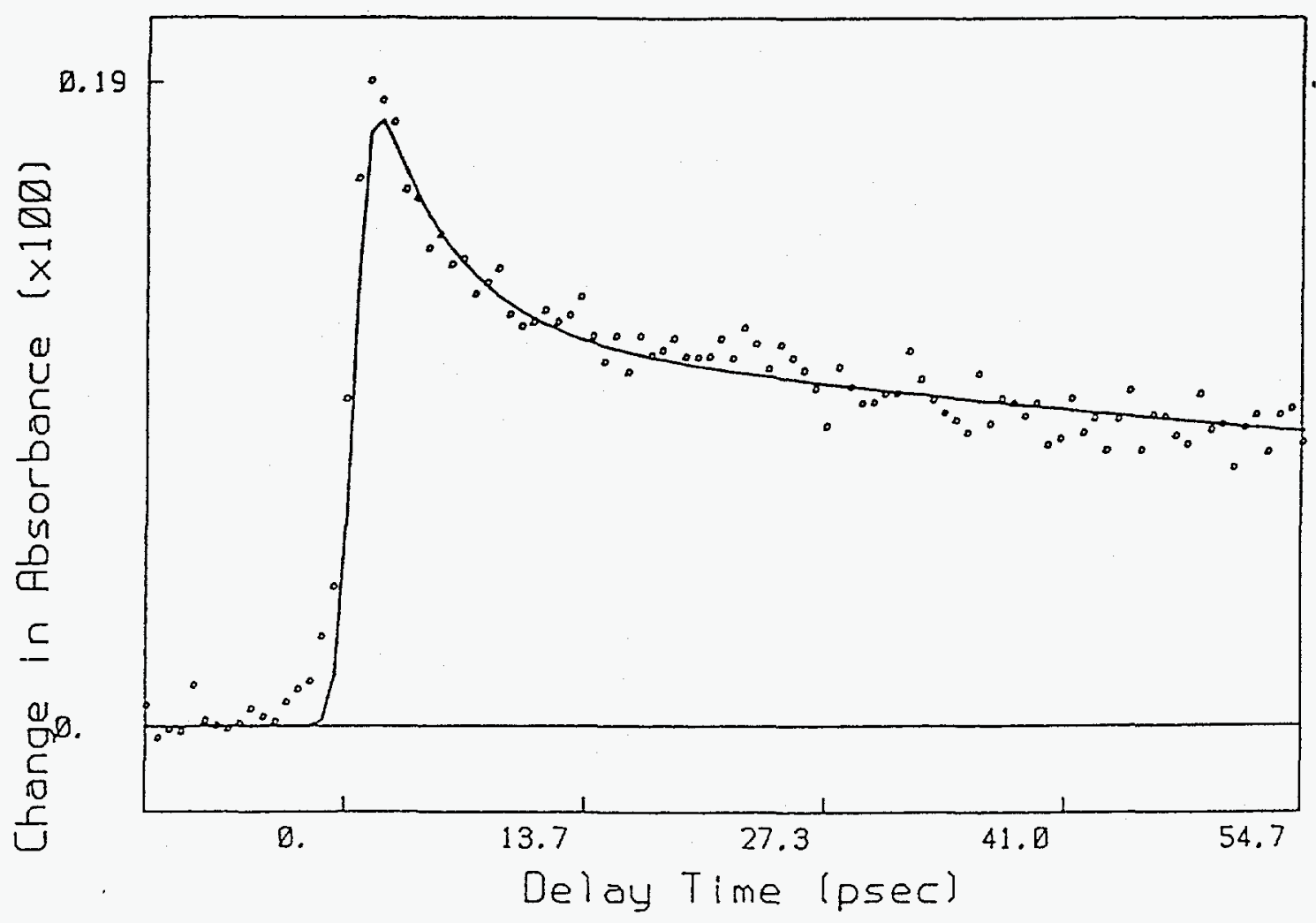

Figure 4.8 - The Change in Absorption at $610 \mathrm{~nm}$ Following Photodissociation of $\mathrm{Ru}_{3}(\mathrm{CO})_{12}$ in Hexane. 


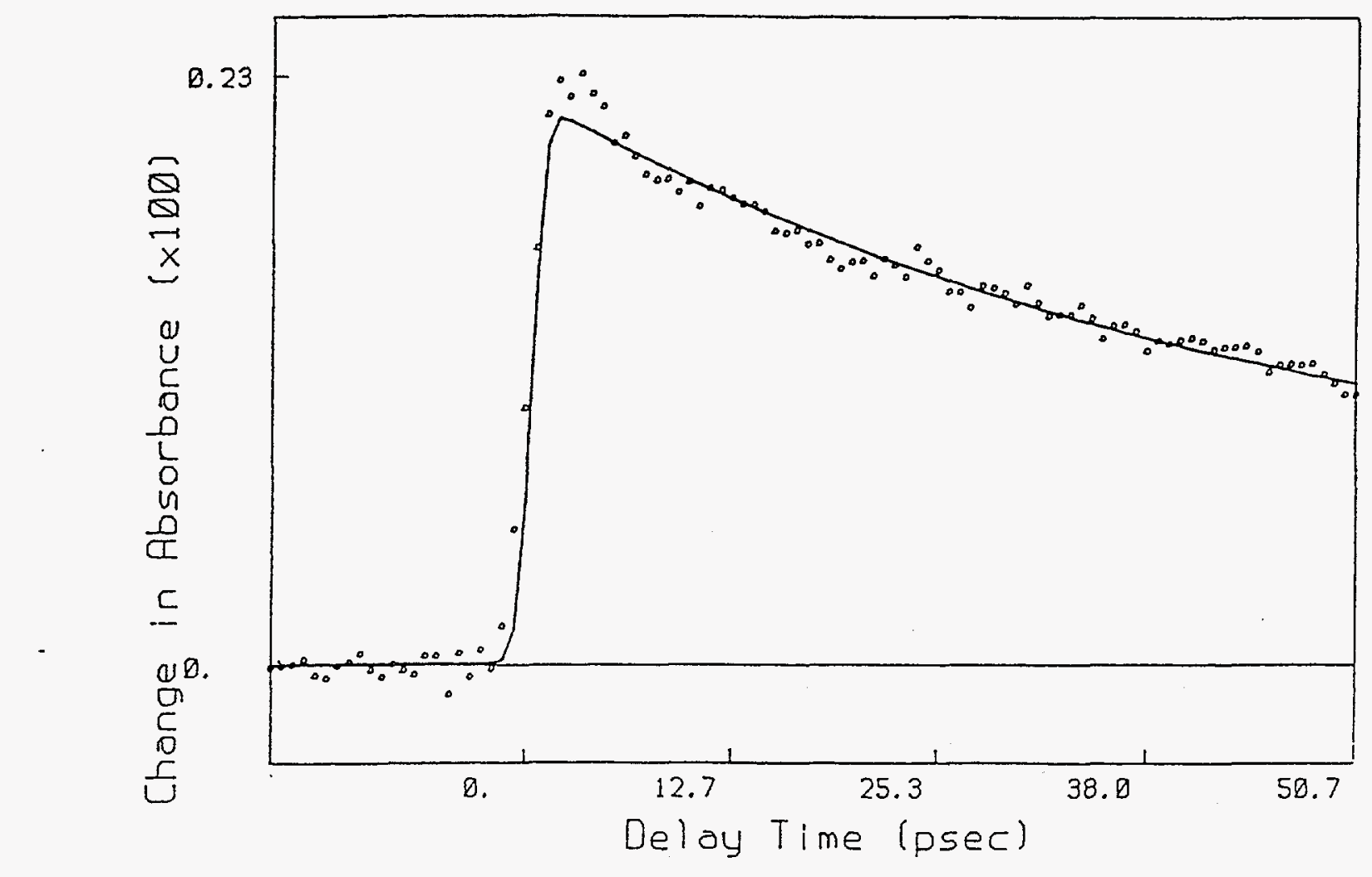

Figure 4.9 - The Change in Absorption at $500 \mathrm{~nm}$ Following Photodissociation of $\mathrm{Ru}_{3}(\mathrm{CO})_{12}$ in Hexane. 


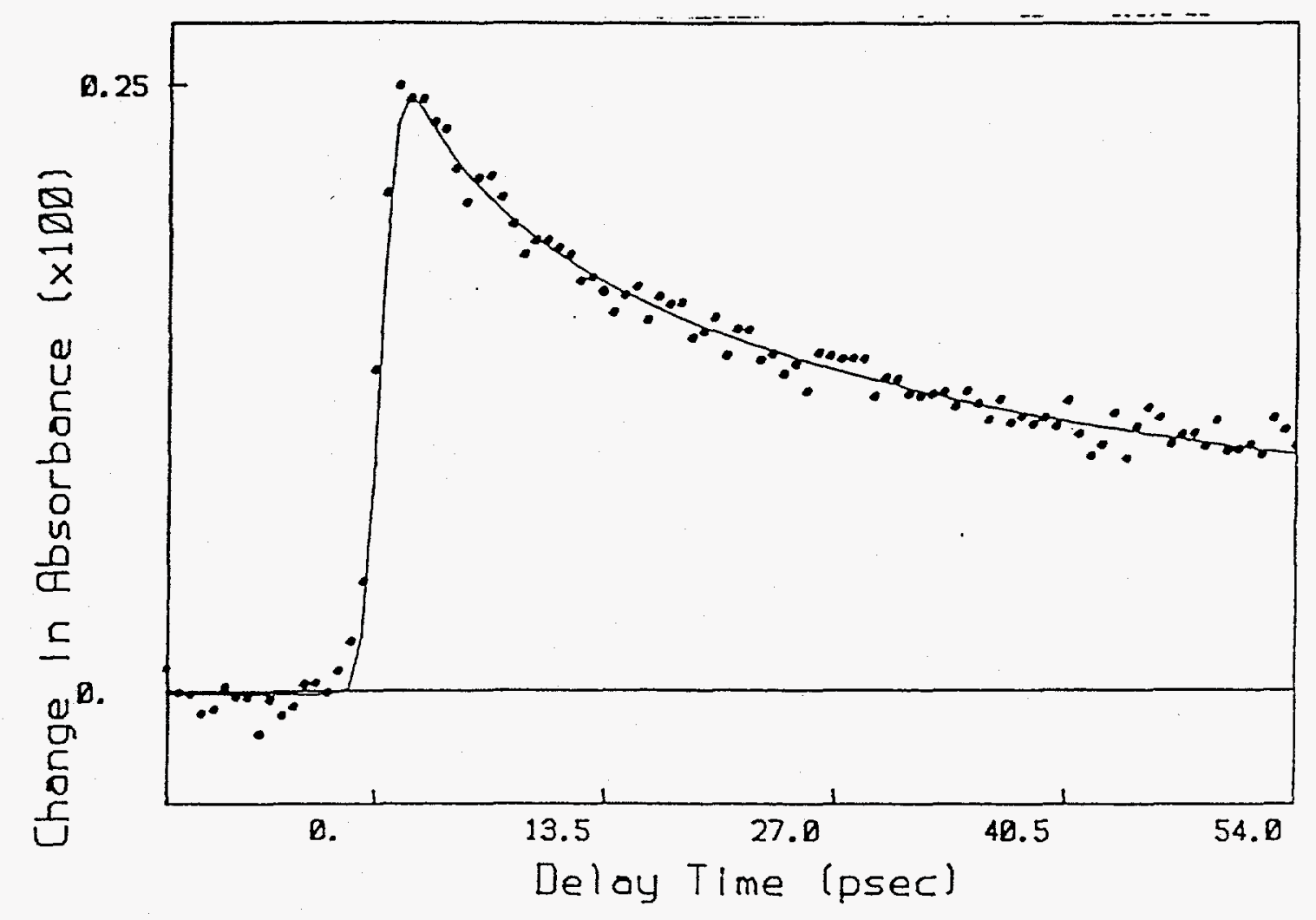

Figure 4.10 - The Change in Absorption at $530 \mathrm{~nm}$ Following Photodissociation of $\mathrm{Ru}_{3}(\mathrm{CO})_{12}$ in Hexane. 
vibrationally excited species, another process is seen at wavelengths longer than the ground state absorption. At all wavelengths between $500-660 \mathrm{~nm}$ there is a long wavelength independent decay in the absorbance of the sample. This component was difficult to reproduce exactly, but was always near $50 \mathrm{ps}(40-80 \mathrm{ps})$. There is also an offset in the absorbance at these wavelengths which is largest near $500 \mathrm{~nm}$. From low temperature matrix studies [67], it is known that a bridged form of $\mathrm{Ru}_{3}(\mathrm{CO})_{12}$ is formed soon after dissociation. The structure of the intermediate was identified as bridged from absorptions in the infrared that are diagnostic of bridging CO's. The bridged isomer has a strong absorption centered near $500 \mathrm{~nm}(\varepsilon=3300)$. This bridged species is coordinatively unsaturated and is known to undergo substitution by two electron donors and isomerization to an axially substituted all terminal structure. This substituted species also has an absorption near $500 \mathrm{~nm}$ which is weaker than the absorption of the bridging species ( $\varepsilon=1000$ ). Our data is consistent with a fraction of the molecules forming the bridged structure soon after dissociation with substitution and isomerization to the all terminal substituted structure occurring in approximately $50 \mathrm{ps}$. The size of the offset is approximately $1 / 3$ of the original absorbance which is consistent with going from the bridged species ( $\varepsilon=3300)$ to the all terminal substituted species $(\varepsilon=1000)$. In addition the fluctuations in the time constant for this process could be due to the different mixtures of isomers present in the hexane solvent (see above). Because every isomer, especially unsaturated isomers, have different affinities for bonding with the unsaturated metal cluster, the change in the composition of the solvent would effect the observed rate of substitution and isomerization. Figure 4.11 summarizes the ultraviolet photochemistry of $\mathrm{Ru}_{3}(\mathrm{CO})_{12}$ 


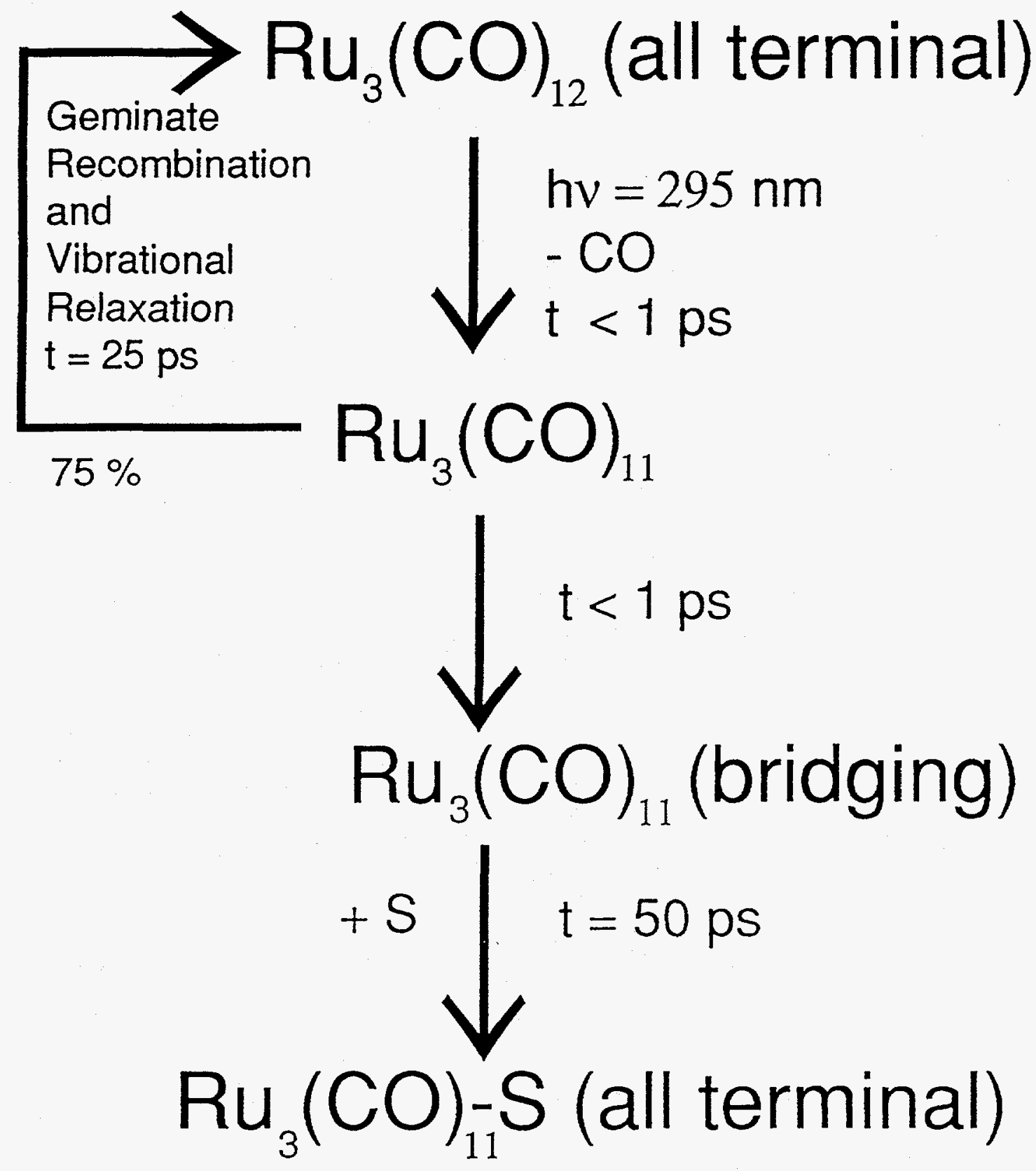

Figure 4.11 - Reaction Scheme for the Short Wavelength Excitation of $\mathrm{Ru}_{3}(\mathrm{CO})_{12}$. 


\section{The Ultraviolet Excitation of $\mathrm{Fe}_{3}(\mathrm{CO})_{12}$}

As mentioned above, ultraviolet excitation of $\mathrm{Fe}_{3}(\mathrm{CO})_{12}$ leads to dissociation of a $\mathrm{CO}$ ligand. However this dissociation leads to significantly different dynamics for $\mathrm{Fe}_{3}(\mathrm{CO})_{11}$ from what was found for $\mathrm{Ru}_{3}(\mathrm{CO})_{11}$ (see above). The first major difference between the dynamics of the two metal carbonyl clusters is that no recombination and vibrational relaxation of $\mathrm{Fe}_{3}(\mathrm{CO})_{11}$ and $\mathrm{CO}$ occurs. This is apparent from the ground state bleach at $600 \mathrm{~nm}$ (see figure 4.12). The recovery of the ground state absorption occurs only on a $400 \mathrm{ps}$ time scale. This is too long to be due to recombination and vibrational relaxation (the recovery of the ground state $\mathrm{Ru}_{3}(\mathrm{CO})_{12}$ occurs in $25 \mathrm{ps}$ ). The dynamics that do occur happen on two time scales. At all wavelengths where transient absorption are measured (400-480 nm, figure 4.13 and $700-740 \mathrm{~nm}$, figure 4.14 ) there are two components, a fast component of approximately 10 ps and a slower 400 ps component. The fast component is on the right time scale for vibrational relaxation, but it lacks the common trend of faster relaxation and longer wavelengths and progressively slower dynamics at shorter wavelengths. In addition it is not clear what species would be vibrationally relaxing. As mentioned above, no molecules are returning to the ground state on this time scale. Also an increasing absorption is not seen on this time scale. Another process that could account for the disappearance of the intermediate which absorbs at this wavelength is fragmentation of the cluster. If an intermediate is produced in the photodissociation that absorbs at these wavelengths, but fragments to produce mono and dinuclear metal carbonyls, no increase of absorption would be expected because the mono and dinuclear iron compounds do not have absorption in the visible region of the spectrum. Further work especially in the infrared is required to determine what process is responsible 


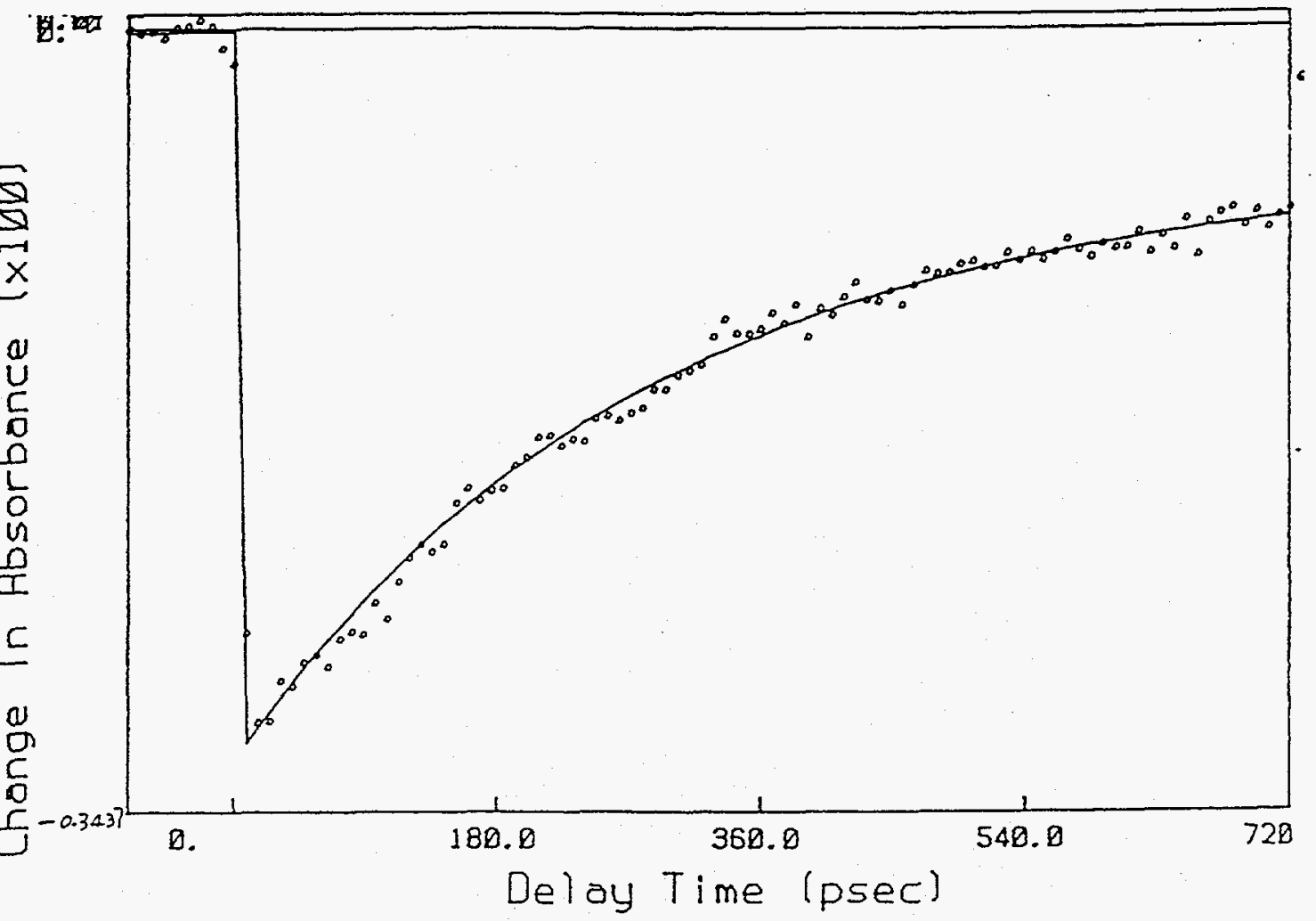

Figure 4.12 - The Change in Absorption at $600 \mathrm{~nm}$ Following Photodissociation of $\mathrm{Fe}_{3}(\mathrm{CO})_{12}$ in Hexane. 


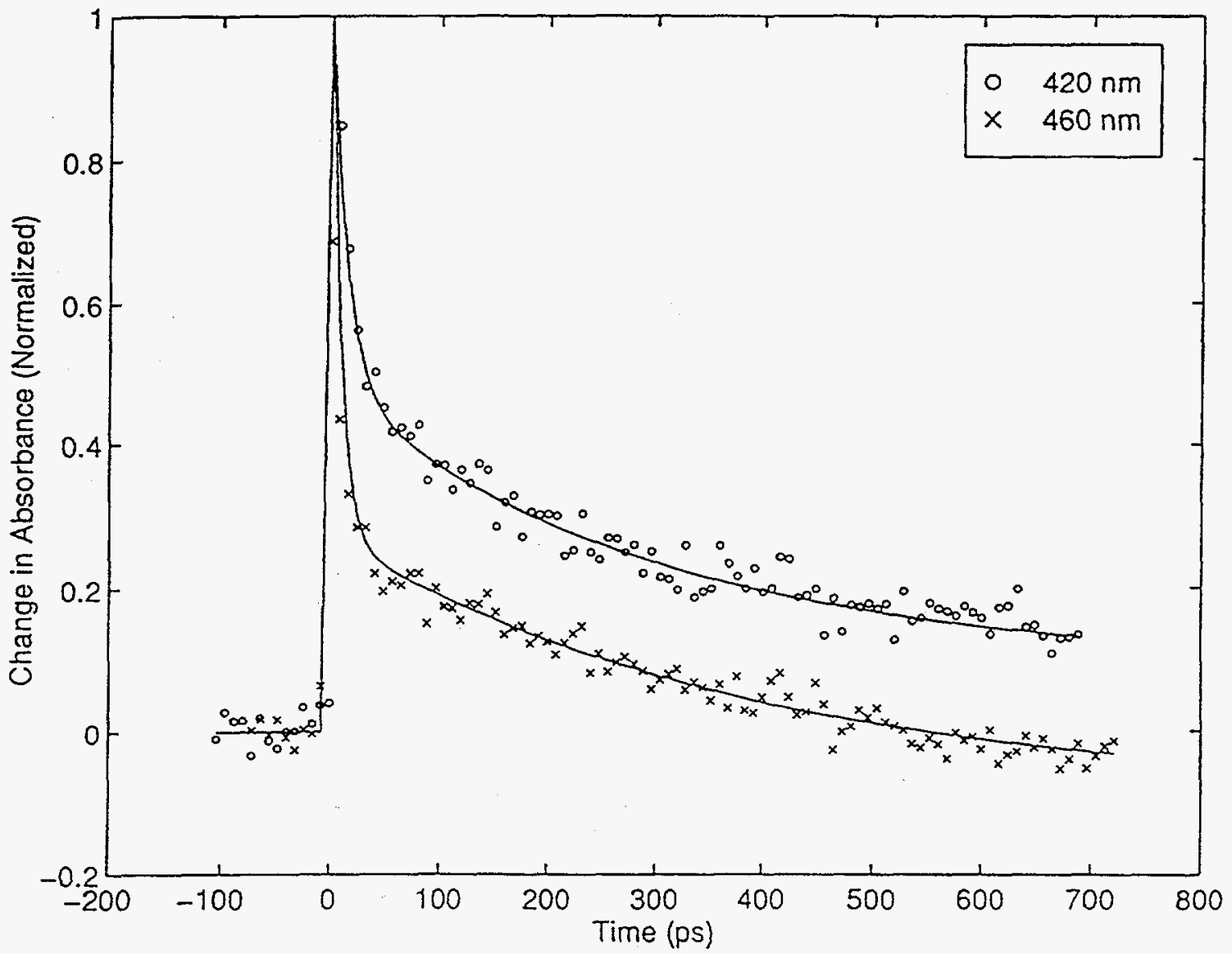

Figure 4.13 - The Change in Absorption at $420 \mathrm{~nm}$ and $460 \mathrm{~nm}$ Following Photodissociation of $\mathrm{Fe}_{3}(\mathrm{CO})_{12}$ in Hexane. 


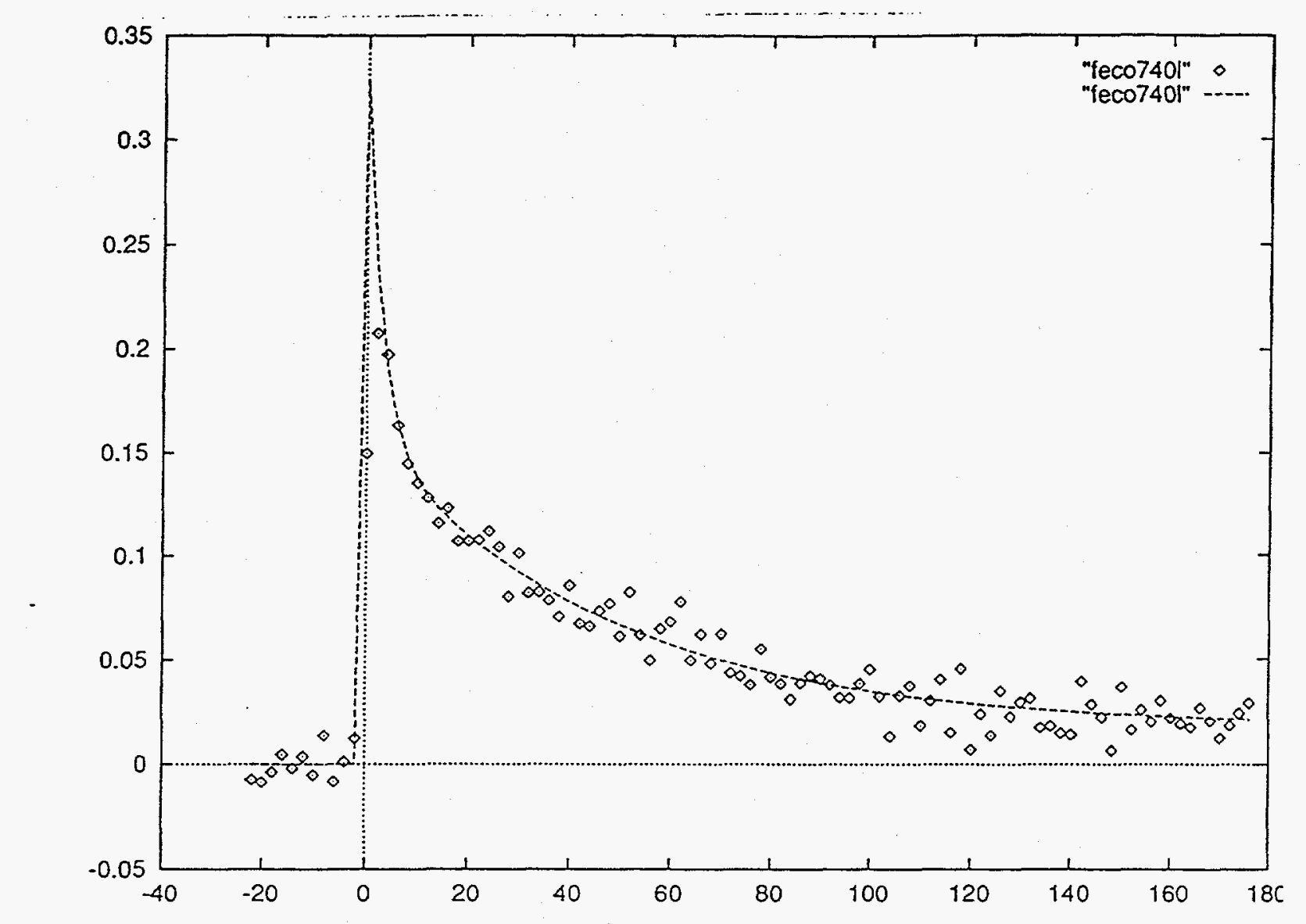

Figure 4.14 - The Change in Absorption at $740 \mathrm{~nm}$ Following Photodissociation of $\mathrm{Fe}_{3}(\mathrm{CO})_{12}$ in Hexane. 
for this fast component.

The other longer component of $400 \mathrm{ps}$ is found both in the decay of the transient absorption and the recovery of the bleach. This component is interpreted in a manner similar to that of $\mathrm{Ru}_{3}(\mathrm{CO})_{12}$. An unsaturated bridging isomer is formed following photodissociation, which causes the transient absorption at $400-500 \mathrm{~nm}$ and $700-740 \mathrm{~nm}$ and can react with two electron donors and isomerize to an all terminal structure. As the reaction and isomerization occurs, absorbance goes down at wavelengths where the bridging isomer absorbs (presumably $400-500 \mathrm{~nm}$ and $700-740 \mathrm{~nm}$ ), and absorbance goes up at wavelengths where the substituted all terminal species absorbs, which could be expected to be near where the all terminal ground state absorbs $(600 \mathrm{~nm})$. This would correspond to a significantly more stable bridging isomer for $\mathrm{Fe}_{3}(\mathrm{CO})_{12}$ (lifetime $400 \mathrm{ps}$ ) than $\mathrm{Ru}_{3}(\mathrm{CO})_{12}$ (lifetime $50 \mathrm{ps}$ ). This is consistent with work that shows $\mathrm{Fe}_{3}(\mathrm{CO})_{12}$ has a tendency to form bridged structures $[62,64,66]$. It is predominately bridged in solid form and in low temperature matrices and has some bridging characters even in room temperature solution. $\mathrm{Ru}_{3}(\mathrm{CO})_{12}$ does not show this strong tendency to bridge. Just as in $\mathrm{Ru}_{3}(\mathrm{CO})_{12}$ there was some variability from sample to sample in the rate of substitution by a solvent molecule and isomerization to the all-terminal structure. This again could be due to the different compositions of hexane solvent. In addition, the disappearance of the bridging isomer and appearance of the all terminal species appear to be somewhat nonexponential possibly indicating a diffusive process, although the signal-to-noise was not sufficient to determine the exact form of the decay and recovery. Figure 4.15 summarizes the ultraviolet photochemistry of $\mathrm{Fe}_{3}(\mathrm{CO})_{12}$. 


$$
\begin{aligned}
& \mathrm{Fe}_{3}(\mathrm{CO})_{12} \text { (all terminal) } \\
& \qquad \begin{array}{l}
\mathrm{hv}=295 \mathrm{~nm} \\
\mathrm{CO} \\
\mathrm{t}<1 \mathrm{ps}
\end{array} \\
& \left.\downarrow \mathrm{Fe}_{3}(\mathrm{CO})_{11} \mathrm{~S} \text { (all terminal }\right) \\
& \mathrm{Fe}_{3}(\mathrm{CO})_{11}(\mathrm{bridging}) \\
& \mathrm{t}=400 \mathrm{ps})_{11}\left(\mathrm{CO}(\mathrm{CO})_{5}, \ldots\right)
\end{aligned}
$$

Figure 4.15 - Reaction Scheme for the Short Wavelength Excitation of $\mathrm{Fe}_{3}(\mathrm{CO})_{12}$. 


\section{Conclusion}

Although much still needs to be learned about the underlying principles that govern these reactions, this study does illuminate the basic-dynamics of these systems following excitation. The dynamics following excitation are summarized in figures 5,9 , and 13 . Some dynamics are common to all three reactions studied here while others occur in only one or two of the systems. The most interesting common feature is that all species isomerize to a bridged structure after excitation. In the case of long wavelength excitation of $\mathrm{Fe}_{3}(\mathrm{CO})_{12}$ the bridged species is an isomer that reverts back to the ground state in approximately $150 \mathrm{ps.} \mathrm{In} \mathrm{the} \mathrm{shorter} \mathrm{wavelength} \mathrm{excitation,} \mathrm{the} \mathrm{bridged} \mathrm{species} \mathrm{has} \mathrm{lost} \mathrm{a}$ $\mathrm{CO}$ ligand to produce $\mathrm{M}_{3}(\mathrm{CO})_{11}$ and has a lifetime of $400 \mathrm{ps}$ for $\mathrm{Fe}_{3}(\mathrm{CO})_{11}$ and $50 \mathrm{ps}$ for $\mathrm{Ru}_{3}(\mathrm{CO})_{11}$. Why this isomerization to the bridged structure occurs in all these reactions is still unclear. On the other hand while a majority of the photodissociated $\mathrm{Ru}_{3}(\mathrm{CO})_{12}$ 's undergo geminate recombination and vibrational relaxation in $25 \mathrm{ps,} \mathrm{no} \mathrm{direct} \mathrm{geminate}$ recombination and vibrational relaxation occurs following the excitation of $\mathrm{Fe}_{3}(\mathrm{CO})_{12}$ at either $295 \mathrm{~nm}$ or $590 \mathrm{~nm}$. Perhaps the isomerization to the stable bridged structures of the iron systems precludes immediate reformation of the bond.

To investigate these processes more definitively, several types of experiments need to be conducted on these systems. One group of experiments would involve varying the temperature of the solution and the concentration of potential ligands to see the affect on the rates of the dynamics. By changing the temperature, unimolecular reactions could be differentiated from diffusional reactions. In addition the temperature dependence would give accurate estimates of the barrier heights for the unimolecular reactions. Changing the concentration of potential ligands in solution would also distinguish unimolecular and 
bimolecular processes. The reactivity of an intermediate with different ligands would help determine the structure of the intermediate involved and indicate the parameters controlling the reactions. Besides changing temperature and concentration another important step in studying these reactions will be probing them in the infrared. The CO ligands are strong absorbers and are fairly diagnostic of the structure. In addition, the large number of infrared studies on the photochemistry of these clusters in low temperature matrices, should make identification of these intermediates more straightforward.

Finally it will be important to study the photochemistry of these species in systems where they are technologically useful. The usefulness of these compounds comes primarily from there ability to photocatalyze the movement of double bonds within alkenes and the isomerization of alcohols to ketones with quantum yields $>100$ (i.e. 100 catalyzed reactions for every photon absorbed $[66,68]$. Once the photochemistry of the clusters is understood in the absence of the reacting species, the same excitation can be studied in the presence of reactive alkenes and ketones. The alkenes and ketones could be probed independently in the infrared and should provide additional information to help elucidate the mechanism of the reaction. Once the mechanism is understood attempts to optimize the reaction rate and yield by changing the conditions of the reactions or the structure of the starting material can be made. 


\section{Conclusion}

When I began work in this field six years ago a picture of the dynamics following $\mathrm{I}_{2}$ photodissociation was just being completed. Work by various groups had mapped out the dynamics in a variety of environments, from molecular solvents to compressed noble gases, with a variety of techniques and provided a fairly complete description of the principles at work. As I leave this work, I leave the legacy of the dynamics of $I_{2}$ - as a completely open question. My contribution in a sense has been simply adding a negative charge to what was already known. But this small perturbation on the system has an incredible impact on the dynamics. Even in a nonpolar solvent where the effect of the charge might be expected to be minimal, the vibrational energy relaxation rate is increased by a factor of 30 over $I_{2}$. But the relaxation rate changes only $20 \%$ in going from a nonpolar solvent, $\mathrm{CCl}_{4}$, to a very polar solvent, methanol. After spending a significant portion of my graduate work studying this system, these dynamics are still a mystery to me. However, this mystery has reminded me truly vast and varied the field of chemistry is. $I_{2}$ although an important prototype is just the small tip of a very large iceberg.

The work presented in this dissertation addresses a number of types of questions. The study of the solvation and vibrational relaxation of $\mathrm{M}(\mathrm{CO})_{6}(\mathrm{M}=\mathrm{Cr}, \mathrm{Mo}, \mathrm{W})$ is fundamentally an extension of the $I_{2}$ work to polyatomic systems. Following UV excitation a $\mathrm{CO}$ is dissociated from the hexacarbonyl in less than 500 fs. The resulting pentacarbonyl fragment is extremely electrophilic and begins to form a bond with a solvent molecule in $<1$ ps. Just as in $I_{2}$ this bond formation can be monitored by changes in the visible absorption spectrum. The vibrational relaxation process is different for all three species. The $\mathrm{Cr}(\mathrm{CO})_{5} \cdot \mathrm{S}$ vibrationally relaxes on two time scales $18 \mathrm{ps}$ and $150 \mathrm{ps}$. The 
longer time scale cooling is assigned to vibrational relaxation of a $\mathrm{CO}$ group which is poorly coupled to the rest of the molecule. $\mathrm{Mo}(\mathrm{CO})_{5} \cdot \mathrm{S}$ has a single vibrational relaxation time of $18 \mathrm{ps}$. $\mathrm{W}(\mathrm{CO})_{5} \mathrm{~S}$ also relaxes on a single time scale, but is over twice as long, 42 ps, as the other two complexes. To understand the reason for the differences between the dynamics of these complexes, it will be necessary to monitor the specific modes of the molecules during the vibrational relaxation process. To get this mode specific information a technique such as transient infrared spectroscopy or transient raman spectroscopy will be needed.

The photodynamics of another metal carbonyl system $\mathrm{M}_{3}(\mathrm{CO})_{12}(\mathrm{M}=\mathrm{Fe}$ and $\mathrm{Ru})$ was studied with ultrafast absorption spectroscopy and showed a number of process occurring. Long wavelength excitation of $\mathrm{Fe}_{3}(\mathrm{CO})_{12}$ causes breaking of a metal-metal bond. The molecules can then isomerize to a carbonyl bridging isomer or fragment to mono or dinuclear complexes. The isomerized molecules revert back to the original structure in $150 \mathrm{ps}$, implying a barrier of $4.3 \mathrm{kcal} / \mathrm{mol}$. Excitation of $\mathrm{Fe}_{3}(\mathrm{CO})_{12}$ at $295 \mathrm{~nm}$ causes dissociation of $\mathrm{CO}$ ligand. Once again the two channels available appear to be isomerization to a bridged structure and fragmentation to mono and dinuclear complexes. The bridged structure isomerizes back to an all terminal structure in $400 \mathrm{ps}$. The photochemistry of $\mathrm{Ru}_{3}(\mathrm{CO})_{12}$ following $295 \mathrm{~nm}$ excitation is quite different than $\mathrm{Fe}_{3}(\mathrm{CO})_{12}$. The initial step is once again $\mathrm{CO}$ dissociation, but in this case a large percentage of the molecules geminately recombine and the vibrationally relax to form the starting material in $25 \mathrm{ps}$. The molecules that do not dissociate isomerize to form a bridged $\mathrm{Ru}_{3}(\mathrm{CO})_{11}$ structure. This bridged structure can then react with a solvent molecule and isomerize to the all terminal structure in approximately $50 \mathrm{ps}$. To study complicated 
reactions such as these, it will again be important to probe the molecules with a structurally sensitive probe such as time-resolved infrared or raman spectroscopy. With these techniques the mechanisms of complicated reaction can be determined and allow optimization of the reaction in a strategic manner.

A significant portion of my early work was devoted to extending ultrafast spectroscopy into the infrared. The changes in the infrared absorption spectrum following excitation with a visible or ultraviolet pulse were measured with a cw infrared laser (carbon monoxide laser). The intensity of the infrared beam was then read at a specific delay time after the excitation pulse by combining the infrared beam with an upconverting pulse that is synchronized in time with the pump pulse. Unfortunately, the noise characteristics did not allow the study of chemically interesting systems. However subsequent work on transient infrared spectroscopy in this groups has made significant progress toward studies of reaction dynamics in the infrared. Future extensions of this work to study a larger portion of the spectrum will require work on transient raman spectroscopy.

Overall, I think progress in understanding reactions requires work in all of the general areas discussed here. Work to extend ultrafast spectrometers wavelength for pumping and probing from the ultraviolet to the infrared will allow a wider variety of molecules to be studied and better understood. Studies of basics processes especially in new systems, and environments will further clarify the principles governing these processes and studies of more complex reactions will show how basic processes interact and provide a new more direct perspective on how chemistry occurs. 


\section{References}

1. M. Berg, A. L. Harris, J. K. Brown and C. B. Harris, Opt. Lett. 9, 50 (1984).

2. R. M. Osgood, W. C. Eppers, Jr., and E. R. Nichols, IEEE J. Quant. Electron. QE-6, 145 (1970).

3. A. K. Knudsen, Ph.D. Thesis, University of California, Berkeley, 29 (1983).

4. A. E. Siegman, Lasers (University Science Books, Mill Valley, CA) 42 (1986).

5. T. M. Jedju, M. W. Roberson and L. Rothberg, App. Opt. 31, 20 (1992).

6. P. A. Hansen, J. N. Moore and R. M. Hochstrasser, Chem. Phys. 131, 149 (1989).

7. T. P. Dougherty and E. J. Heilweil, Chem. Phys. Lett. 227, 12 (1994).

8. S. E. Bromberg, Ph.D. Thesis, University of California, Berkeley, in preparation.

9. J. C. Owrutsky, D. Raftery, R. M. Hochstrasser, Ann. Rev. Phys. Chem. 45, 519 (1994) and references therein.

10. W. Kaiser, Ed. Ultrashort Laser Pulses and Applications (Springer-Verlag: Berlin, 1988) and references therein.

11. P. F. Barbara, W. H. Knox, G. A. Mourou, A. H. Zewail, A. H.; Eds. Ultrafast Phenomena (Springer Series in Chemical Physics 60; Springer: Berlin, 1994).

12. A. L. Harris, J. K. Brown, C. B. Harris, Ann. Rev. Phys. Chem. 39, 341 (1988).

13. T. J. Chuang, G. W. Hoffman, K. B. Eisenthal, Chem. Phys. Lett. 25, 201 (1974).

14. D. J. Nesbitt, J. T. Hynes, J. Chem. Phys. 77, 2130 (1982).

15. A. L. Harris, M. Berg, C. B. Harris, J. Chem. Phys. 84, 788 (1986).

16. A. G. Joly, K. A. Nelson, J. Phys. Chem. 93, 2876 (1989).

17. X. Xie, J. D. Simon, J. Am. Chem. Soc. 112, 1130 (1990).

18. J. C. King, J. Z. Zhang, B. J. Schwartz, C. B. Harris, C. B. J. Chem. Phys. 99, 7595 (1993).

19. E. J. Heilweil, R. R. Cavanaugh, J. C. Stephenson, Chem Phys. Lett. 134, 181 (1987). 
20. K. E. Schultz, D. J. Russell, C. B. Harris, J. Phys. Chem. 97, 5431 (1992).

21. A. E. Johnson, N. E. Levinger, P. F. Barbara, J. Phys. Chem. 96, 7841 (1992).

22. J. C. Alfano, Y. Kimura, P. K. Walhout, P. F. Barbara, Chem. Phys. 175, 147 (1993).

23. D. A. V. Kliner, J. C. Alfano, P. F. Barbara, J. Chem. Phys. 98, 5375 (1993).

24. P. Fornier de Violet, R. Bonneau, J. Joussot-Dubien, Chem. Phys. Lett. 19, 251 (1973).

25. U. Banin, S. Ruhman, J. Chem. Phys. 98, 4391 (1993).

26. U. Banin, S. Ruhman, J. Chem. Phys. 99, 9318 (1993).

27. U. Banin, R. Kosloff, S. Ruhman, Isr. J. Chem. 33, 141 (1993).

28. U. Banin, R. Kosloff, S. Ruhman, Chem. Phys. 183, 289 (1994).

29. A. I. Popov, R. E. Buckles, Inorganic Synthesis, 5 (McGraw-Hill, New York, 1957).

30. W. Gabes, D. J. Stufkens, Spectrochimica Acta 30A, 1835 (1974).

31. H. Bony, M. Shapiro, A. Yogev, Chem. Phys. Lett. 107, 603 (1984).

32. Because $\mathrm{I}_{2}$ was irreversibly formed in these conditions, the $\mathrm{I}-$ is presumed to react with $\mathrm{CCl}_{4}$ to produce $\mathrm{CCl}_{3} \mathrm{I}+\mathrm{Cl}$.

33. P. Fornier de Violet, Rev. Chem. Interm. 4, 121 (1981).

34. $\varepsilon_{\mathrm{T} 3}=2.5 \times 10^{4} \mathrm{vs} . \varepsilon_{\mathrm{I} 2}=1.5 \times 10^{4}$

35. $\mathrm{I}_{2}-$ and $\mathrm{Br}_{2}$-both have absorptions at $800 \mathrm{~nm}-\mathrm{C}$. J. Delbecq, W. Hayes, P. H. Yuster, Phys. Rev. 121, 1043 (1961).

36. J. C. Owrutsky, Y. R. Kim, M. Li, M. J. Sarisky, R. M. Hochstrasser, Chem. Phys. Lett. 184, 368 (1991).

37. F. A. Cotton, G. Wilkinson, Advanced Inorganic Chemistry 5th ed. (J. Wiley and Sons, 1988) 1383.

38. J. O. M. Bockris, A. K. Reddy, Modern Electrochemistry (Plenum 1970) Sec. 3.8.6. 
39. B. J. Schwartz, J. C. King, J. Z. Zhang, C. B. Harris, Chem. Phys. Lett. 203, 503 (1993).

40. Because it is not known whether the 5-10\% that do not reform the trihalides formed a metastable complex and dissociated from that or dissociated directly and never formed the metastable complex, only a lower limit can be estimated.

41. P. Barbara, private communication.

42. E. C. M. Chen, W. E. Wentworth, J. Phys. Chem. 89, 4099 (1985).

43. A. G. Joly and K. A. Nelson, Chem. Phys. 152, 59, (1991).

44. J. D. Simon and X. Xie, J. Phys. Chem. 93, 291 (1989).

45. M. Lee and C. B. Harris, J. Am. Chem. Soc. 111, 8963 (1989); (b) J. Z. Zhang and C. B. Harris, J. Chem. Phys. 95, 4024 (1991).

46. P. H. Anfinrud, C. H. Han, T. Lian, and R. M. Hochstrasser, J. Phys. Chem. 95, 574 (1991).

47. E. J. Heilweil, R. R. Cavanaugh and J. C. Stephenson, J. Chem. Phys. 89, 230 (1988); (b) E. J. Heilweil, R. R. Cavanaugh and J. C. Stephenson, Chem. Phys. Lett. 134(2), 181 (1987).

48. J. R. Sprague, S. M. Arrivo and K. G. Spears, J. Phys. Chem. 95, 10528 (1991); (b) L. Wang, X. Zhu and K. G. Spears, J. Phys. Chem. 93, 2 (1989).

49. S. C. Yu, X. Xu, R. Lingle, Jr. and J. B. Hopkins, J. Am. Chem. Soc. 112, 3668 (1990).

50. C. Moralejo and C. H. Langford, J. Photochem. and Photobio. A, 59, N3:285 (1991).

51 G. L. Geoffroy and M. S. Wrighton, Organometallic Photochemistry (Academic, New York, 1978).

52. J. K. Burdett, J. M. Grzybowski, R. N. Perutz, M. Poliakoff, J. J. Turner, and R. F. Turner, Inorg. Chem. 17(1), 147 (1978).

53. M. J. Almond, A. J. Downs, and R. N. Perutz, Inorg. Chem. 24, 275 (1985).

54. S. P. Church, F. Grevels, H. Hermann, and K. Schaffner, Inorg. Chem. 24, 418 (1985).

55. S. K. Nayak and T. J. Burkey, Organometallics, 10, 3745 (1991). 
56. J. M. Kelly, C. Long, and R. Bonneau, J. Phys. Chem. 87, 3344 (1983).

57. J. T. Hynes, R. Kapral and B. M. Torrie, J. Chem. Phys. 72, 177 (1980).

58. M. L. Lee and C. B. Harris, unpublished results, 1989.

59. P. O. Stoutland, R. B. Dyer, and W. H. Woodruff, Science, 257, N5078:1913 (1992).

60. W. Kaiser, Ultrashort Laser Pulses and Applications (Springer-Verlag, Berlin, 1988) p. 303.

61. T. Desiderato, Jr. and G. R. Dobson, J. Chem. Ed. 59, 753 (1982).

62. C. H. Wei and L. F. Dahl, J. Am. Chem. Soc. 91, 1351 (1969).

63. F. A. Cotton and J. M. Troupe, J. Am. Chem. Soc. 96, 4155 (1974).

64. F. A. Cotton and D. L. Hunter, Inorg. Chim. Acta, 11, L9 (1974).

65. N. Binstedt, J. Evans, N. Greaves and R. J. Price, J. Chem. Soc., Chem. Comm. 1330 (1987).

66. J. G. Bentsen and M. S. Wrighton, J. Am. Chem. Soc. 109, 4530 (1987).

67. M. F. Desrosiers, D. A. Wink, R. Trautman, A. E. Friedman and P. C. Ford, J. Am. Chem. Soc. 108, 1917 (1986).

68. N. Iranpoor and E. Mottaghinejad, J. Organomet. Chem. 423, 399 (1992). 